Chapman University

Chapman University Digital Commons

Economics Faculty Articles and Research

Economics

$1-2016$

\title{
Seller Beware: Supply and Demand Reduction and Price Manipulation in Multiple-Unit Uniform Price Auctions
}

\author{
Abel Winn \\ Chapman University, winn@chapman.edu \\ Michael Parente \\ Office of the Federal Public Defender \\ David Porter \\ Chapman University, dporter@chapman.edu
}

Follow this and additional works at: http://digitalcommons.chapman.edu/economics_articles

Part of the Economic Theory Commons

\section{Recommended Citation}

Winn, A. M., Parente, M. L. and Porter, D. (2016), Seller Beware: Supply and Demand Reduction and Price Manipulation in MultipleUnit Uniform Price Auctions. Southern Economic Journal, 82(3): 760-780. doi: 10.1002/soej.12086

This Article is brought to you for free and open access by the Economics at Chapman University Digital Commons. It has been accepted for inclusion in Economics Faculty Articles and Research by an authorized administrator of Chapman University Digital Commons. For more information, please contactlaughtin@chapman.edu. 


\section{Seller Beware: Supply and Demand Reduction and Price Manipulation in Multiple-Unit Uniform Price Auctions}

\section{Comments}

This is an earlier version of the following article:

Winn, A. M., Parente, M. L. and Porter, D. (2016), Seller Beware: Supply and Demand Reduction and Price Manipulation in Multiple-Unit Uniform Price Auctions. Southern Economic Journal, 82(3): 760-780. doi: 10.1002 /soej. 12086

which has been published in final form at DOI: 10.1002/soej.12086. This article may be used for noncommercial purposes in accordance with Wiley Terms and Conditions for Self-Archiving.

\section{Copyright}

Southern Economic Association 
Seller Beware: Supply and Demand Reduction and Price Manipulation in Multiple-Unit Uniform Price Auctions

\author{
Abel Winn \\ Chapman University \\ E-mail: winn@chapman.edu \\ Michael Parente \\ Office of the Federal Public Defender \\ David Porter \\ Chapman University
}

February 20, 2015

\begin{abstract}
We experimentally compare under-revelation of supply and demand across alternative variations of ascending and descending twosided price clock auctions. We find that buyers reduce demand more when the price is ascending but sellers' behavior is consistent across clock directions. As a result, the clock price rule has empirical effects on efficiency even though it is theoretically neutral.
\end{abstract}


"It is good for nothing," cries the buyer; but when he has gone his way, then he boasts.

-Proverbs 20:14

Auctions are popular tools for allocating scarce resources in a timely manner. Krishna (2009) notes that the most widespread auction rules are iteration (participants may revise their bids) and an ascending price. Cramton (1998) suggests two reasons why these rules might be so popular. First, iteration provides feedback to the bidders on their private valuation of winning compared to the valuations of their competitors. This assists the participants in the price discovery process. Second, the ascending price rule confers a sense of legitimacy on the outcome, because the losing bidders are given multiple opportunities to outbid the winner(s), but ultimately decline to do so. The strong track record of ascending price auctions has lead economists to study them in multiple contexts, including the sale of treasury bills (Ausubel and Cramton, 1998), carbon emission permits (Cramton and Kerr, 1999), electromagnetic spectrum licenses (Banks et al., 2003), nitrous oxide emission permits (Porter, et al., 2009) and even the provision of public goods (Levati and Neugebauer, 2004).

The ascending price rule is popular for "one-sided" auctions, in which supply is fixed exogenously and buyers are the only active participants. However, for "two-sided" auctions - in which supply is determined endogenously and both buyers and sellers are active - the Double Auction (DA) institution (Smith 1962) is usually deemed more appropriate, particularly for environments in which participants wish to buy or sell multiple units. The DA essentially consists of multiple single-unit auctions in which buyers call out successively higher bids and sellers successively lower offers until an agreed price is reached. Note that this process, like the one-sided ascending price auction, also provides feedback to buyers (sellers) and offers losing participants multiple opportunities to outbid (undersell) the winners. 
A third salutary feature of the DA is that it discourages participants from strategically reducing the number of units they demand or supply in an effort to manipulate the market price. If all trades in an auction are executed at a uniform price it is profitable for buyers (sellers) to reduce their demand for (supply of) some units if doing so sufficiently lowers (raises) the price at which they buy (sell) the remaining units. ${ }^{1}$ Consequently, a uniform price auction is likely to be inefficient. Traders have the option of strategically reducing demand or supply to manipulate prices in a DA, but to do so profitably would require an overwhelming amount of coordination, because the price for each unit is determined independently. As a result, DAs routinely exploit all of the available gains from trade.

The incentive to strategically reduce is strongest when there is some asymmetry in the participants' message space and/or their ability to withhold units to affect the price (i.e., market power). In a posted offer market, for example, sellers set prices and buyers decide how many units to purchase. Holt (1989) notes that in such markets prices tend to approach the competitive equilibrium from above or fail to converge to it altogether. Davis and Holt (1994) show that posted offer prices tend to be higher - and efficiency lower - when supply is configured in such a way that one seller can profitably raise prices by withholding some of his output.

Markets with symmetrical message space and market power provide a weaker incentive to strategically reduce, because the price effect of supply reduction may be offset by demand reduction, and vice versa. Yet even under these conditions traders may attempt to manipulate prices. Bronfman, et al. (1996) conducted laboratory experiments on a tatonnement auction, in

\footnotetext{
${ }^{1}$ For a theoretical model showing that all uniform price multiple-unit auctions encourage demand reduction, see Asuebel and Cramton (2002). For evidence of demand reduction in laboratory experiments, see Alsemgeest, Noussair and Olson (1998), Kagel and Levin (2001) and Porter and Vragov (2006). For evidence of demand reduction in multiple-unit field experiments, see List and Lucking-Reiley (2000) and Engelbrecht-Wiggans, List and Reiley (2006).
} 
which traders reported the quantity of units they were willing to buy and sell in response to provisional price announcements. They found that traders under-revealed supply and demand by about a third of their units. McCabe, Rassenti and Smith (1993) studied a uniform price double auction (UPDA) institution. In the UPDA a provisional uniform price is iteratively reported in response to buy and sell orders from the traders, and all contracts trade at the uniform price when some market-closing criterion is met. In at least $49 \%$ of their auctions one sixth or more of the profitable units were withheld. ${ }^{2}$

But while the DA is generally more efficient than uniform price institutions, it has three undesirable features. First, the DA generates greater price volatility. A dramatic example is the 2010 "flash crash,” in which the Dow Jones Industrial Average fell by almost 1,000 points only to recover a few minutes later. The event had spillover effects on futures markets as well, causing the E-mini S\&P 500 prices to fall by over 5\% (Easley, Lopez de Prado and O’Hara 2011). Price volatility may undercut the perceived fairness of the trading process, and may even drive risk averse traders from the market, reducing the available gains from trade (Pagano, 1989). Moreover, Budish, Cramton and Shim (2013) have shown that stock market price volatility causes market correlations to break down at sufficiently small time intervals. This opens arbitrage opportunities for high frequency traders, who compete on response time rather than price. Budish, Cramton and Shim (2013) argue that this creates an arms race for speed that is socially wasteful, widens the market spread and diminishes liquidity. To discourage this arms race they propose replacing the existing DA market design with frequent two-sided call auctions.

\footnotetext{
${ }^{2}$ McCabe, Rassenti and Smith (1994) do not report summary statistics of demand or supply reduction, but we were able to construct a lower bound of based on the reported of efficiencies in their Appendix B.
} 
Second, the discriminatory pricing structure of a DA also forces participants to reveal some information on their maximum willingness-to-pay (WTP) and willingness-to-accept (WTA). The buyer who pays the highest price in a DA has revealed information about himself that may be costly in later negotiations. Ditto the seller who accepted the lowest price. A uniform pricing rule, in contrast, eliminates intra-auction price volatility and minimizes the information on WTP and WTA that the winners must disclose.

Finally, DAs are not well suited to complex environments. For example, the FCC plans an incentive auction in 2015 to transfer a large portion of the radio frequency spectrum from broadcast television to mobile broadband. Television stations relinquishing their spectrum rights may do so in a number of different ways, including channel sharing with another station, moving from their current frequency to a VHF frequency, or going off the air altogether. Consequently, a broadcaster's chosen course of action will depend on the tradeoffs it poses and the prices offered for each. Moreover, the geographic size of broadcast licenses may encompass multiple broadband licenses, so that single-unit transactions are not always possible. These features (among others) make the DA an inappropriate format for the incentive auction. Instead, the FCC plans to implement a design proposed by Milgrom et al. (2012) using sequential but interdependent auctions with price clocks. First, a set of descending price clock auctions (one for each method of relinquishing licenses) will determine the supply of spectrum for a geographic region. Then, an ascending price auction will allocate the spectrum among buyers. In principle, these clocks can run simultaneously as we test here.

Given the interest in multiple-unit two-sided uniform price auctions - particularly auctions using a price clock - it is relevant to study these institutions in light of earlier work by McCabe, Rassenti and Smith (1992) - hereafter MRS. They conducted experiments using clock 
auction formats, but none of their mechanisms used an ascending price as the sole method for price discovery. They did, however, test a descending price auction in which experienced traders obtained an average of $94 \%$ of the available surplus. It was dubbed Dutch-English (DE) because the auction presented improving terms of trade (Dutch) to buyers and worsening terms of trade (English) to sellers as it progressed. The auction used a "price clock" which displayed an initial provisional price that was set high and then reduced by predetermined decrements. As the provisional price fell buyers could commit to buying additional units at or below the provisional price, while sellers could reduce the number of units they were willing to offer at or below the provisional price. The auction closed at the final price when the total commitments to buy equaled those to sell.

One of the striking features of the DE format is its performance in comparison to the two alternative two-sided uniform price institutions that MRS tested: the Double English (EE) and Double Dutch (DD) auctions. These institutions used one price clock for buyers and a second for sellers. In the EE the price on the buyers' clock started low and ticked up at predetermined intervals. The price on the sellers' clock started high and ticked down using the same intervals. At the initial prices buyers and sellers indicated how many units they were willing to buy and sell at the prices on their respective clocks. Only one clock was active at a time. The price on the buyers' clock increased until buyers had reduced their demand sufficiently to result in excess supply. At this point the price on the sellers' clock fell until sellers had reduced their commitments to sell sufficiently to result in excess demand. The auction concluded when both clocks displayed the same price.

MRS's DD auction was precisely the reverse of the EE. The price on the buyers' clock started high and ticked down over time, while the price on the sellers' clock started low and 
ticked up. As the buyers' price fell they increased their demand for units until there was excess demand. The sellers' price would then rise until they had increased their commitments to sell enough units to result in excess supply. Like the EE, the auction concluded when both clocks displayed the same price.

The distinguishing feature of the EE is that it provides worsening terms of trade to both sides of the auction. MRS's traders engaged in significant demand and supply reduction in an effort to stop their own price clock and extract price concessions from the other side of the market. In contrast, the DD provides improving terms of trade to both sides of the auction. In response, traders did not withhold as much of their demand or supply. These differences in behavior resulted in more trades (and higher efficiency) in the DD than the EE. Across the last five auctions of their sessions the average efficiency was less than $80 \%$ in the EE, but almost $100 \%$ in the DD.

We have already noted that the DE achieved 94\% efficiency. This is remarkable, because the DE presents improving terms of trade only to buyers, yet it was almost as efficient as the DD, which presents improving terms to both sides. The high efficiency of the DE relative to the EE suggests that buyers are more responsive to the direction of the clock price than are sellers. If this is true, then an English-Dutch (ED) auction would not perform as well as the DE. An ED auction would use an initially low provisional price that increases over time, and allow buyers and sellers to respond by decreasing demand and increasing supply respectively. However, MRS did not conduct an ED auction, so we cannot know for certain if there is an asymmetry in the behavior of buyers and sellers. This omission is significant in light of the prevalence of ascending price auctions in both the laboratory and the field. 
In this study we report the results of a set of laboratory experiments that explicitly test the impact of clock direction on under-revelation among buyers and sellers. Our experiments were designed to answer the following three research questions:

Q1: Do worsening terms of trade encourage a greater increase in under-revelation among buyers than among sellers?

Q2: If buyers are more responsive than sellers to worsening terms of trade, does the clock direction affect an auction's efficiency?

Q3: If buyers are more responsive than sellers to worsening terms of trade, does the clock direction affect an auction's uniform price?

The results of our experiments indicate that we can answer the first two research question in the affirmative. Buyers reduced demand more when they faced an ascending price, but sellers reduced supply by the same amount whether the price clock was ascending or descending. As a result the ascending clock led to more under-revelation, which in turn rendered it less efficient than the descending clock. For research question Q3 we find the answer to be a qualified yes. On average, prices were lower in the ascending auction, but for the experiments we conducted by hand this can be explained by differences in the Nash Equilibrium price across clock directions. For the experiments we conducted on computer terminals, however, the difference in prices was greater than the game theoretic prediction for most auctions.

\section{Experimental Design}

\subsection{Trading Environment}

As a testbed for comparing ascending and descending price clocks, we adopt MRS's schedule of induced costs and values. This is shown in Figure 1 along with the trader role associated with each step of the supply and demand curves. This environment is well suited to the study of supply and demand reduction for three reasons. First, the supply and demand curves 
are symmetrical about the competitive equilibrium. Consequently, the optimal strategies of buyers and sellers are symmetrical when facing improving or worsening terms of trade. For instance, trader B1 in an ascending clock auction faces precisely the same problem as trader S1 in a descending clock auction. Second, the environment contains a mix of "large traders" and “small traders." The former were those who could buy or sell six units in an auction, the latter could buy or sell three units. Large traders had an advantage in attempting to manipulate the price in that they could reduce demand or supply by a greater number of units. Finally, for a given price direction there is a family of Nash Equilibria that is consistent with the competitive equilibrium and there are no Nash Equilibria that are inconsistent with the competitive equilibrium. This provides a straightforward baseline against which to compare buyer and seller behavior.

\section{[Figure 1]}

For the following analysis it is important to note that prices in our experiments were always multiples of five cents. Let $M$ equal the price, in cents, consistent with the mid-point of the competitive equilibrium price tunnel. If the price is ascending, then the Nash Equilibrium price is $M-5$ and no trader under-reveals supply or demand. To see that this is an equilibrium note that if all other traders truthfully reveal their costs and values, the marginal seller S4 can stop the price clock at $M$ - 5 with his final unit to earn a profit of five on each of his three units. (This need not be done by the marginal seller, sellers S1, S2 or S3 could also stop the clock at that price if all other sellers revealed their costs truthfully.) In response to this any buyer could reduce their demand by one unit to force the clock to stop early at $M$ - 10. But this reduction is not profitable for any buyer. 
Table 1 displays the profit that each buyer would earn from buying all of his units at a price of $M$ or $M$ - 5 or dropping one unit to achieve a price of $M-10$. (Buyer B5 is excluded from the table because he would earn zero profit at any of these prices.) Notice that all inframarginal buyers earn a greater profit by purchasing all of their units at $M$ - 5 than by purchasing one fewer unit at $M-10$. However, notice that if seller S4 attempted to stop the price at $M$ there are three buyers (B1, B3 and B4) who would be willing to reduce demand by one unit to stop it at $M-10$. Moreover, as we show in Appendix A, there is no coalition of buyers who could profitably reduce demand to hold the price below $M-10$, nor is there a coalition of sellers who could profitably withhold supply to push the price above $M-5$. Thus, all Nash Equilibria with an ascending clock are characterized by a price of $M-5$ and no strategic reduction. By symmetry, all Nash Equilibria with a descending clock are characterized by a price of $M+5$ and no strategic reduction.

However, the traders in our experiments knew only their own values or costs. Consequently, they could not calculate any Nash Equilibria ex ante and we have no reason to believe that they would refrain from attempting to influence the price through under-revelation.

\section{[Table 1]}

Replicating MRS, we added (or subtracted) a random constant from the interval [ $\$ 1.00$, \$4.90] to all values and costs each period to maintain uncertainty about the market clearing prices. Figure 2 shows the midpoint of the competitive equilibrium (CE) price tunnel in each period, which ranged from $\$ 2.50$ to $\$ 6.00$. In addition, we rotated buyers and sellers along their respective demand and supply curves. Across 15 iterations (or periods) in each session, a trader participated at each of the five respective buyer or seller roles three times.

\section{[Figure 2]}




\subsection{Institutions}

Our design (displayed in Table 2) consisted of two treatment variables. The first was whether the price ascended (ED) over the course of the auction or descended (DE). The ED treatment presented buyers with worsening terms of trade and sellers with improving terms of trade, while the DE treatment reversed these terms for both sides of the market. We can address research question $Q 1$ by comparing under-revelation across price clock treatments to determine whether the terms of trade affected buyer behavior more than seller behavior. By comparing efficiency and average prices across these treatments we can also answer research questions Q2 and Q3. Notice, however, that the Nash Equilibrium prices are different for the ED and DE treatments ( $M-5$ and $M+5$ respectively), so that for $Q 3$ we are interested in whether the clock direction results in price differences that are greater than the game theoretic prediction.

The second treatment variable was whether the auction format was hand-run (Hand), facilitated by a human auctioneer, or computerized (Comp), facilitated by a price clock. MRS ran their auctions by hand, and our hand-run treatment was an attempt to find an asymmetry between buyers and sellers using their protocols. We then conducted the computerized experiments as a robustness check. ${ }^{3}$ The interaction of our two treatment variables gives us four treatments: ED_Hand, DE_Hand, ED_Comp and DE_Comp. We describe the pricing institutions first.

\section{[Table 2]}

\footnotetext{
${ }^{3}$ The hand-run experiments were conducted at an East Coast university, while the computerized experiments were conducted at a university on the West Coast. Consequently, the computerized sessions simultaneously test for robustness to the auction implementation and the subject pool.
} 
Characteristic of clock auctions, the prices were announced and traders adjusted quantities in response. In the ED sessions, the starting price was set to zero in each period and increased in response to excess demand. By default, at the starting price buyers automatically demanded all of the units on their demand schedules, totaling 24 units, while sellers supplied zero units. Thus, the initial excess demand was always 24 .

As the price ascended, buyers could reduce their demand in single unit decrements and sellers could increase their supply in single unit increments, though they were allowed to make multiple reductions/additions at the same price. In either case, excess demand fell by one unit each time a trader initiated an alteration. Initially the price rose by 10-cent increments; when excess demand fell to 10 units or less the price increment was reduced to five cents. When the excess demand converged to zero the auction was closed. All of the units that were still demanded by buyers were satisfied by the units that had been supplied by sellers and all transactions occurred at the final, market-clearing price.

In the sessions with a DE pricing rule, both sides of the market were presented with a single descending price. We consistently started the price at $\$ 7.00$, above all traders' values and costs. At the starting price buyers were (by default) unwilling to purchase any units and sellers offered every unit on their supply schedules, creating an excess supply of 24 units. In response to decreasing price announcements, sellers could reduce supply and buyers could increase demand, both of which reduced the excess supply by single-unit decrements. The price continued to fall by 10-cent decrements with excess supply greater than 10 and by five-cent decrements thereafter until a price was reached at which quantity supplied equaled quantity demanded. All transactions occurred simultaneously at this price. 
Now we turn to the auction format. In the hand-run experiments a human auctioneer coordinated the auctions. The auctioneer called out prices verbally and traders indicated a desire to alter their quantities supplied or demanded by raising an ID card. To recognize an alteration, the auctioneer called out the trader's ID number (in first-come, first-served order), then announced the new excess supply or demand, and finally repeated the price to allow for additional alterations by the same trader or others at that price. When no more traders raised their ID cards, the auctioneer announced a higher price, using the price increments or decrements described above.

In the computerized experiments the role of the auctioneer was supplied by an interactive software interface. An automated price clock on their screens showed traders the current price. The price clock incremented or decremented the price every two seconds so long as there was excess demand or supply. A button on traders' screens allowed them to alter the number of units supplied or demanded. Each click of the button altered a trader's supply or demand by one unit. Each time the button was clicked, the price clock paused on its current price for an additional second. This allowed traders to alter the number of units supplied or demanded by multiple units at the same price.

The exact excess demand or supply was prominently displayed on the screen with a colored background. At the start of each period the background was green, indicating that excess demand or supply was greater than 10 units and the price would adjust in 10-cent increments or decrements. When the displayed excess demand or supply fell to 10 units the background color changed to yellow, indicating that the price would adjust in five-cent increments or decrements. When supply equaled demand the background color changed to red to indicate that the auction had concluded. 


\subsection{Procedures}

We randomly recruited subjects from a pool of undergraduate students who had agreed to receive invitations to economic experiments on campus. ${ }^{4}$ Before each session, we took the subjects through a hypothetical example of how the auction would proceed. ${ }^{5}$ They were allowed to ask questions throughout the instructions, after which they participated in a practice round to become familiar with the trading rules. In the hand-run treatments the same auctioneer announced prices and managed traders in all sessions and periods in order to maintain uniformity across pricing rules within the hand-run treatment cells.

In addition to a $\$ 7$ participation bonus, traders in the hand-run sessions earned $\$ 20.00$ on average. In the computerized sessions the average trader earned $\$ 19.96$ in addition to the participation bonus. Including time for instructions, the hand-run sessions typically lasted 45 60 minutes, while the computerized sessions lasted 25 - 35 minutes.

140 students participated as traders, with ten traders in each experimental session. We conducted three sessions of the ED_Hand and DE_Hand treatments, yielding 90 auctions for analysis. In addition, we conducted four sessions of the ED_Comp and DE_Comp treatments, giving us 120 auctions.

\section{Results}

Summary statistics are provided in Table 3 by treatment of the prevalence of underrevelation, efficiency and price deviation from the midpoint of the CE price tunnel, and trader earnings as a percentage of the Nash Equilibrium baseline. There was considerable evolution in

\footnotetext{
4 This method of recruitment was used at both universities.

5 The instructions and example we used are available in Appendix B.
} 
trader behavior over time, so for each category we provide the average in the first five and final five auctions.

\section{[Table 3]}

\subsection{Under-Revelation}

We measure under-revelation as the percentage of units not demanded (or supplied) at market clearing prices below value (or above cost). This measure is consistent for buyers or sellers irrespective of clock direction. Specifically, the under-revelation by trader $i$ in period $t, \delta_{i t}$, can be expressed as:

$$
\delta_{i t}=\frac{Q_{i t}-q_{i t}}{Q_{i t}}
$$

Where $Q_{i t}$ is the total number of units on the demand (supply) schedule of trader $i$ valued more (costing less) than the market clearing price in period $t$ and $q_{i t}$ is the number of trades transacted by trader $i$ in period $t$.

Under-revelation was widespread although it was not an individually profitable strategy and became less common with experience (see Figures 3 and 4). Across all of our experiments there were 1680 instances in which traders who were not extra-marginal could under-reveal to manipulate the uniform price. They did so in 919 cases, a frequency of 54.7\%. For each case of under-revelation, we calculated the trader's profit and compared it to the profit he would have earned if he had acted as a price taker at the Nash Equilibrium price. An overwhelming majority of the under-revelation was unprofitable, with earnings lower than the price-taking baseline in 820 cases (89.2\%). The profitability of under-revelation did not vary systematically by role or treatment cell. 
Figures 3a and 3b display the average delta among buyers in the hand-run and computerized sessions respectively. The buyers show a distinct sensitivity to clock direction. In the hand-run treatments, demand reduction was higher, on average, with an ED rule than a DE rule in 13 of 15 periods. In the computerized treatments average demand reduction was higher with an ED clock in 14 periods, though it did show convergence in periods 12 through 15 . This was primarily due to an increase in demand reduction under the DE clock in those periods.

\section{[Figure 3]}

Sellers reduced supply at very similar rates under both an ascending and descending clock (see Figures 3c and 3d). In the hand-run experiments average supply reduction was substantially higher under a DE price rule for the first two periods, but appears to have converged by period three or four. In the computerized experiments average supply reduction was indistinguishable throughout the sessions.

To formally test for the influence of the clock direction, we use the following random-effects regression model:

$$
y_{i t}=\alpha+\beta_{1} E D+\beta_{2} f(t)+\mu_{i}+\varepsilon_{i t}
$$

In regression (1), $y_{i t}$ is the dependent variable of interest in period $t$ of session $i^{6}$ and $E D$ is a dummy variable indicating whether an ED clock was used. The term $f(t)$ is a regressionspecific time trend variable taking on one of three functional forms. For datasets in which the $y_{i t}$ asymptotically converge to a value from above or below, we specify $f(t)=1 / t$ and

\footnotetext{
${ }^{6}$ In the case of under-revelation $i$ indexes the subject rather than the session.
} 
$f(t)=\log (t)$ respectively. For datasets in which the $y_{i t}$ show a linear relationship with $t$, we specify $f(t)=t$. The $\mu_{i}$ are random effects assumed to be $\sim N\left(0, \sigma^{2}\right)$ and we correct the error term for an AR(1) process. We organize our findings around our dependent variables measuring under-revelation, efficiency, and deviations in price from the competitive equilibrium. For each of these variables we fit the regression model to the data from the hand-run and computerized experiments separately.

Table 4 displays the estimates from separately fitting under-revelation among buyers and sellers to regression model (1). The estimates for the hand-run data indicate that demand reduction under the ED and DE rules diverged over time, whereas supply reduction converged rather quickly under these pricing rules. The hand-run buyer regression estimates that buyers under-revealed an additional $16.1 \%$ in ED_Hand relative to DE_Hand $(p=0.027)$. This corresponds roughly to large buyers reducing demand by one additional unit, or small buyers reducing 0.5 additional units on average. This is moderated in the early periods by the estimated time trend for the ED_Hand treatment. Notice that the coefficient of ED * 1/t is $-0.339(p=$ 0.002). For $t \leq 2$, this overwhelms the estimated coefficient of ED. As $t$ increases, however, the marginal effect of the time trend diminishes, so that by period 3 buyers under-reveal more under an ascending clock than a descending clock.

For sellers in the hand-run experiments the model finds no significant main effect of the pricing rule. However, the coefficients for $1 / t$ and $\mathrm{ED} * 1 / t$ are $0.554(p<0.001)$ and $-0.487(p<$ 0.001) respectively. Thus, supply reduction was higher under the DE rule in early periods, but converged as the sessions progressed. We conducted period-wise Wald tests to determine how many periods supply reduction was statistically significantly higher in DE_Hand than in 
ED_Hand. The tests revealed statistically significant differences in only the first four periods ( $p$ $<0.05)$.

The regression estimates using data from the computerized experiments also show that buyers responded asymmetrically to the clock direction (though this faded over time) while sellers did not. In the buyer regression, the estimated coefficient of ED is $0.311(p<0.001)$, equivalent to nearly two (one) additional unit(s) reduced by large (small) buyers under an ED clock. The estimated time trend for the ED sessions is negative and significant ( $p=0.027$, however, and indicates that demand reduction fell by 1.7 percentage points each period. Periodwise Wald tests indicate that the difference in under-revelation was statistically significant for the first eleven periods $(p<0.05)$ and insignificant thereafter $(p>0.1)$. In the seller regression the estimates for $\mathrm{ED}$ and $\mathrm{ED} * t$ are both small and statistically insignificant. We may therefore conclude that sellers in the computerized session were unresponsive to the direction of the clock.

\section{[Table 4]}

Our results indicate that we may answer research question $Q 1$ in the affirmative: worsening terms of trade encouraged a greater increase in under-revelation among buyers than among sellers. To our knowledge, these are the first experiments to show a link between clock direction and under-revelation, and an explanation for these results is not readily available in the extant auction literature. The tendency of buyers in multi-unit English auctions to reduce demand has been known for quite some time. Alsemgeest, Nousair and Olson (1998), Kagel and Levin (2001) and Porter and Vragov (2006) all found that English auctions for multiple units encouraged under-revelation and generated lower revenue relative to uniform price sealed bid auctions. Kagel and Levin (2001) showed (and Porter and Vragov, 2006 speculate) that this was due to the fact that bidders in the English auctions had information about one another's 
withdrawals, which facilitated collusion. However, this does not explain our findings because traders in our experiments received information on changes in excess supply or demand in both the ED and DE treatments, yet it was primarily the buyers whose under-revelation changed.

The experimental investigation with results most similar to our own was performed by Brown, Plott and Sullivan (2008). They conducted laboratory auctions in which eight buyers bid for eight items in simultaneous auctions. Valuations were assigned so that each buyer had the highest value for one item, the second highest value for another item, and so on. This provided an opportunity for collusive under-revelation, in which each buyer bid only on his own most highly valued item, winning it at the lowest possible price. In one treatment they sold the items with simultaneous open outcry English auctions (i.e., prices ascended but were not controlled by a price clock). In a second they used simultaneous Dutch clock auctions. Brown, Plott and Sullivan (2008) report that buyers practiced the collusive strategy in the English auctions, but bid competitively in the Dutch auctions. However, they show that collusion was a Nash Equilibrium in the English auctions, but not the Dutch auctions, due to the inability to punish defection in the latter. In our experiments the Nash Equilibria were symmetrical across price institutions.

Finally, McCabe, Rassenti and Smith (1990) conducted one-sided multiple-unit English and Dutch auctions. They found that prices were slightly lower than the theoretical prediction in the English auctions and higher than the theoretical prediction in the Dutch. However, although their auctions allocated multiple units, each bidder could win only one unit. Thus, underrevelation was not an equilibrium strategy in their experiments. The high prices in their Dutch auctions may therefore be due to risk averse bidders. The low prices in their English auctions may have been caused by bidders with relatively low values dropping out of the auction early. 
Our own experiments were designed to determine the existence of an asymmetry between buyers and sellers, rather than to uncover the source of the asymmetry. However, we offer one hypothesis that we consider plausible, if speculative. Notice that under-revealing more in the face of worsening terms of trade is consistent with loss aversion (Kahneman and Tversky 1979, Tversky and Kahneman 1991). It is well known that agents are often more eager to avoid losses than they are to avoid gains. In the ED treatments the buyers saw their potential profits falling over the course of the auction, whereas in the DE treatments they saw their potential profits increasing. Loss aversion may have motivated them to under-reveal more to stop the ED clock than to prolong the progress of the DE clock. If this was the case, then the fact that the sellers responded substantially less to the clock direction suggests that they had little or no loss aversion. That is, an agent's degree of loss aversion may be susceptible to framing effects, such as whether they are a buyer or seller. We believe this explanation should be the subject of future experimental inquiry.

\subsection{Efficiency}

Research question Q2 asks whether the clock direction affects an auction's efficiency. We have noted the close link between strategic reductionunder-revelation and efficiency. As a result of this link we would expect the clock direction to influence the observed efficiencies as well. If buyers reduce demand more under an ED clock but sellers are unresponsive to the clock direction then we would expect more under-revelation in the ED treatments relative to the $\mathrm{DE}$ treatments, and therefore lower efficiency. Moreover, since demand reduction diverged in the hand-run experiments and converged in the computerized experiments, we would expect similar patterns of divergence and convergence in the efficiency data, though the durations may be different. This is because the relationship between under-revelation and efficiency is a noisy 
one. Demand reduction among buyers with higher values will impact efficiency more substantially than reduction among those with lower values.

\section{[Figure 4]}

Figure 4 displays average efficiencies by period. In the hand-run experiments average efficiency shows a quick convergence after the first two periods, in which it was actually higher under the ED clock. This convergence ended in period nine, where there is a visible separation in which the DE_Hand dominates the ED_Hand. In the computerized experiments efficiency appears to be higher under a DE clock for the first six periods and virtually identical thereafter.

\section{[Table 5]}

Our regression models support these findings (see Table 5). The model for the hand-run data estimates that efficiency was $45.5 \%$ in the first period of DE_Hand $(p<0.001)$, while it was 18.1 percentage points higher in the same period of ED_Hand $(p=0.008)$. However, the estimated coefficient for ED * $\log (\mathrm{t})$ is negative and significant $(p=0.001)$, indicating that efficiency grew faster under a DE clock. The model estimates that by the $10^{\text {th }}$ period of DE_Hand efficiency had increased by 42.7 percentage points $(p<0.001)$ to $87.7 \%$. In the same period of ED_Hand it had increased by only 16.9 percentage points to $80.5 \%$. Using period-wise Wald tests, we find that efficiency was significantly higher $(p<0.05)$ in DE_Hand for the last seven periods.

In the computerized sessions our model estimates that efficiency was initially 15.1 percentage points lower in ED_Comp than in DE_Comp ( $p=0.017)$, but this difference disappeared over time. The estimated coefficient for ED $* t$ is positive and significant $(p=$ 0.027), and indicates that efficiency grew 1.1 percentage points faster per period with an ED 
clock. Period-wise Wald tests find that efficiency was significantly higher in DE_Hand $(p<$ 0.05) for the first five periods and marginally significantly higher in period six $(p=0.069)$.

Finally, it is worth noting that the computerized auctions were noticeably less efficient than the hand-run ones, even though they started at a higher average level of efficiency. In the final five periods of the hand-run sessions the average efficiencies were $80.5 \%$ for the ED clock and $89.4 \%$ for the DE. In the computerized sessions these averages were $73.8 \%$ for ED and 76.4\% for DE. Using the average efficiency per session as our unit of observation we conducted three Mann-Whitney tests, one for each clock direction and a third pooling all observations. The first two tests indicate that efficiency is significantly higher in the hand-run experiments at the $5 \%$ level regardless of the clock direction $(p=0.034$ in both cases). The pooled test finds efficiency to be higher in the hand-run experiments at the $1 \%$ significance level $(p=0.003)$.

The hand-run and computerized experiments were conducted at separate locations, so it is possible that the differences in efficiency reflect differences across subject pools. It may also be that the hand-run format was more conducive to learning, so that traders in that format discarded fewer high value and low cost units. Yet another possibility is that the difference is inherent in the details of the formats themselves.

Under both auction formats a majority of traders’ activity tended to happen in the last few seconds of the auction. It was not uncommon, for instance, for excess supply or demand to fall from ten or more units to zero units in the final tick of the clock. In the hand-run experiments traders were allowed to alter their trading commitments multiple times at the same price, but this required raising their ID cards multiple times. The auctioneer attempted to recognize IDs in first come, first served order, and in many cases multiple ID cards were raised at roughly the same time at the final price. Consequently, the auctioneer prioritized alterations at the final price by 
cycling through traders. In the computerized experiments traders did not have to wait to be recognized and alterations were prioritized by which traders clicked their buttons the fastest. Under this prioritization scheme, one buyer (seller) could reduce all of his units at a given price before any sellers had managed to supply (demand) them. One consequence of this could be that alterations were more evenly spread out between buyers and sellers in the hand-run experiments. A second consequence could be that, in the race to reduce units at the end of an auction, traders in the electronic experiments clicked the buttons on their screens more times than they intended. In either case the result would be lower levels of reduction in the hand-run experiments.

We tested whether reduction was lower in the hand-run experiments by conducting a Mann-Whitney test with average under-revelation by session as the unit of observation. Overall, participants under-revealed by $20.5 \%$ in the hand-run sessions and $31 \%$ in the computerized sessions. The two samples are significantly different at the $5 \%$ level $(p=0.014)$. To test whether the electronic interface encouraged accidental reductions we measured the frequency with which traders reduced all of their units. (We excluded auctions in which the trader was extra marginal and reduction of all units was the Nash Equilibrium strategy.) Reducing all units strongly suggests an error on the trader's part because it guarantees that his earnings for the auction will be zero. The average trader reduced all of his units in $6 \%$ of auctions in the handrun experiments and $10 \%$ of units in the electronic auctions. A Mann-Whitney test confirms that the distributions are statistically different across auction formats $(p=0.043)$.

A final piece of evidence that the auction format influenced efficiency through underrevelation is the variance of traders' reduction across rounds. For each participant we measured the variance in the percent of units he reduced across all auctions in which he was not an extra 
marginal trader. In the electronic experiments, where the number of units reduced was dependent on whether one was among the first to start reducing, the average variance was 9 percentage points. In the hand-run experiments, where the auctioneer cycled through traders who tried to reduce simultaneously, the average variance was 6 percentage points. The distributions are statistically different according to a Mann-Whitney test $(p<0.001)$.

These results strongly suggest that efficiency was degraded by chaotic trader behavior in the last few seconds of an auction, and that a human auctioneer kept the chaos in check to some extent. In many applications in the field a human auctioneer would be impractical, yet it may still be possible to enhance a uniform-price auction's efficiency through simple rules that promote a more orderly processing of traders' decisions. For example, rather than processing each decision sequentially, the auction software may process them in batches, with all orders submitted at the same price increment processed simultaneously. Under such a simultaneous processing rule, the software could cycle through each trader in much the same way as our human auctioneer did, executing one order from a given trader at a time until all orders were processed or there was no excess supply or demand. Alternatively, the software could explicitly favor higher trade volume by first executing all orders in the batch that increase the traders' commitments, and then executing the orders that reduce them if there was still excess supply or demand. This processing rule may be appropriate as a counterbalance to traders' tendency to under-reveal.

\subsection{Price}

Finally, we turn to whether the clock direction affects an auction's uniform price (research question Q3). Because the Nash Equilibrium prices are slightly higher for the DE (M + 5) than the ED (M - 5) we are particularly interested in whether under-revelation generates a 
larger difference in prices than the game theoretic prediction. Figure 5 displays the average deviation from the midpoint of the CE tunnel by period. In both auction formats the clock direction influenced prices, although they were rarely exactly equal to the Nash Equilibrium in any treatment. In the ED sessions the final price was equal to $M-5$ in $24.4 \%$ of the hand-run auctions and $20 \%$ of the computerized auctions. With a DE clock the final price equaled $M+5$ in $20 \%$ of the hand-run auctions and $18.3 \%$ of the computerized auctions.

\section{[Figure 5]}

However, prices in the majority of auctions were within the CE price tunnel. In $55 \%$ of the computerized auctions (66 of 120) the final price was within 10 cents of the CE midpoint. The prices were even more consistent with the CE in the hand-run experiments: $86.7 \%$ of the hand-run auctions (78 of 90) generated CE prices. In the computerized experiments the two clock directions resulted in prices that were extremely disparate in the early periods but converged over the duration of the sessions. In the hand-run experiments the price differences were generally consistent with the Nash Equilibrium.

\section{[Table 6]}

We use the deviation from the CE mid-point as a dependent variable in regression model (1) for both auction formats (see Table 6). ${ }^{7}$ If prices did not systematically deviate from the Nash Equilibrium predictions then we would expect the estimated constant to be 5 and the sum of the constant and estimated coefficient of ED to equal -5. For the hand-run experiments the estimated constant term is 2.34, and this is not significantly different from 5 (Wald Test, $p=$ 0.376). The estimated coefficient of ED is $-8.27(p=0.052)$, and its sum with the estimated

\footnotetext{
${ }^{7}$ Recall from Figure 1 that the price tunnel spans 20 cents, so taken from the midpoint of the tunnel a price in the interval $[-10,10]$ is consistent with the competitive equilibrium.
} 
constant is -5.93 . A Wald test cannot reject the null hypothesis that this sum is equal to -5 ( $p=$ 0.757). Thus, we can conclude that prices in the hand-run experiments were consistent with the Nash Equilibrium on average. This was persistent across the duration of the experiments, as the time trend variables are not significant in the hand-run model.

The model estimates using data from the electronic experiments confirm that in those sessions the clock direction's influence was profound in the initial auctions but waned over time. The estimated constant term indicates that prices in the DE_Comp were almost 19 cents above the CE midpoint in the first auction $(p=0.002)$. Prices for the same auction were more than 36 cents below the midpoint in the ED_Comp, as the coefficient for ED is $-55.30(p<0.001)$. However, the time trend coefficients show strong convergence over time. $\log (\mathrm{t})$ is negative and marginally significant $(p=0.062)$, while ED $* \log (t)$ is positive and highly significant $(\mathrm{p}<$

0.001). Because the time trend variables are designated in logs of base 10 , the most straightforward interpretation of their coefficients is the change in prices as of the tenth auction. Using this interpretation, prices in the DE_Comp had fallen by more than 12 cents and prices in the ED_Comp had risen by almost 45 cents. Using period-wise Wald tests, we find that prices in the DE_Comp were significantly greater than 5 in the first 4 auctions $(p<0.043)$ and not significantly different than 5 thereafter $(p \geq 0.092)$. A similar analysis indicates that prices in the ED_Comp were statistically significantly less than -5 in the first 12 auctions $(p \leq 0.025)$ and were consistent with the Nash Equilibrium in only the final 3 auctions ( $p \geq 0.075)$.

\section{Concluding Remarks}

MRS's early work in multi-unit clock auctions suggested that buyers (but not sellers) under-reveal more when they face worsening terms of trade than when they face improving terms of trade. We explicitly test for this asymmetry in both a hand-run and computerized 
environment. Our experiments reveal that the asymmetry is real, although its pattern is not consistent. In our hand-run auctions buyer and seller behavior diverges over time, so that it takes a few periods for the asymmetry to emerge. In our computerized auctions the asymmetry is apparent (and large) from the very first auction, but diminishes with experience.

As a result of the observed behavioral asymmetry, prices and efficiency are generally higher when the auction uses a descending price rule. For two-sided call auctions this implies that the DE institution is preferable from a social perspective, though it will likely be more popular among sellers than buyers. An interesting question for future research is whether buyers' response to the direction of the price clock carries over to one-sided auctions as well as two-sided auctions. If so, then sellers in multi-unit auctions in the field may be able to enhance their revenues and improve social welfare simply by implementing a descending price rule.

In addition to the asymmetry in buyer behavior, our experiments indicate that the rules by which traders' orders are processed can have a substantial impact on allocative efficiency. Gains from trade were 6.7 to 13 percentage points higher with a human auctioneer than with a computerized auction format. This seems to be due to the fact that the computerized format enabled a more chaotic entry of orders near the close of the auction, which promoted trader error and increased the amount of under-revelation. This shortcoming in the computerized auctions might be overcome by executing the traders' orders in batches and giving priority to orders that will create trades. This type of processing rule may be especially appropriate in a field application such as the FCC's incentive auctions, where one of the primary aims is to maximize the amount of spectrum released by the incumbent license holders. 


\section{References}

Alsemgeest, P., Noussair, C., and Olson, M. (1998). Experimental comparisons of auctions under single- and multi-unit demand. Economic Inquiry, 36(1), pp. 87-97.

Ausubel, L. M., and Cramton, P. (1998). Auctioning Securities. Working paper.

Ausubel, L. M., and Cramton, P. (2002). Demand reduction and inefficiency in multi-unit auctions. Working paper.

Banks, J., Olson, M., Porter, D., Rassenti, S., and Smith, V. (2003). Theory, experiment and the federal communications commission spectrum auctions. Journal of Economic Behavior and Organization, vol. 51(3), pp. $303-350$.

Bronfman, Corinne, Kevin McCabe, David Porter, Stephen Rassenti and Vernon Smith. (1996). An experimental examination of the Walrasian tatonnement mechanism. RAND Journal of Economics, vol. 27(4), pp. 681-699.

Brown, Alexander, Charles R. Plott and Heidi J. Sullivan. (2008). Collusion facilitating and collusion breaking power of simultaneous ascending and descending price auctions. Economic Inquiry, Vol. 47(3), pp. 395-424.

Budish, Eric B., Peter Cramton and John J. Shim. (2013). The high-frequency trading arms race: frequent batch auctions as a market design response. Chicago Booth Research Paper No. 14-03.

Cramton, P. (1998). Ascending Auctions. European Economic Review, vol. 42(3-5), pp. 745 756.

Cramton, P., and Kerr, S. (1999). The Distributional Effects of Carbon Regulation in Thomas Sterner (ed.) The Market and the Environment, Cheltenham, UK: Edward Elgar, chp. 12.

Davis, Douglas D. and Charles A. Holt. (1994). Market power and mergers in laboratory markets with posted prices. RAND Journal of Economics, vol. 25(3), 467-487.

Easley, David, Marcos Lopez de Prado and Maureen O’Hara. (2011). The microstructure of the "flash crash": flow toxicity, liquidity crashes and the probability of informed trading. The Journal of Portfolio Management, 37(2), 118-128.

Engelbrecht-Wiggans, R., List, J. A., and Reiley, D. H. (2006). Demand reduction in multiunit auctions with varying numbers of bidders: theory and evidence from a field experiment. International Economic Review, 47(1), 203-231.

Holt, Charles A. (1989). The exercise of market power in laboratory experiments. Journal of Law and Economics, vol. 32(2), S107 - S130. 
Kagel, J. H., and Levin, D. (2001). Behavior in multi-unit demand auctions: experiments with uniform price and dynamic Vickrey auctions. Econometrica, vol. 69(2), pp. 413-454.

Kahneman, D., and Tversky, A. (1979). Prospect theory of decisions under risk. Econometrica, vol. 47(2), pp. 263-291.

Krishna, V. (2009). Auction Theory. San Diego: Academic Press, $2^{\text {nd }}$ edition.

Levati, M. V., and Neugebauer, T. (2004). An application of the English clock market mechanism to public goods games. Experimental Economics, vol. 7(2), pp. $153-169$.

List, J. A., and Lucking-Reiley, D. (2000). Demand reduction in multiunit auctions: evidence from a sportscard field experiment. American Economic Review, 90(4), 961972.

McCabe, K. A., Rassenti, S. J., and Smith, V. L. (1990). Auction institutional design: Theory and behavior of simultaneous multiple-unit generalizations of the Dutch and English auctions. American Economic Review, vol. 80(5), pp. 1276-1283.

. (1992). Designing call auction institutions: Is double Dutch the best? The Economic Journal, vol. 102(410), pp. 9-23.

. (1993). Designing a Uniform Price Double Auction; An Experimental Evaluation. In Daniel Friedman and John Rust (Eds.), The Double Auction Market: Institutions, Theories, and Evidence (307-332). Cambridge, MA: Perseus Publishing.

Milgrom, Paul, Lawrence Ausubel, Jon Levin and Ilya Segal. (2012). Incentive auction rules option and discussion.

Pagano, Marco. (1989). Endogenous market thinness and stock price volatility. Review of Economic Studies, 56(2), 269-287.

Porter, D., Rassenti, S., Shobe, W., Smith, V., and Winn, A. (2009). The design, testing and implementation of Virginia's NOx allowance auction. Journal of Economic Behavior and Organization, vol. 69(2), $190-200$.

Porter, D., and Vragov, R. (2006). An experimental examination of demand reduction in multi-unit versions of the uniform-price, Vickrey, and English auctions. Managerial and Decision Economics, 27(6), 445-458.

Smith, V. L. (1962). An experimental study of competitive market behavior. Journal of Political Economy, 70(2), 111-137.

Tversky, Amos and Daniel Kahneman (1991). Loss aversion in riskless choice: A referencedependent model. Quarterly Journal of Economics, vol. 106(4), pp. 1039-1061. 


\section{Figures and Tables}

Figure 1. Experimental environment with values and costs (in cents) normalized such that the midpoint of the competitive equilibrium tunnel is zero.

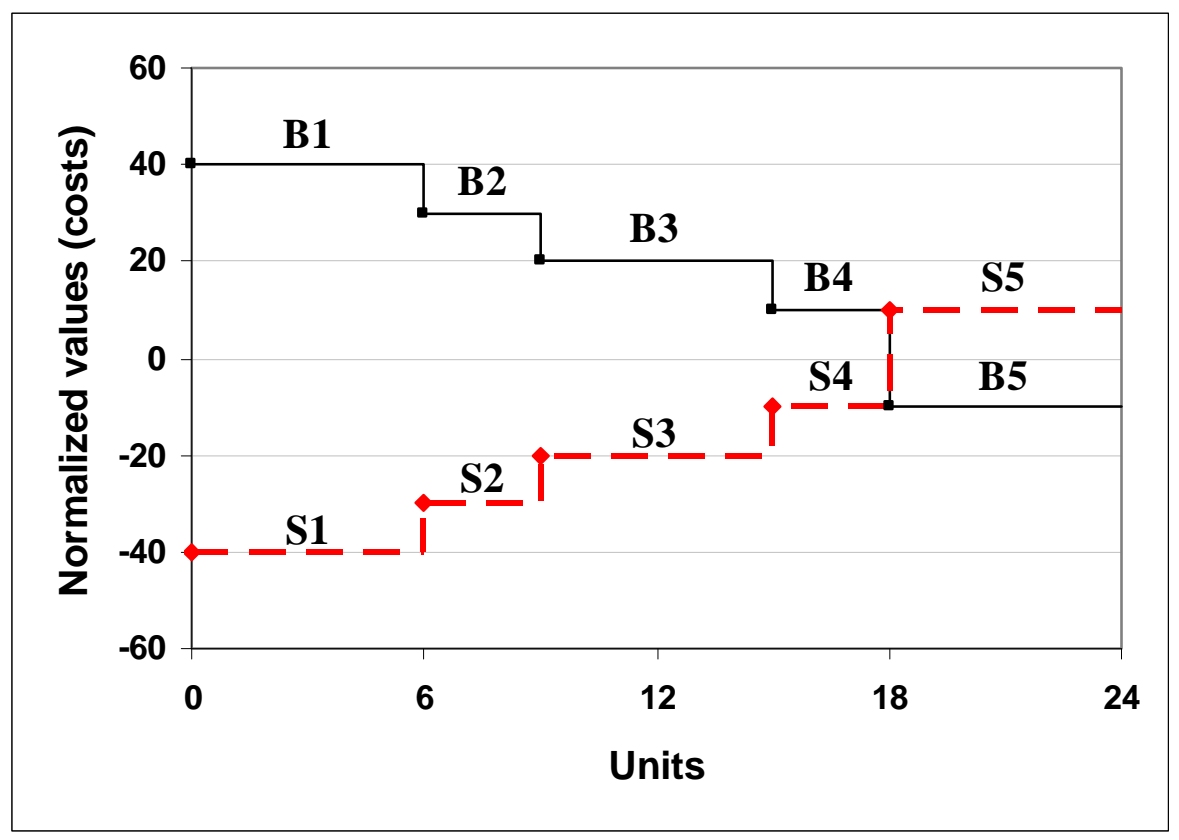


Figure 2. Midpoint competitive equilibrium (CE) prices for periods 1 - 15.

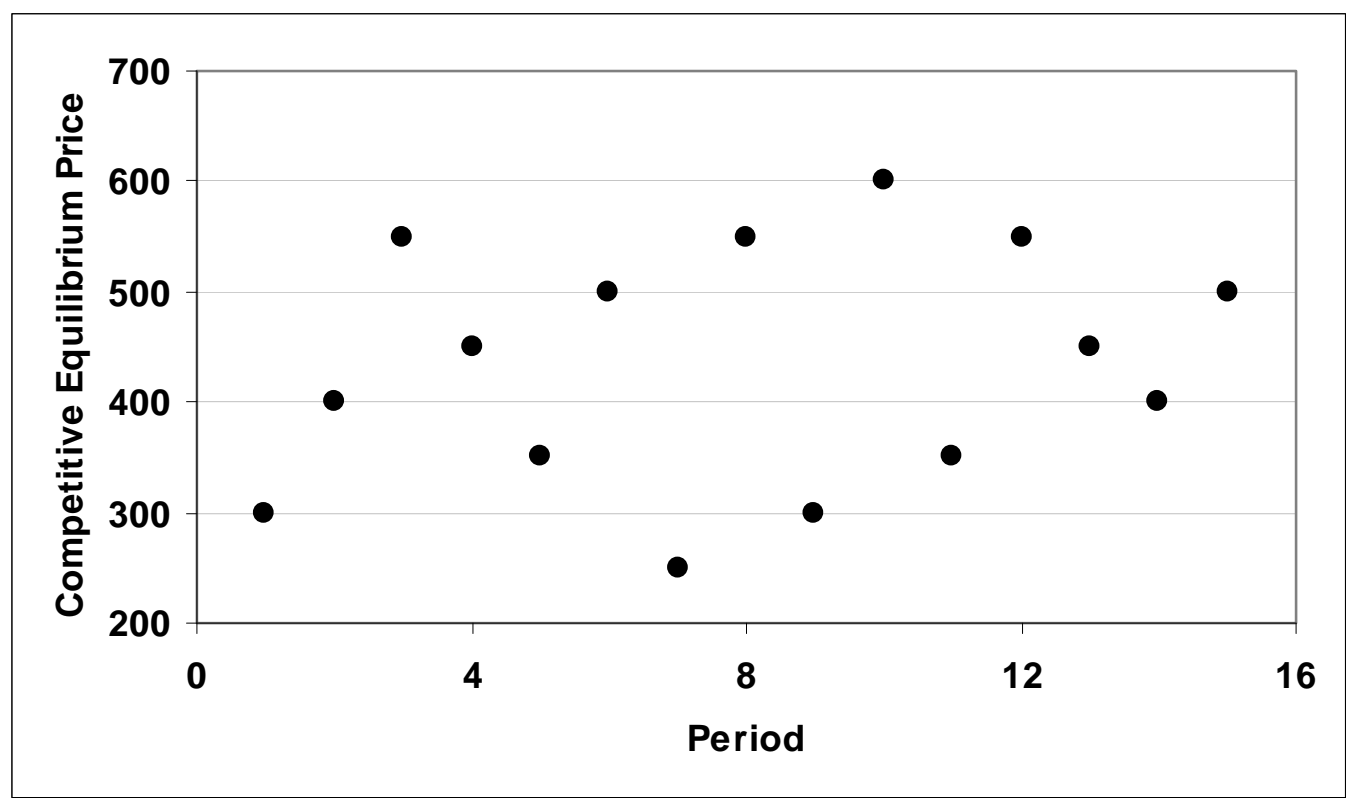


Figure 3. Average Under-Revelation a) Buyers - Hand-Run b) Buyers - Computerized c) Sellers - HandRun d) Sellers - Computerized

a) Buyers in the Hand-Run Experiments

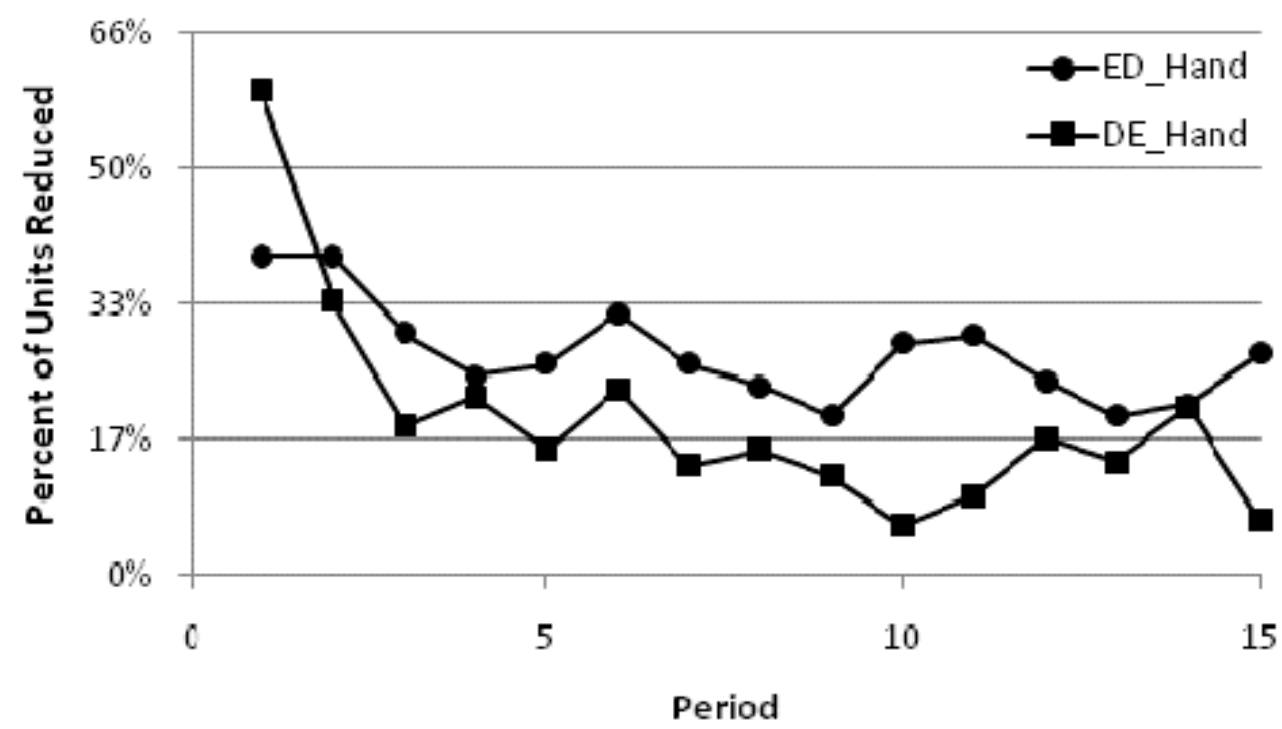

b) Buyers in the Computerized Experiments

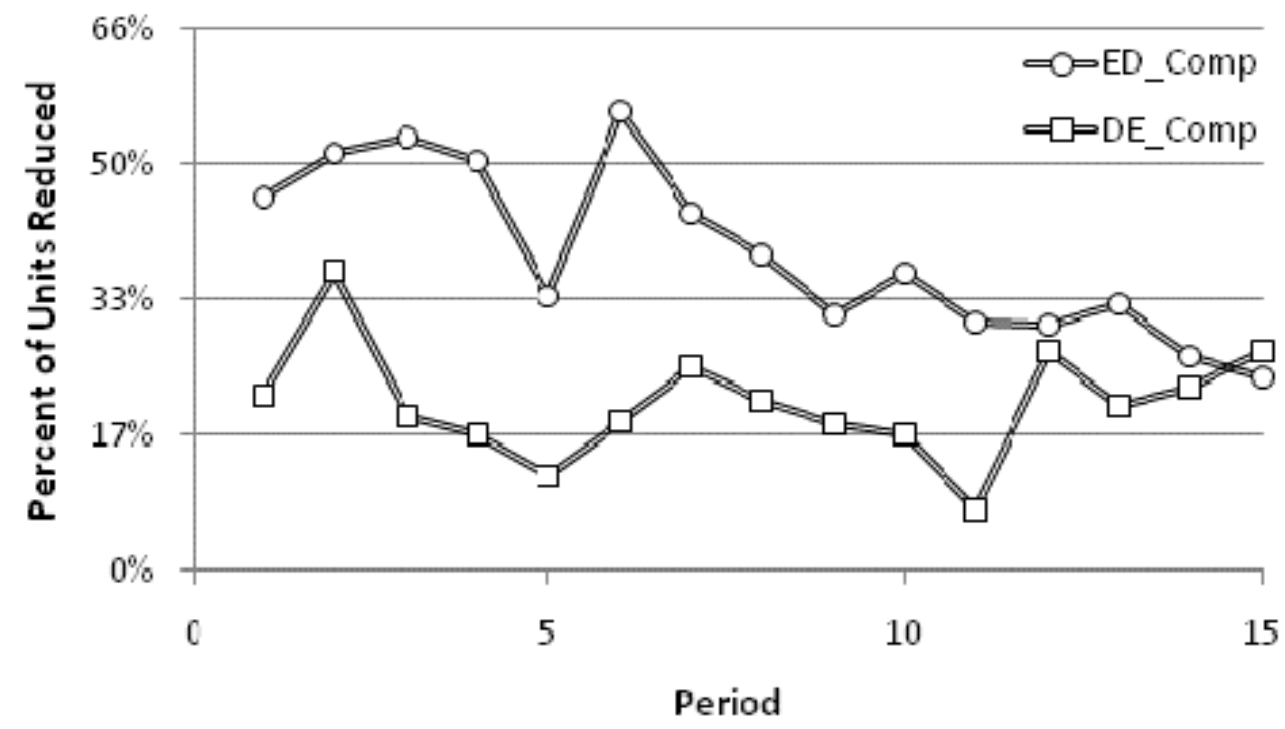


c) Sellers in the Hand-Run Experiments

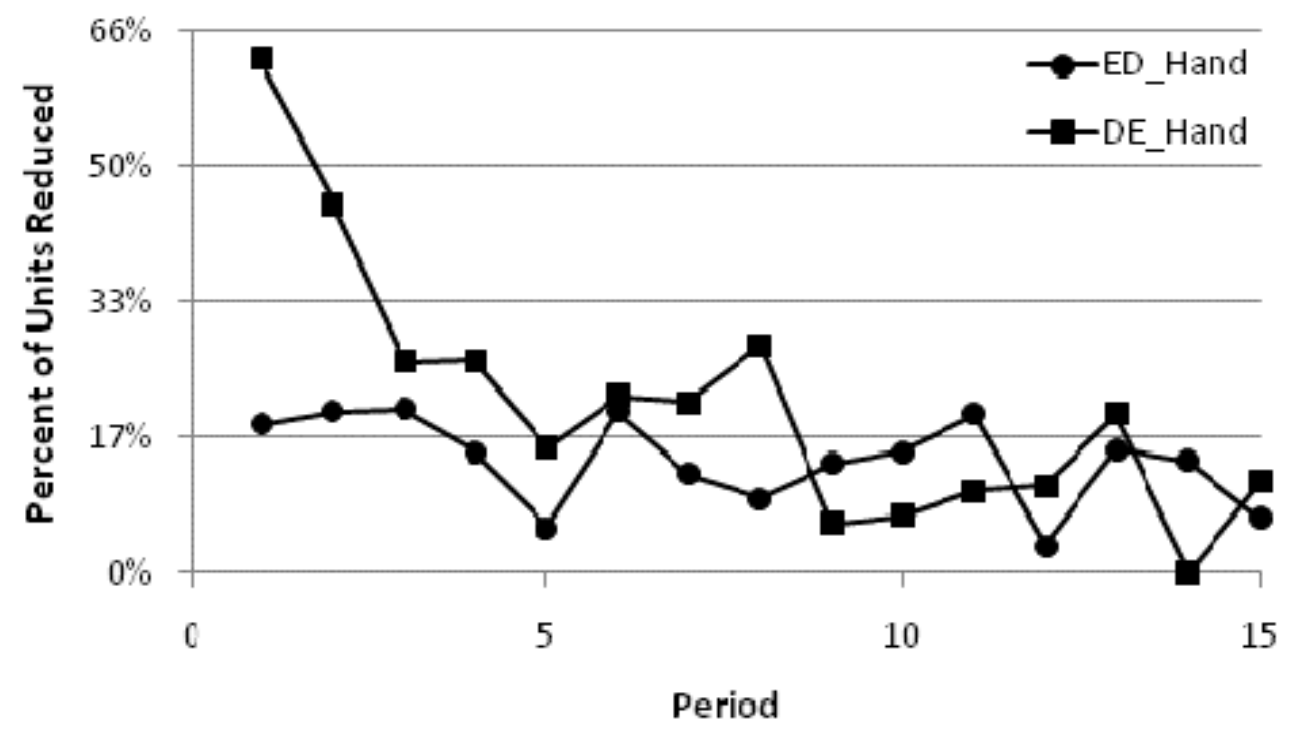

d) Sellers in the Computerized Experiments

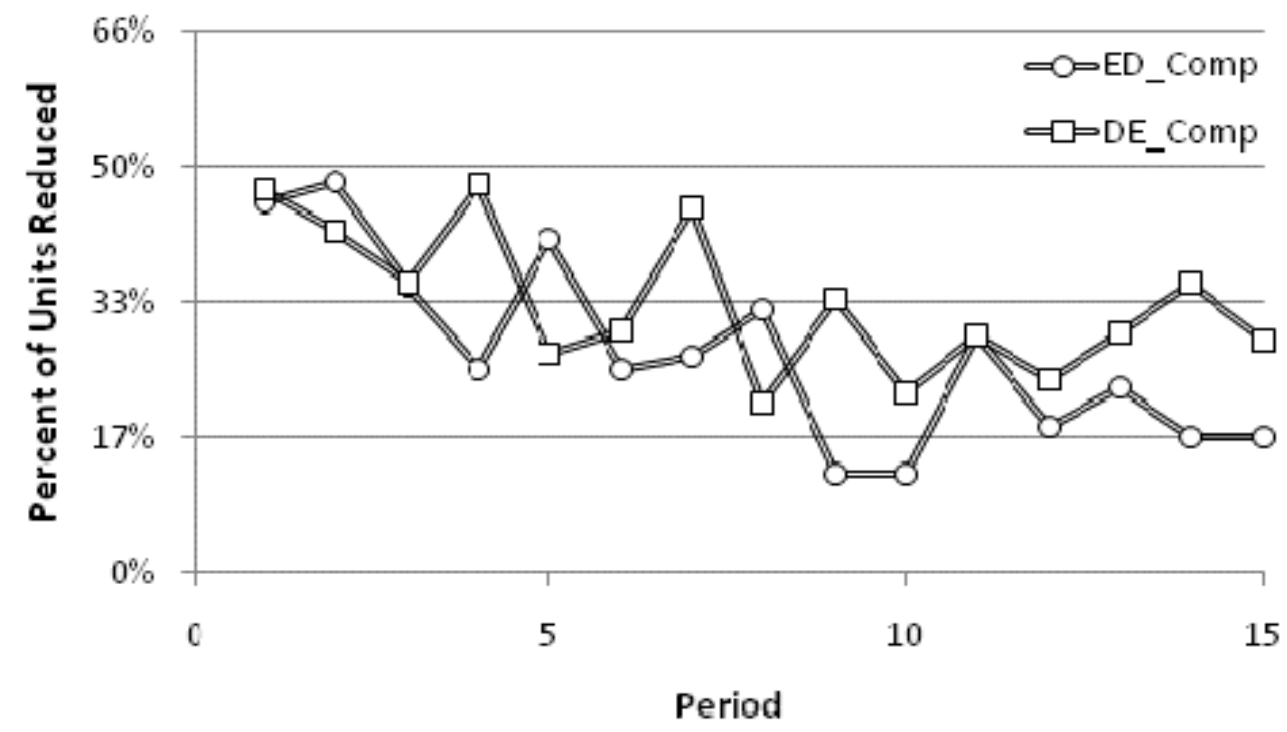


Figure 4. Evolution of Average Efficiency by Treatment

a) Hand-Run Sessions

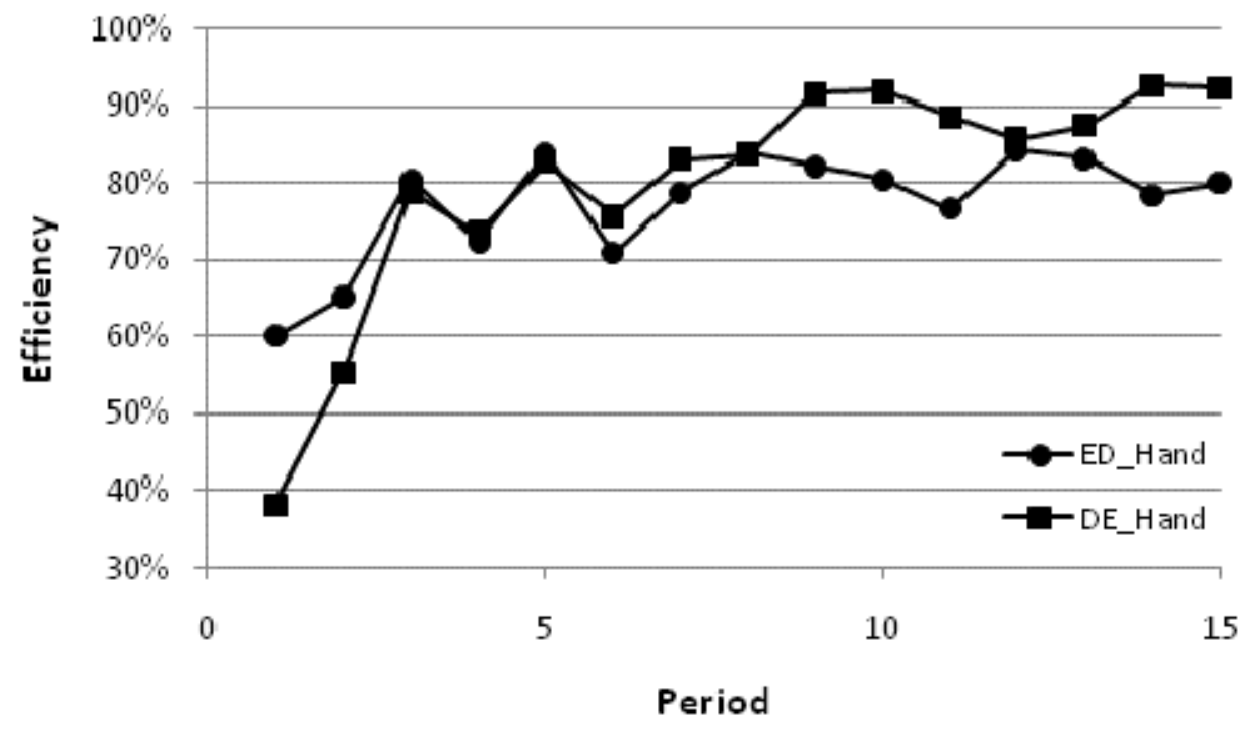

b) Computerized Sessions

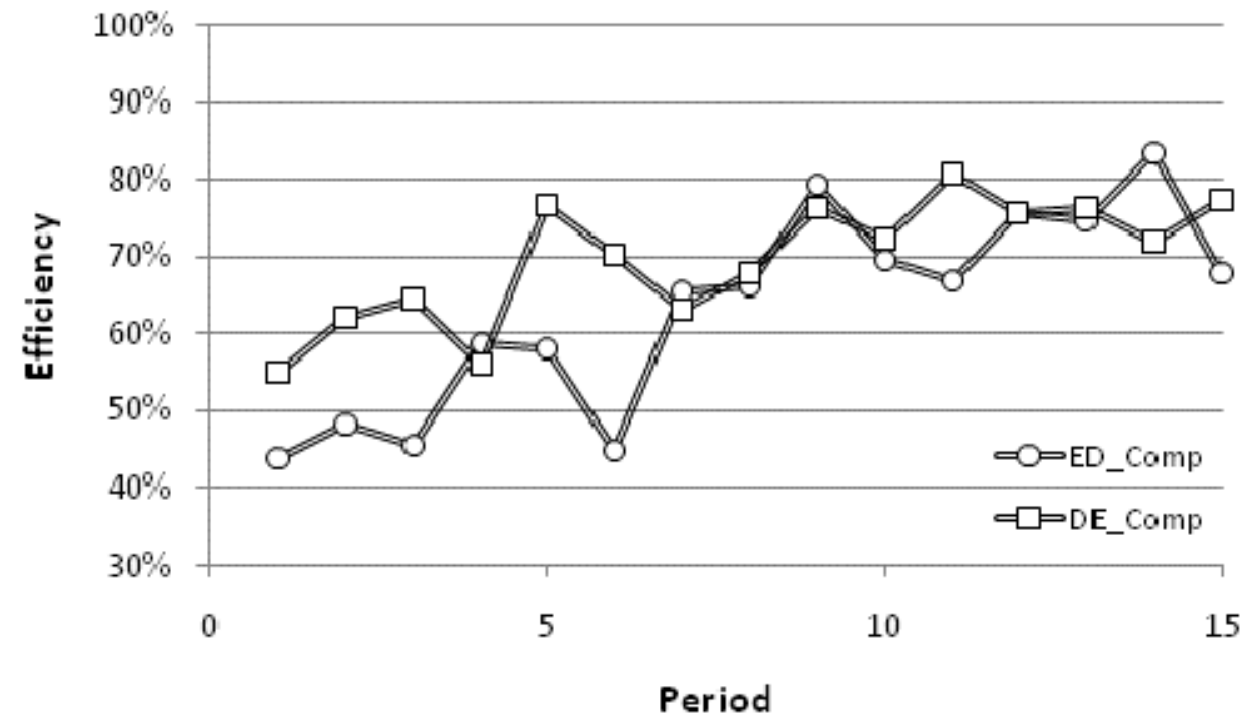


Figure 5. Deviation from the Competitive Equilibrium Price

a) Hand-Run Sessions

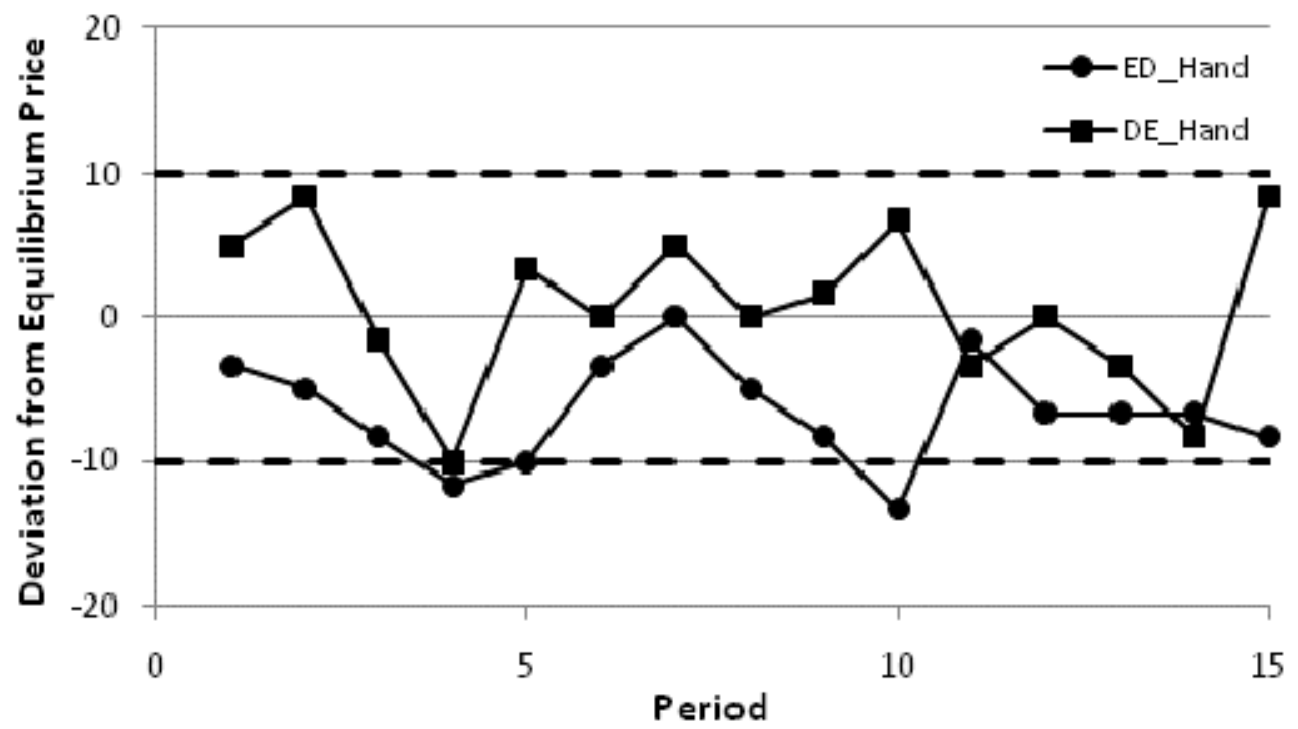

b) Computerized Sessions

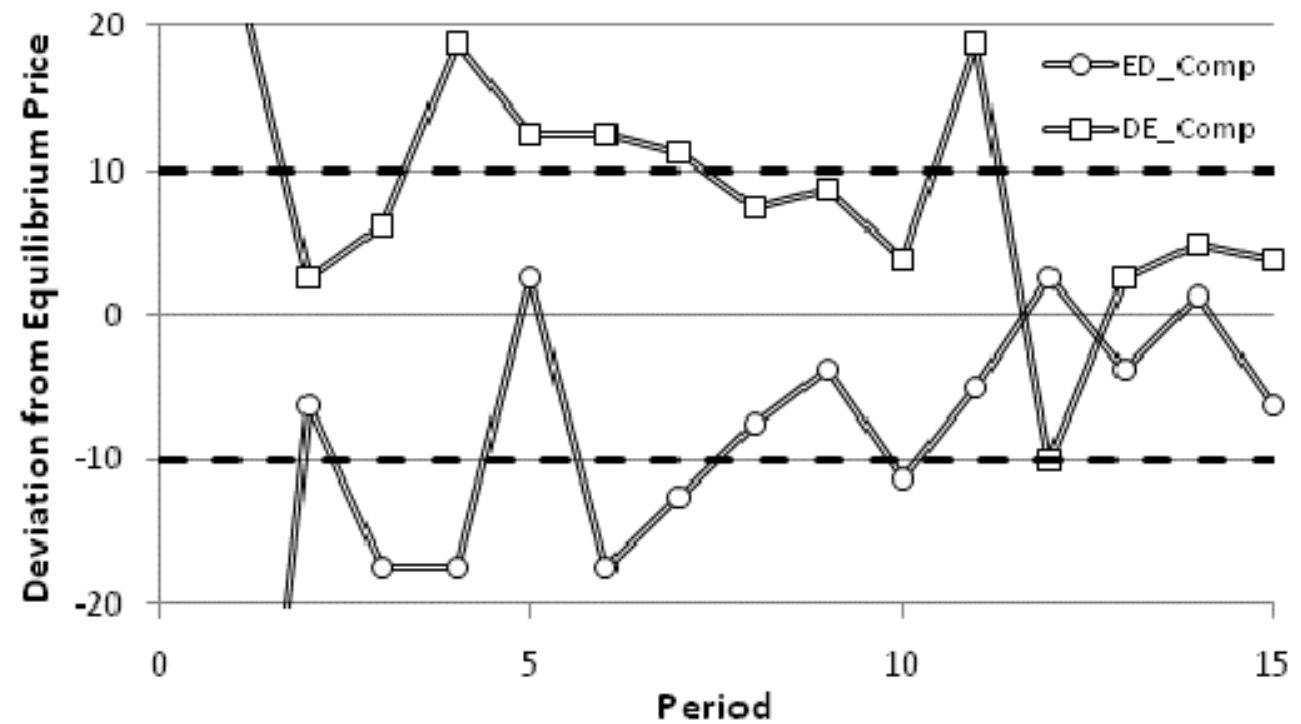


Table 1. Profit for each buyer if he 1) buys all of his units at a price of $M$, 2) buys all of his units at a price of $M$ - 5 or 3) drops one unit of demand to achieve a price of $M$ - 10. (Buyer B5 earns no profit at any of these prices and is therefore excluded from the analysis.)

\begin{tabular}{ccccccccccc}
\hline \hline & \multicolumn{3}{c}{ Buy all units at price $M$} & \multicolumn{3}{c}{ Buy all units at price $M-5$} & \multicolumn{3}{c}{ Drop one unit to achieve } \\
price $M-10$
\end{tabular}


Table 2. Treatment design

\begin{tabular}{lllccccc}
\hline \hline Treatment & $\begin{array}{l}\text { Auction } \\
\text { Format }\end{array}$ & $\begin{array}{l}\text { Clock } \\
\text { Direction }\end{array}$ & Sessions & $\begin{array}{c}\text { Participants } \\
\text { per Session }\end{array}$ & $\begin{array}{c}\text { Total } \\
\text { Participants }\end{array}$ & $\begin{array}{c}\text { Auctions } \\
\text { per } \\
\text { Session }\end{array}$ & $\begin{array}{c}\text { Total } \\
\text { Auctions }\end{array}$ \\
ED_Hand & Hand-run & Ascending & 3 & 10 & 30 & 15 & 45 \\
DE_Hand & Hand-run & Descending & 3 & 10 & 30 & 15 & 45 \\
ED_Comp & Electronic & Ascending & 4 & 10 & 40 & 15 & 60 \\
DE_Comp & Electronic & Descending & 4 & 10 & 40 & 15 & 60 \\
& & & & & & & $\mathbf{1 4 0}$ \\
& & Total: & $\mathbf{1 4}$ & & & & \\
\hline \hline
\end{tabular}


Table 3. Descriptive statistics of experimental results for the first five and last five in auctions each treatment

\begin{tabular}{lcccccccccc}
\hline \hline & $\begin{array}{c}\text { Under-Revelation as a } \\
\text { \% of Traders } \\
\text { Endowments }\end{array}$ & Efficiency & & Price Deviation & \multicolumn{2}{c}{$\begin{array}{c}\text { Buyer Profits } \\
\text { from CE Midpoint }\end{array}$} & $\begin{array}{c}\text { Relative to Nash } \\
\text { Equilibrium }\end{array}$ & $\begin{array}{c}\text { Relative to Nash } \\
\text { Equilibrium }\end{array}$ \\
\hline Treatment & Auctions & Auctions & Auctions & Auctions & Auctions & Auctions & Auctions & Auctions & Auctions & Auctions \\
& $1-5$ & $11-15$ & $1-5$ & $11-15$ & $1-5$ & $11-15$ & $1-5$ & $11-15$ & $1-5$ & $11-15$ \\
ED_Hand & $23.6 \%$ & $17.8 \%$ & $72.3 \%$ & $80.5 \%$ & -7.7 & -6.0 & $74.0 \%$ & $77.3 \%$ & $69.7 \%$ & $85.4 \%$ \\
DE_Hand & $32.2 \%$ & $11.9 \%$ & $65.7 \%$ & $89.4 \%$ & 1.0 & -1.3 & $82.6 \%$ & $116.1 \%$ & $54.2 \%$ & $71.1 \%$ \\
ED_Comp & $42.6 \%$ & $24.5 \%$ & $50.9 \%$ & $73.8 \%$ & -18.8 & -2.2 & $80.7 \%$ & $65.7 \%$ & $7.4 \%$ & $85.6 \%$ \\
DE_Comp & $30.3 \%$ & $24.9 \%$ & $62.9 \%$ & $76.4 \%$ & 12.8 & 4.0 & $42.1 \%$ & $84.7 \%$ & $77.1 \%$ & $70.6 \%$ \\
\hline \hline
\end{tabular}


Table 4. Estimates from regression models of under-revelation

\begin{tabular}{|c|c|c|c|c|}
\hline \multirow[b]{2}{*}{ Regressor } & \multicolumn{2}{|c|}{$\underline{\text { Hand-Run }}$} & \multicolumn{2}{|c|}{ Computerized } \\
\hline & Buyers & Sellers & Buyers & Sellers \\
\hline \multirow[t]{2}{*}{$\alpha$} & 0.072 & $0.087^{*}$ & $0.229^{* *}$ & $0.430^{* *}$ \\
\hline & $(0.052)$ & $(0.036)$ & $(0.063)$ & $(0.053)$ \\
\hline \multirow[t]{2}{*}{ ED } & $0.161^{*}$ & 0.036 & $0.311^{* *}$ & 0.006 \\
\hline & $(0.073)$ & $(0.051)$ & $(0.084)$ & $(0.081)$ \\
\hline \multirow[t]{2}{*}{$\mathrm{t}$} & & & -0.002 & $-0.012^{*}$ \\
\hline & -- & -- & $(0.006)$ & $(0.005)$ \\
\hline \multirow[t]{2}{*}{$\mathrm{ED} * \mathrm{t}$} & & & $-0.017^{*}$ & -0.008 \\
\hline & -- & -- & $(0.008)$ & $(0.008)$ \\
\hline \multirow[t]{2}{*}{$1 / \mathrm{t}$} & $0.516^{* *}$ & $0.554^{* *}$ & & \\
\hline & $(0.078)$ & $(0.080)$ & -- & -- \\
\hline \multirow[t]{2}{*}{$\mathrm{ED} * 1 / \mathrm{t}$} & $-0.339^{* *}$ & $-0.487^{* *}$ & & \\
\hline & $(0.108)$ & $(0.115)$ & -- & -- \\
\hline Observations & 356 & 325 & 450 & 445 \\
\hline $\mathrm{R}^{2}$ & 0.109 & 0.186 & 0.110 & 0.056 \\
\hline Wald $\chi^{2}$ & 51.19 & 52.51 & 23.22 & 18.07 \\
\hline \multicolumn{5}{|c|}{ * Significant at 5\% level } \\
\hline \multicolumn{5}{|c|}{ ** Significant at $1 \%$ level } \\
\hline
\end{tabular}


Table 5. Estimates from regression models of efficiency

\begin{tabular}{lcc}
\hline \hline Regressor & Hand-Run & Computerized \\
\hline$\alpha$ & $0.455^{* *}$ & $0.588^{* *}$ \\
& $(0.056)$ & $(0.045)$ \\
ED & $0.181^{* *}$ & $-0.151^{*}$ \\
& $(0.069)$ & $(0.064)$ \\
$\mathrm{t}$ & -- & $0.014^{* *}$ \\
& & $(0.003)$ \\
ED * $\mathrm{t}$ & -- & $0.011^{*}$ \\
& & $(0.005)$ \\
Log(t) & $0.427^{* *}$ & -- \\
& $(0.056)$ & - \\
ED * Log(t) & $-0.258^{* *}$ & \\
& $(0.079)$ & \\
Observations & 90 & 0.333 \\
$\mathrm{R}^{2}$ & 0.531 & 67.61 \\
Wald $\chi^{2}$ & 68.57 & \\
$*$ Significant at $5 \%$ level & \\
$* *$ Significant at 1\% level & \\
\hline \hline
\end{tabular}


Table 6. Estimates from regression models of deviation from the competitive equilibrium price

\begin{tabular}{lll}
\hline \hline Regressor & Hand-Run & Computerized \\
\hline$\alpha$ & 2.34 & $18.72^{* *}$ \\
& $(3.00)$ & $(5.90)$ \\
ED & $-8.27^{\dagger}$ & $-55.30^{* *}$ \\
& $(4.25)$ & $(8.36)$ \\
$\mathrm{t}$ & -0.19 & -- \\
& $(0.30)$ & \\
ED * $\mathrm{t}$ & 0.11 & -- \\
& $(0.42)$ & \\
Log(t) & -- & $-12.61^{\dagger}$ \\
& & $(6.75)$ \\
ED * Log(t) & -- & $44.95^{* *}$ \\
& & $(9.66)$ \\
Observations & 90 & 118 \\
$\mathrm{R}^{2}$ & 0.162 & 0.381 \\
Wald $\chi^{2}$ & 8.41 & 60.09 \\
\hline$\dagger$ Significant at $10 \%$ level & \\
$* *$ Significant at $1 \%$ level & \\
\hline \hline
\end{tabular}




\section{Appendix A. Under-revelation and trader profits}

In Section 1 we showed that in the case of an ascending price auction no buyer can profitably reduce demand to push the price from $M-5$ to $M$ - 10. In this appendix we demonstrate that no coalition of buyers could profitably reduce demand in order to reduce the price even further. We also show that no coalition of sellers could profitably reduce supply to increase the price. Since the supply and demand curves are symmetrical, our proof for the buyers (sellers) in the ED auctions holds for the sellers (buyers) in the DE auctions.

Given the supply curve, there are three prices less than $M$ - 10 that buyers could achieve through coordinated demand reduction. Reducing demand by nine units would achieve a price of $M$ - 20, reducing demand by 15 units would achieve a price of $M$ - 30 and reducing demand by 18 units would achieve a price of $M$ - 40. In Table A.1 we show the maximum number of units by which each buyer could reduce his demand and increase his profit for each of these prices. Notice that the buyers could not profitably reduce demand by enough units to achieve the lowest prices of $M-30$ or $M-40$. Buyers would be willing to reduce demand by a total of only 11 and 13 units to achieve these prices, while reductions of 15 and 18 units would be necessary to achieve them.

To achieve a price of $M$ - 20 the buyers could profitably reduce demand by 9 units, which is exactly the number needed for that price. However, the sellers could easily reduce supply to make this demand reduction unprofitable. They would need to reduce supply by only one unit to push the price back up to $M-10$. Seller S3's induced cost per unit is $M-20$. Thus he would be willing to reduce supply by one unit in order to achieve a price of $M$ - 10 and earn a positive 
profit. Consequently, there is no coalition of buyers that could profitably reduce demand to increase their profits.

Regarding the sellers we have shown in section 1 that the buyers would be willing to reduce demand in order to prevent a price equal to $M$. We now consider whether the sellers could profitably reduce supply to achieve a higher price. In Table A.2 we show the maximum number of units each seller would be willing to withhold in order to achieve a price of $M+10, M$ $+20, M+30$ or $M+40$. Notice that, similar to the buyers, there is no coalition of sellers who could profitably increase the price to $M+30$ or $M+40$. Those prices require supply reductions of 15 and 18 units, while sellers would only be willing to withhold 14 and 15 units to achieve them. The sellers would be willing to withhold a total of 13 units for a price of $M+20$, while only 9 units would need to be withheld. However, buyer B3 values six units at exactly $M+20$, and could therefore profitably withhold five of them to lower the price.

The final possibility is that the sellers withhold supply to push the price to the top of the equilibrium price tunnel, $M+10$. Sellers S1 through S4 could profitably withhold a total of six units to achieve this price, while only three units of reduction would be necessary. However, the buyers could then increase their profits by withholding a total of seven units of demand to push the price back to $M-10$. In Table A.3 we show that buyers B1 through B4 would all be willing to withhold at least one unit of demand in order to prevent a price of $M+10$, and the total number of units by which demand could be profitably reduced is eight. Consequently, there is no coalition of sellers that could profitably reduce supply to achieve a price higher than $M$ - 5 . Any coalition that tried to do so could be thwarted by a coalition of buyers who could profitably reduce demand to hold the price down. 
Table A.1. The maximum number of units by which each buyer would be willing to reduce demand to achieve a price lower than $M$ - 5 . Reported profits (in cents) are the profits a buyer would receive if a lower price were achieved given the number of units by which he reduced demand.

\begin{tabular}{|c|c|c|c|c|c|c|c|c|}
\hline \multirow[b]{3}{*}{ Buyer } & \multicolumn{8}{|c|}{ Price } \\
\hline & \multicolumn{2}{|c|}{$M-5$} & \multicolumn{2}{|c|}{$M-20$} & \multicolumn{2}{|c|}{$M-30$} & \multicolumn{2}{|c|}{$M-40$} \\
\hline & $\begin{array}{c}\text { Units } \\
\text { Bought }\end{array}$ & Profit & $\begin{array}{c}\text { Units } \\
\text { Bought }\end{array}$ & Profit & $\begin{array}{c}\text { Units } \\
\text { Bought }\end{array}$ & Profit & $\begin{array}{c}\text { Units } \\
\text { Bought }\end{array}$ & Profit \\
\hline B1 & 6 & 270 & 5 & 300 & 4 & 280 & 4 & 320 \\
\hline B2 & 3 & 105 & 3 & 105 & 2 & 120 & 2 & 140 \\
\hline B3 & 6 & 150 & 4 & 160 & 4 & 200 & 3 & 180 \\
\hline B4 & 3 & 45 & 2 & 60 & 2 & 80 & 1 & 50 \\
\hline B5 & 0 & 0 & 1 & 10 & 1 & 20 & 1 & 30 \\
\hline \multicolumn{3}{|c|}{ Total Reduction } & \multicolumn{2}{|l|}{9} & \multicolumn{2}{|l|}{11} & \multicolumn{2}{|l|}{13} \\
\hline \multicolumn{3}{|c|}{ Reduction Needed } & \multicolumn{2}{|l|}{9} & \multicolumn{2}{|l|}{15} & \multicolumn{2}{|l|}{18} \\
\hline
\end{tabular}


Table A.2. The maximum number of units each seller would be willing to withhold to achieve a price greater than $M$ - 5 . Reported profits (in cents) are the profits a seller would receive if a higher price were achieved given the number of units by which he reduced supply.

\begin{tabular}{|c|c|c|c|c|c|c|c|c|c|c|}
\hline \multirow[b]{3}{*}{ Seller } & \multicolumn{10}{|c|}{ Price } \\
\hline & \multicolumn{2}{|c|}{$M-5$} & \multicolumn{2}{|c|}{$M+10$} & \multicolumn{2}{|c|}{$M+20$} & \multicolumn{2}{|c|}{$M+30$} & \multicolumn{2}{|c|}{$M+40$} \\
\hline & Units Sold & Profit & Units Sold & Profit & Units Sold & Profit & Units Sold & Profit & Units Sold & Profit \\
\hline S1 & 6 & 210 & 5 & 250 & 4 & 240 & 4 & 280 & 3 & 240 \\
\hline S2 & 3 & 75 & 2 & 80 & 2 & 100 & 2 & 120 & 2 & 140 \\
\hline S3 & 6 & 90 & 4 & 120 & 3 & 120 & 2 & 100 & 2 & 120 \\
\hline S4 & 3 & 15 & 1 & 20 & 1 & 30 & 1 & 40 & 1 & 50 \\
\hline S5 & 0 & 0 & 0 & 0 & 1 & 10 & 1 & 20 & 1 & 30 \\
\hline \multicolumn{3}{|c|}{ Supply Reduction } & \multicolumn{2}{|l|}{6} & \multicolumn{2}{|l|}{13} & \multicolumn{2}{|l|}{14} & \multicolumn{2}{|l|}{15} \\
\hline \multicolumn{3}{|c|}{ Reduction Needed } & 3 & & \multicolumn{2}{|l|}{9} & \multicolumn{2}{|l|}{15} & \multicolumn{2}{|l|}{18} \\
\hline
\end{tabular}


Table A.3. The maximum number of units by which each buyer would be willing to reduce demand to achieve a price of $M$ - 10 rather than $M+10$. Reported profits (in cents) are the profits a buyer would receive if a lower price were achieved given the number of units by which he reduced demand.

\begin{tabular}{lcccc}
\hline \hline & \multicolumn{4}{c}{ Price } \\
\multicolumn{2}{c}{$M+10$} & \multicolumn{2}{c}{$M-10$} \\
\hline Buyer & $\begin{array}{c}\text { Units } \\
\text { Bought }\end{array}$ & Profit & Units & Profit \\
B1 & 6 & 180 & 4 & 300 \\
B2 & 3 & 60 & 2 & 105 \\
B3 & 6 & 60 & 3 & 160 \\
B4 & 3 & 0 & 1 & 60 \\
B5 & 0 & 0 & 0 & 10 \\
& & & & \\
Total Reduction & & 8 & \\
Reduction Needed & & 7 & \\
\hline \hline
\end{tabular}


NOT FOR PUBLICATION

Participant Instructions 
Note: The experiments in this paper were originally part of a larger research project which compared one-sided and two-sided auctions. To keep the nomenclature more neutral across onesided and two-sided environments the protocols of those experiments called for sellers to be referred to as “Type 1" participants and buyers as “Type 2" participants. The language in the instructions uses these terms. 


\section{Appendix B. Instructions for the hand-run auctions}

\section{English-Dutch Auctions}

This is an experiment in the economics of decision making, and you will be paid for your decisions in cash. Before we begin, you will be given an "accounting sheet" and provided with an ID card that you will use for making decisions.

This experiment contains two types of participants “Type One” and “Type Two.” Your accounting sheet indicates your type.

Type one: you have been given units (labeled unit 1, unit 2, unit 3 ...) and a "transfer cost” for transferring each unit to others. Type two: you do not have units, but you have been given a "value" for receiving units from others. You are only able to transfer (receive) the units shown on your accounting sheet. The values and costs on your sheets are private and will not be revealed to other participants.

\section{Your cash earnings:}

Type one participants: for each unit you transfer, you will earn the "transfer price" (which I'll explain next) minus the "transfer cost" given on your accounting sheet. For example, if the transfer price was $\$ 2$ and your transfer cost was $\$ 1$, you would earn $\$ 1$ for each unit you transferred. 
Type two participants: for each unit you receive, you will earn the value on your accounting sheet minus the transfer price. For example, if your value for each unit was $\$ 3$ and the transfer price was $\$ 2$, you would earn $\$ 1$ for each unit you received.

Experimental earnings will be multiplied by an exchange rate to determine your cash earnings in dollars. For this experiment the exchange rate is $\underline{2.00}$ This means that your final earnings from the experiment will be multiplied by 2 to determine your earnings in cash.

\section{The transfer price:}

The price for transferring units will be determined by a decision process in which both types participate. The process is divided into several rounds.

1. To begin, I will announce an initial transfer price. At this price (which starts high) Type Ones are automatically willing to transfer all of their assigned units. Type Ones are unwilling to receive any units.

2. If at the starting price, Type Ones want to transfer more units than Type Twos are willing to receive, I will announce a new lower price.

3. At each price announcement, either type may raise their ID card to either reduce by one unit the amount they are willing to transfer (for Type Ones) or to increase by one unit the amount they are willing to receive (for Type Twos).

4. When you raise your ID card to reduce (or add) a unit, I will call out your ID number to recognize your reduction (addition) depending on your type. However, I will not publicly announce your type. If multiple participants raise their cards at once, I will randomly 
select ID numbers. After recognizing an ID\#, I will re-announce the price so that the same ID or any other participant may be recognized for further reductions (additions) at the same price.

5. This process will continue until the total number of units that Type Ones want to transfer equals the number that Type Twos want to receive; it is only at this final transfer price, that units are received and transferred.

6. For example, if at a price of \$5, Type Ones want to transfer a total of 10 units and Type Twos want to receive a total of 10 units, then the process will end. I will announce that the final transfer price is $\$ 5$.

Type one: You will earn the transfer price on each unit you transfer minus your transfer cost (shown on your accounting sheet).

Type two: You will earn your private values for each unit you receive minus the transfer price (applied to each unit).

7. We will repeat this process several times calling each repetition a "period." Each period will begin from scratch with new accounting sheets, costs and values assigned to each participant. Your type will remain the same throughout the experiment.

Now we will begin a practice period to review your accounting sheet and the rules. The practice session does not count toward your earnings.

No talking is permitted during the decision process. If you have a question, please raise your hand and a monitor will come by for clarification. 


\section{Accounting Sheet}

Your type, units and values (costs) are provided on your accounting sheets.

\section{EXAMPLE}

Accounting Sheet

Type One

subject \#

$\begin{array}{lc}\text { Unit 1 } & 50 \\ \text { Unit 2 } & 50 \\ \text { Unit 3 } & 0 \\ \text { Unit 4 } & 0 \\ \text { Unit 5 } & 0 \\ \text { Unit 6 } & 0\end{array}$

\begin{tabular}{|c|c|c|}
\multicolumn{1}{c}{ Transfer price } & \multicolumn{1}{c}{$\begin{array}{c}\text { Earnings per } \\
\text { transfer }\end{array}$} \\
\hline & 50 & \\
\hline \multicolumn{3}{|c|}{} \\
\hline \\
Units for transfer $\quad$ Units Received Units transferred \\
\hline 2 & & \\
\hline
\end{tabular}

Total Earnings

PRACTICE

Accounting Sheet

Type Two

subject \#

Unit 1

Unit 2

Unit 3

Unit 4

Unit 5

Unit 6

Values
100
100
0
0
0
0

Whenever a period ends, the monitor will

announce the transfer price. Write this transfer price

into the "transfer price" box. Next you will receive a

note confirming the number of units you received (or

transferred) as well as your earnings.

Type 1: you earn money for each unit

transferred.

Earnings $=($ Price - Cost $) *$ Units Transferred

Type two: you earn money for each unit

received.

Earnings $=($ Value - Price $) *$ Units Received

\begin{tabular}{|c|c|c|}
\multicolumn{1}{c}{ Value per unit } & \multicolumn{1}{c}{$\begin{array}{c}\text { Earnings per } \\
\text { unit }\end{array}$} \\
\hline 100 & & \\
\hline
\end{tabular}

Units for

transfer

0 


\section{Dutch-English Auctions}

ent in the economics of decision making, and you will be paid for your decisions in cash. Before we begin, you will be given an "accounting sheet” and provided with an ID card that you will use for making decisions.

This experiment contains two types of participants “Type One” and “Type Two.” Your accounting sheet indicates your type.

Type one: you have been given units (labeled unit 1, unit 2, unit 3 ...) and a "transfer cost” for transferring each unit to others. Type two: you do not have units, but you have been given a "value" for receiving units from others. You are only able to transfer (receive) the units

shown on your accounting sheet. The values and costs on your sheets are private and will not be revealed to other participants.

\section{Your cash earnings:}

Type one participants: for each unit you transfer, you will earn the "transfer price" (which I'll explain next) minus the "transfer cost” given on your accounting sheet. For example, if the transfer price was $\$ 2$ and your transfer cost was $\$ 1$, you would earn $\$ 1$ for each unit you transferred. 
Type two participants: for each unit you receive, you will earn the value on your accounting sheet minus the transfer price. For example, if your value for each unit was $\$ 3$ and the transfer price was $\$ 2$, you would earn $\$ 1$ for each unit you received.

Experimental earnings will be multiplied by an exchange rate to determine your cash earnings in dollars. For this experiment the exchange rate is $\underline{2.00}$ This means that your final earnings from the experiment will be multiplied by 2 to determine your earnings in cash.

\section{The transfer price:}

The price for transferring units will be determined by a decision process in which both types participate. The process is divided into several rounds.

8. To begin, I will announce an initial transfer price. At this price (which starts low) Type Ones are unwilling to transfer any of their assigned units. Type Ones are willing to receive all of their units.

9. If at the starting price, Type Ones want to receive more units than Type Twos are willing to transfer, then I will announce a new higher price.

10. At each price announcement, either type may raise their ID card to either reduce by one unit the amount they are willing to receive (for Type Twos) or to increase by one unit the amount they are willing to transfer (for Type Ones).

11. When you raise your ID card to reduce (or add) a unit, I will call out your ID number to recognize your reduction (addition) depending on your type. However, I will not publicly announce your type. If multiple participants raise their cards at once, I will randomly select ID numbers. After recognizing an ID\#, I will re-announce the price so that the same ID or any other participant may be recognized for further reductions (additions) at 
the same price.

12. This process will continue until the total number of units that Type Ones want to transfer equals the number that Type Twos want to receive; it is only at this final transfer price, that units are received and transferred.

13. For example, if at a price of $\$ 5$, Type Ones want to transfer a total of 10 units and Type Ones want to receive a total of 10 units, then the process will end. I will announce that the final transfer price is $\$ 5$.

Type one: You will earn the transfer price on any units you transfer minus your transfer cost (shown on your accounting sheet).

Type two: You will earn your private values for each unit received minus the transfer price (applied to each unit).

14. We will repeat this process several times calling each repetition a "period.” Each period will begin from scratch with new accounting sheets, costs and values assigned to each participant. Your type will remain the same throughout the experiment.

Now we will begin a practice period to review your accounting sheet and the rules. The practice session does not count toward your earnings.

No talking is permitted during the decision process. If you have a question, please raise your hand and a monitor will come by for clarification. 


\section{Accounting Sheet}

Your type, units and values (costs) are provided on your accounting sheets.

\section{EXAMPLE}

Accounting Sheet

Type One

subject \#

$\begin{array}{lc}\text { Unit 1 } & 50 \\ \text { Unit 2 } & 50 \\ \text { Unit 3 } & 0 \\ \text { Unit 4 } & 0 \\ \text { Unit 5 } & 0 \\ \text { Unit 6 } & 0\end{array}$

\begin{tabular}{|c|c|c|}
\multicolumn{1}{c}{ Transfer price } & \multicolumn{1}{c}{$\begin{array}{c}\text { Earnings per } \\
\text { transfer }\end{array}$} \\
\hline & 50 & \\
\hline \multicolumn{3}{|c|}{} \\
\hline \\
Units for transfer $\quad$ Units Received Units transferred \\
\hline 2 & & \\
\hline
\end{tabular}

Total Earnings

PRACTICE

Accounting Sheet

Type Two

subject \#

Unit 1

Unit 2

Unit 3

Unit 4

Unit 5

Unit 6

Values
100
100
0
0
0
0

Whenever a period ends, the monitor will

announce the transfer price. Write this transfer price

into the "transfer price" box. Next you will receive a

note confirming the number of units you received (or

transferred) as well as your earnings.

Type 1: you earn money for each unit

transferred.

Earnings $=($ Price - Cost $) *$ Units Transferred

Type two: you earn money for each unit

received.

Earnings $=($ Value - Price $) *$ Units Received

\begin{tabular}{|c|c|c|}
\multicolumn{1}{c}{ Value per unit } & \multicolumn{1}{c}{$\begin{array}{c}\text { Earnings per } \\
\text { unit }\end{array}$} \\
\hline 100 & & \\
\hline
\end{tabular}

Units for

transfer

0

Units Received 


\section{Appendix C. Written instructions for the computerized auctions}

\section{English-Dutch Auctions}

This is an experiment in the economics of decision making, and you will be paid for your decisions in cash. If you read these instructions carefully and make appropriate decisions, you may earn a considerable amount of money, which will be paid to you in cash at the end of the experiment.

\section{[Slide 1]}

All of your decisions will be entered through the software interface on your computer screen. During the experiment you are not allowed to communicate with any other participant. If you have any questions, the experimenter(s) will be glad to answer them. If you do not follow these instructions you will be excluded from the experiment and deprived of all payments aside from the minimum payment of $\$ 7$ for attending.

\section{[Slide 2]}

This experiment will last for several periods. There are two types of participants: “Type 1” and “Type 2.” Your participant type will be indicated at the top of your screen, and you will remain that type for the entire experiment. 
Type 1 participants will be given units (labeled unit 1, unit 2, unit 3 ...) and a "transfer cost” for transferring each unit to others. Type 1's are only able to transfer the units shown on their computer screens. [Slide 3] In the example on your screen, the participant has been given five units, so he could transfer any number of units between zero and five in this round.

[Questions?]

[Slide 4]

Type 2 participants do not have units, but have been given a "value" for receiving units from others. Type 2's are only able to receive the units shown on their computer screens. [Slide 5] In the example on your screen, the participant has values for up to four units, so he could receive any number of units between zero and four in this round.

[Questions?]

During the experiment the values or transfer costs on your screen will be private and will not be revealed to other participants.

\section{Cash Earnings For Type 1 Participants}




\section{[Slide 6]}

For each unit she transfers, a Type 1 participant will earn the "transfer price” (which I’ll explain shortly) minus the transfer cost given on her screen. In the example on your screen, the current transfer price is $\$ 5.00$ per unit and the transfer cost is $\$ 2.80$ per unit. [Slide 7] This means the participant would earn $\$ 2.20$ for each unit she transferred. In the lower right of the Type 1 participant's screen is her “current profit.” A Type 1's current profit is the amount of money she would earn if she transferred all the units she is currently willing to transfer at the current transfer price. In the example on your screen, the participant is not willing to transfer any units, so her current profit is $\$ 0.00$.

[Questions?]

\section{Cash Earnings for Type 2 Participants}

\section{[Slide 8]}

For each unit he receives, a Type 2 participant will earn the value on his screen minus the transfer price. In the example on your screen, the current transfer price is $\$ 2.50$ per unit and the value is $\$ 4.35$ per unit. [Slide 9] This means the participant would earn $\$ 1.85$ for each unit he received. The current profit is also displayed in the lower right of the Type 2 participant's 
screen. A Type 2's current profit is the amount of money he would earn if he received all of the units he is currently willing to receive at the current transfer price. In the example on your screen, the participant is currently willing to receive four units with a profit of $\$ 1.85$ per unit. Therefore, his current profit is $4 * \$ 1.85=\$ 7.40$.

[Questions?]

Experimental earnings will be multiplied by an exchange rate to determine your cash earnings in dollars. For this experiment the exchange rate is $\underline{2}$. This means that your final earnings from the experiment will be multiplied by 2 to determine your earnings in cash.

\section{The transfer price:}

The price for transferring units will be determined by a decision process in which both types participate. The process is divided into several periods.

\section{[Slide 10]}

1. At the beginning of a period, your screen will display an initial transfer price. At this price Type 2's are automatically willing to receive all of the units for which they have values. That is, they are willing to "demand" every unit on their screens. [Slide 11] The units that a Type 2 is currently demanding are highlighted on his screen in blue, and the total number of units he is demanding is indicated at the bottom of his screen under the words "Personal Demand.” In the example on your screen, the period has just begun, so 
the participant has all four of his units highlighted blue, and his personal demand is displayed as four.

[Questions?]

\section{[Slide 12]}

2. At the initial transfer price, Type 1's are unwilling to transfer any units. That is, they are not "supplying" any of the units on their screens. The units that a Type 1 is currently supplying are highlighted on her screen in blue, and the total number of units she is demanding is indicated at the bottom of her screen under the words "Personal Supply." In the example on your screen, the period has just begun, so the participant does not have any of her units highlighted blue, and her personal supply is displayed as zero.

[Questions?]

\section{[Slide 13]}

3. The total number of units that all Type 2's are willing to receive minus the total number of units that all Type 1's are willing to transfer is called the "excess demand." All participants can see the excess demand in the middle of their screens. If, at a given transfer price, the excess demand is greater than zero (that is, Type 2's want to receive more units than Type 1's are willing to receive), the transfer price will tick up by a predetermined amount. If excess demand is greater than 10, the transfer price will tick up by $\$ 0.10$ each second. If excess demand is 10 or lower, the transfer price will tick up by $\$ 0.05$ each second.

\section{[Questions?]}




\section{[Slide 14]}

4. At a given transfer price, Type 1's can increase the number of units they are willing to transfer by clicking the button labeled "Increase Supply." A Type 1's personal supply will increase by one unit each time she clicks the Increase Supply button. [Slide 15] In the example on your screen, the Type 1 participant has clicked the Increase Supply button once. Notice that one of her units is now highlighted blue, her personal supply has increased to one unit and the excess demand has decreased from 24 units to 23 units.

[Questions?]

\section{[Slide 16]}

5. At a given transfer price, Type 2's can decrease the number of units they are willing to receive by clicking the button labeled "Decrease Demand.” A Type 2's personal demand will decrease by one unit each time he clicks the Decrease Demand button. [Slide 17] In the example on your screen, the Type 2 participant has clicked the Decrease Demand button once. Notice that one of his units is no longer highlighted blue, his personal demand has decreased to three units, and the excess demand has decreased from 23 units to 22 units.

[Questions?]

6. Both Type 1's and Type 2's can click their respective buttons multiple times at the same price. Each time a player clicks the Increase Supply or Decrease Demand button, the transfer price will pause for an additional second before ticking up.

[Questions?] 
7. Notice that whenever a participant of either type clicks his button, the excess demand decreases by one unit. [Slide 18] When the excess demand reaches 10 units, the coloring around the Excess Demand display will change from green to yellow. At this point the transfer price will tick up at a rate of $\$ 0.05$ cents per second. [Slide 19] When the excess demand reaches zero, the coloring will change from yellow to red. Once this has happened it means that the total number of units that Type 1's want to transfer equals the number that Type 2's want to receive.

8. The price at which excess supply reaches zero is the final transfer price for the period. It is only at this final transfer price that all units are received and transferred.

Type 1's will earn the final transfer price on each unit they transfer minus the transfer cost per unit transferred.

Type 2's will earn their private value for each unit they receive minus the final transfer price.

[Questions?]

[Slide 20]

9. We will repeat this process several times, calling each repetition a "period." Each period will begin from scratch with new transfer costs and values assigned to each participant. However, your participant type will remain the same throughout the experiment. At the end of each period, a green button labeled "Continue” will appear on your screen. Once all participants have clicked the Continue button, the next period will begin.

[Questions?] 


\section{[Slide 21]}

10. You will have an experiment history on the right of your screen, which will be updated at the end of each period. The history records, for each period, the final transfer price, the number of units you transferred or received, the profit you earned for the period, and the sum of all your profits up to that period in the experiment. In the example on your screen, the entry for Period 0 shows a profit for the period of \$1.65, but a cumulative profit of $\$ 0.00$. That is because Period 0 is a practice period. You will not be paid for your decisions in Period 0, but the experience you gain may be helpful to you in the remaining periods. You will be paid for your decisions in all periods after Period 0.

[Questions?]

\section{Dutch-English Auctions}

This is an experiment in the economics of decision making, and you will be paid for your decisions in cash. If you read these instructions carefully and make appropriate decisions, you may earn a considerable amount of money, which will be paid to you in cash at the end of the experiment.

\section{[Slide 1]}

All of your decisions will be entered through the software interface on your computer

screen. During the experiment you are not allowed to communicate with any other participant.

If you have any questions, the experimenter(s) will be glad to answer them. If you do not follow 
these instructions you will be excluded from the experiment and deprived of all payments aside from the minimum payment of $\$ 7$ for attending.

\section{[Slide 2]}

This experiment will last for several periods. There are two types of participants: “Type 1” and “Type 2.” Your participant type will be indicated at the top of your screen, and you will remain that type for the entire experiment.

Type 1 participants will be given units (labeled unit 1, unit 2, unit 3 ...) and a "transfer cost” for transferring each unit to others. Type 1's are only able to transfer the units shown on their computer screens. [Slide 3] In the example on your screen, the participant has been given five units, so he could transfer any number of units between zero and five in this round.

[Questions?]

\section{[Slide 4]}

Type 2 participants do not have units, but have been given a "value” for receiving units from others. Type 2's are only able to receive the units shown on their computer screens. [Slide 
5] In the example on your screen, the participant has values for up to four units, so he could receive any number of units between zero and four in this round.

[Questions?]

During the experiment the values or transfer costs on your screen will be private and will not be revealed to other participants.

\section{Cash Earnings For Type 1 Participants}

\section{[Slide 6]}

For each unit she transfers, a Type 1 participant will earn the "transfer price” (which I'll explain shortly) minus the transfer cost given on her screen. In the example on your screen, the current transfer price is $\$ 5.00$ per unit and the transfer cost is $\$ 2.80$ per unit. [Slide 7] This means the participant would earn $\$ 2.20$ for each unit she transferred. In the lower right of the Type 1 participant's screen is her "current profit." A Type 1's current profit is the amount of money she would earn if she transferred all the units she is currently willing to transfer at the current transfer price. In the example on your screen, the participant is currently willing to transfer five units with a profit of $\$ 2.20$ per unit. Therefore, her current profit is $5 * \$ 2.20=$ $\$ 11.00$. 
[Questions?]

\section{Cash Earnings for Type 2 Participants}

\section{[Slide 8]}

For each unit he receives, a Type 2 participant will earn the value on his screen minus the transfer price. In the example on your screen, the current transfer price is $\$ 2.50$ per unit and the value is $\$ 4.35$ per unit. [Slide 9] This means the participant would earn $\$ 1.85$ for each unit he received. The current profit is also displayed in the lower right of the Type 2 participant's screen. A Type 2's current profit is the amount of money he would earn if he received all of the units he is currently willing to receive at the current transfer price. In the example on your screen, the participant is not willing to receive any units, so his current profit is $\$ 0.00$.

[Questions?]

Experimental earnings will be multiplied by an exchange rate to determine your cash earnings in dollars. For this experiment the exchange rate is $\underline{2}$. This means that your final earnings from the experiment will be multiplied by 2 to determine your earnings in cash. 


\section{The transfer price:}

The price for transferring units will be determined by a decision process in which both types participate. The process is divided into several periods.

\section{[Slide 10]}

1. At the beginning of a period, your screen will display an initial transfer price. At this price Type 1's are automatically willing to transfer all of their assigned units. That is, they are willing to "supply" every unit on their screens. [Slide 11] The units that a Type 1 is currently supplying are highlighted on her screen in blue, and the total number of units she is supplying is indicated at the bottom of her screen under the words "Personal Supply.” In the example on your screen, the period has just begun, so the participant has all five of her units highlighted blue, and her personal supply is displayed as five.

[Questions?]

[Slide 12]

2. At the initial transfer price, Type 2's are unwilling to receive any units. That is, they are not "demanding" any of the units on their screens. The units that a Type 2 is currently demanding are highlighted on his screen in blue, and the total number of units he is demanding is indicated at the bottom of his screen under the words "Personal Demand." In the example on your screen, the period has just begun, so the participant does not have any of his units highlighted blue, and his personal demand is displayed as zero.

[Questions?] 


\section{[Slide 13]}

3. The total number of units that all Type 1's are willing to transfer minus the total number of units that all Type 2's are willing to receive is called the "excess supply." All participants can see the excess supply in the middle of their screens. If, at a given transfer price, the excess supply is greater than zero (that is, Type 1's want to transfer more units than Type 2's are willing to receive), the transfer price will tick down by a pre-determined amount. If excess supply is greater than 10 , the transfer price will tick down by $\$ 0.10$ each second. If excess supply is 10 or lower, the transfer price will tick down by $\$ 0.05$ each second.

[Questions?]

\section{[Slide 14]}

4. At a given transfer price, Type 1's can decrease the number of units they are willing to transfer by clicking the button labeled "Decrease Supply.” A Type 1's personal supply will decrease by one unit each time she clicks the Decrease Supply button. [Slide 15] In the example on your screen, the Type 1 participant has clicked the Decrease Supply button once. Notice that one of her units is no longer highlighted blue, her personal supply has decreased to four units and the excess supply has decreased from 24 units to 23 units.

[Questions?]

[Slide 16] 
5. At a given transfer price, Type 2's can increase the number of units they are willing to receive by clicking the button labeled "Increase Demand.” A Type 2's personal demand will increase by one unit each time he clicks the Increase Demand button. [Slide 17] In the example on your screen, the Type 2 participant has clicked the Increase Demand button once. Notice that one of his units is now highlighted blue, his personal demand has increased to one unit, and the excess supply has decreased from 23 units to 22 units.

[Questions?]

6. Both Type 1's and Type 2's can click their respective buttons multiple times at the same price. Each time a player clicks the Decrease Supply or Increase Demand button, the transfer price will pause for an additional second before ticking down.

\section{[Questions?]}

7. Notice that whenever a participant of either type clicks his button, the excess supply decreases by one unit. [Slide 18] When the excess supply reaches 10 units, the coloring around the Excess Supply display will change from green to yellow. At this point the transfer price will tick down at a rate of $\$ 0.05$ cents per second. [Slide 19] When the excess supply reaches zero, the coloring will change from yellow to red. Once this has happened it means that the total number of units that Type 1's want to transfer equals the number that Type 2's want to receive.

8. The price at which excess supply reaches zero is the final transfer price for the period. It is only at this final transfer price that all units are received and transferred.

Type 1's will earn the final transfer price on each unit they transfer minus the transfer cost per unit transferred.

Type 2's will earn their private value for each unit they receive minus the final transfer price. 
[Questions?]

\section{[Slide 20]}

9. We will repeat this process several times, calling each repetition a "period." Each period will begin from scratch with new transfer costs and values assigned to each participant. However, your participant type will remain the same throughout the experiment. At the end of each period, a green button labeled "Continue" will appear on your screen. Once all participants have clicked the Continue button, the next period will begin.

[Questions?]

\section{[Slide 21]}

10. You will have an experiment history on the right of your screen, which will be updated at the end of each period. The history records, for each period, the final transfer price, the number of units you transferred or received, the profit you earned for the period, and the sum of all your profits up to that period in the experiment. In the example on your screen, the entry for Period 0 shows a profit for the period of $\$ 0.75$, but a cumulative profit of $\$ 0.00$. That is because Period 0 is a practice period. You will not be paid for your decisions in Period 0, but the experience you gain may be helpful to you in the remaining periods. You will be paid for your decisions in all periods after Period 0.

[Questions?] 


\section{Appendix D. Instruction slides for computerized experiments}

\section{English-Dutch Auctions}

Slide 1

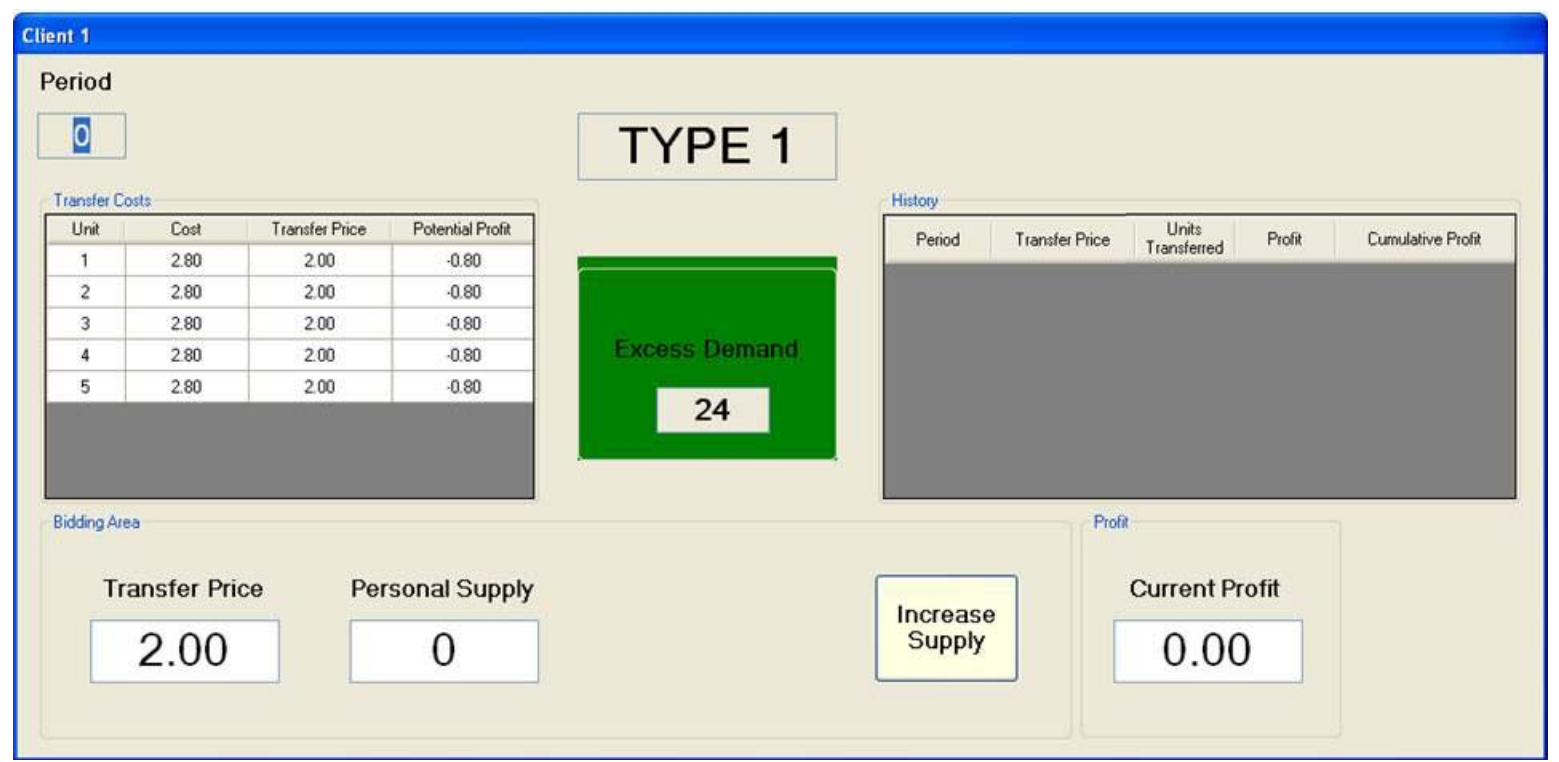

Slide 2

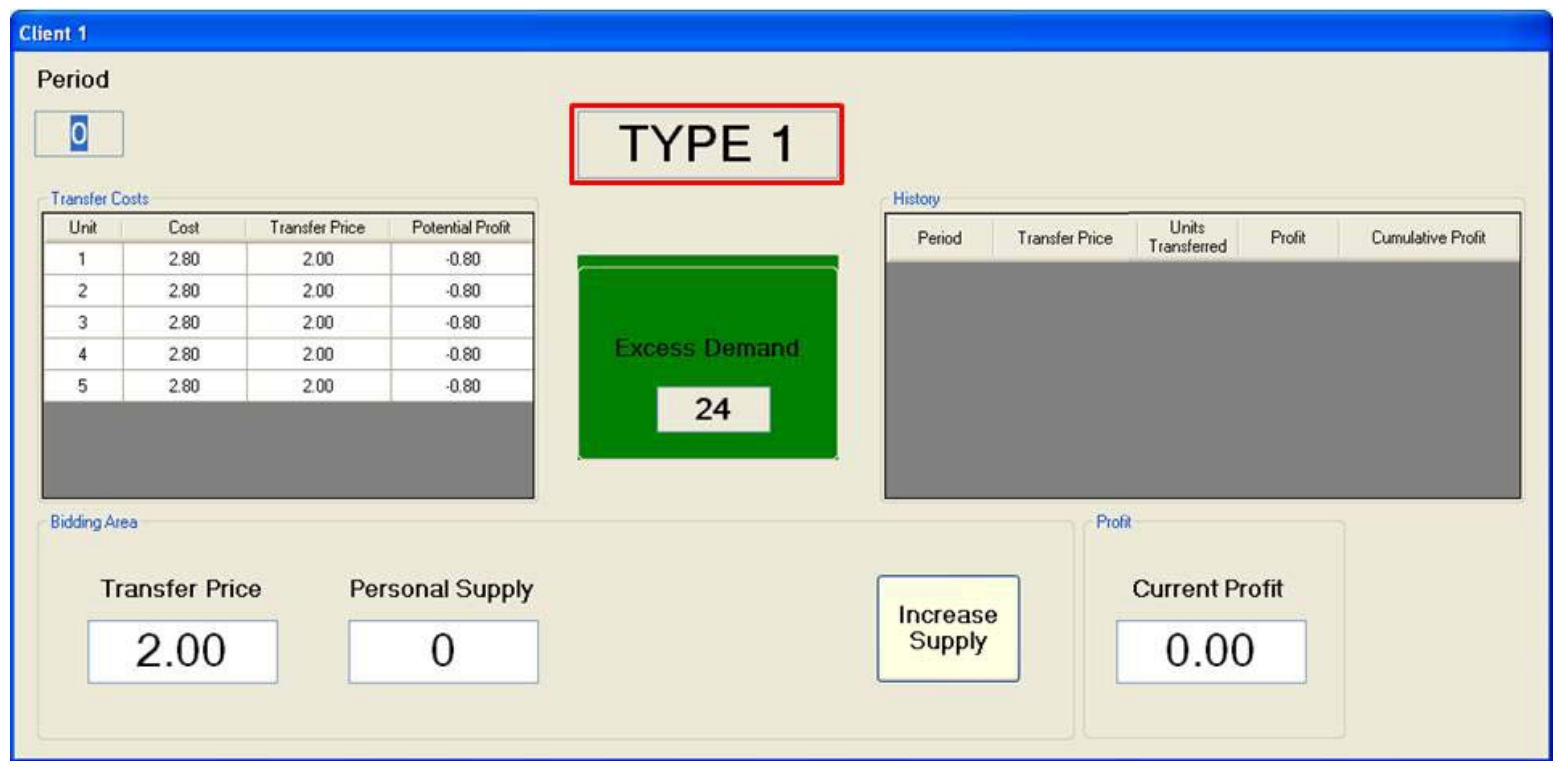


Slide 3

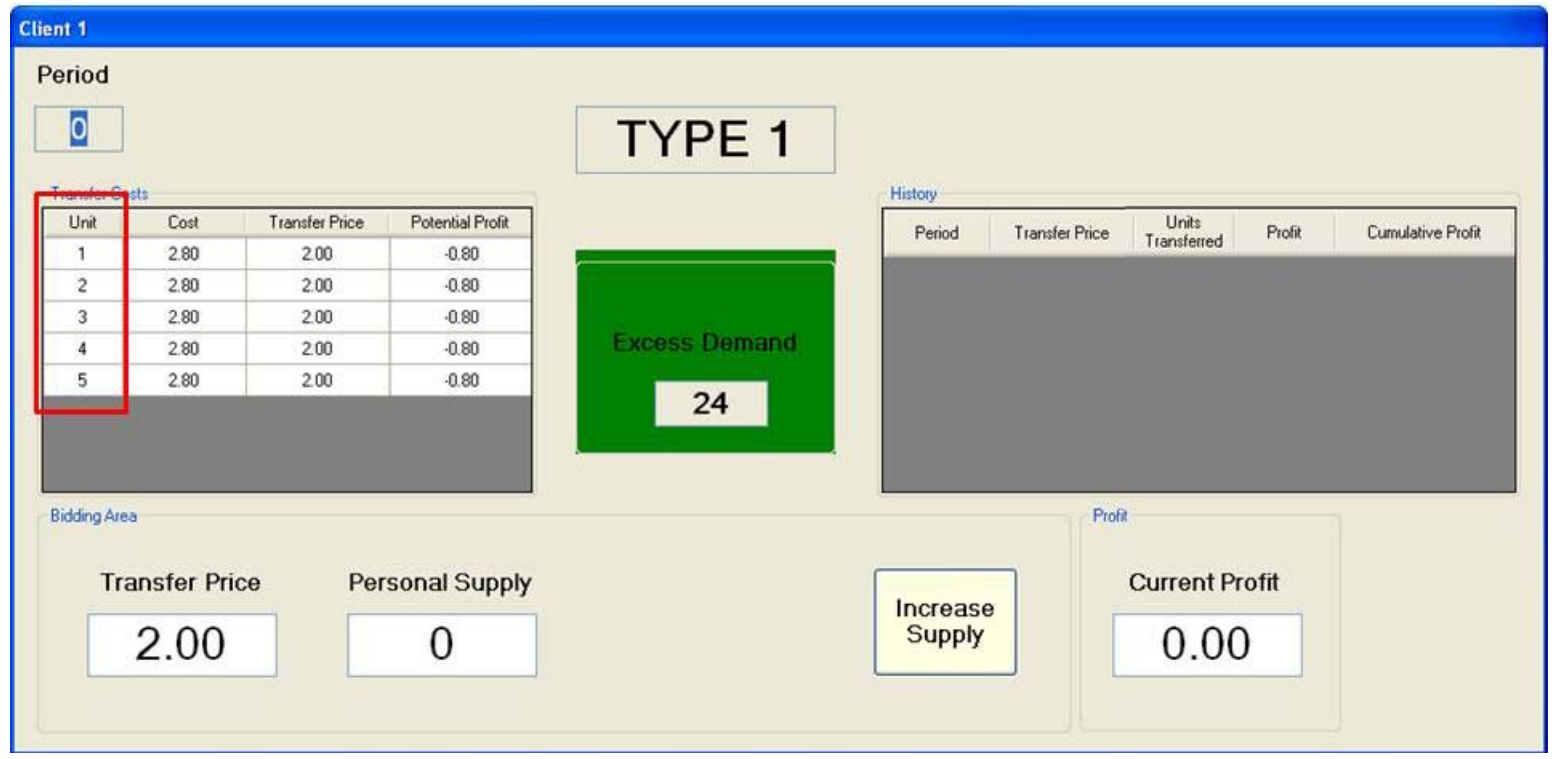

Slide 4

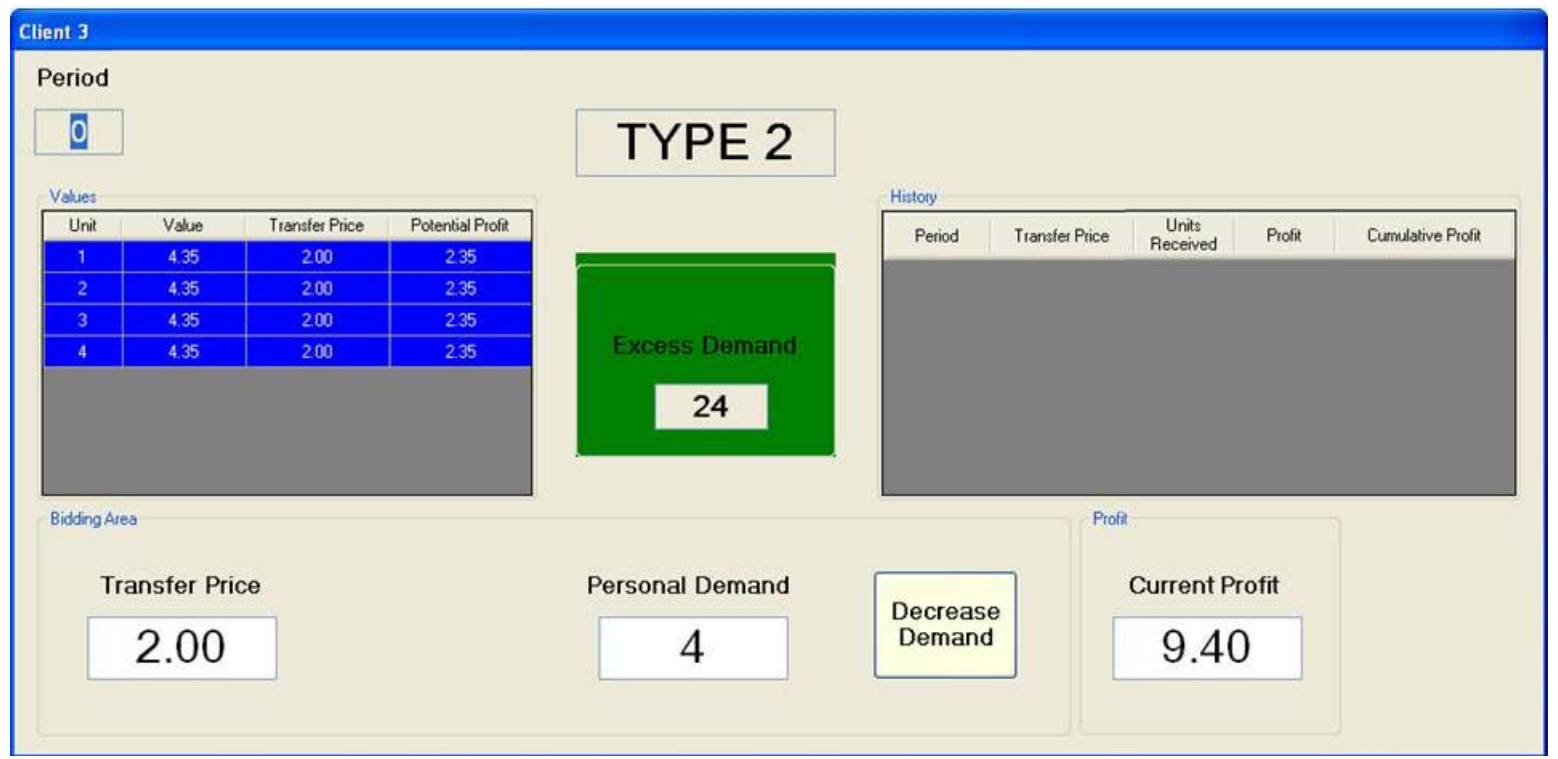


Slide 5

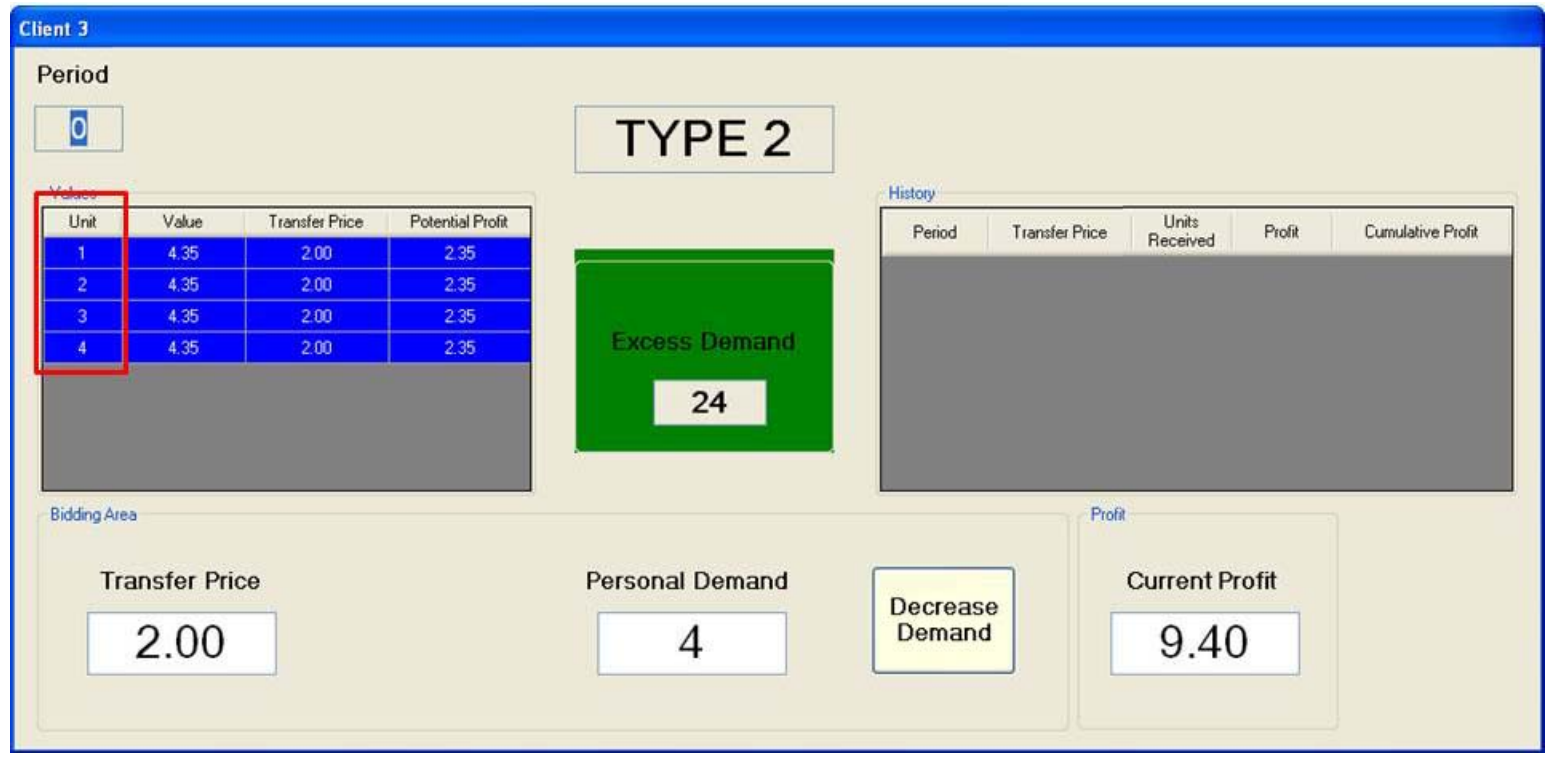

Slide 6

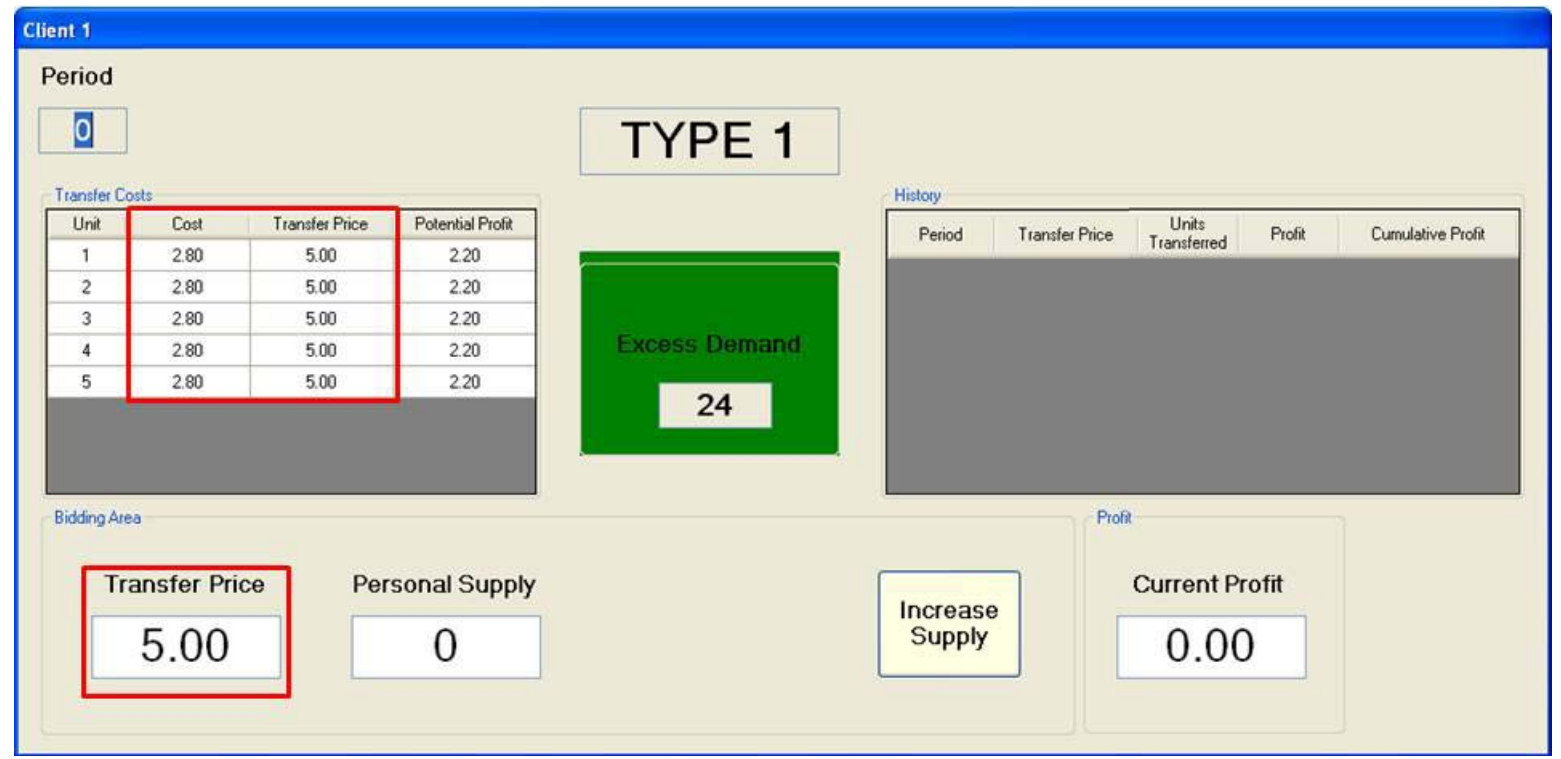


Slide 7

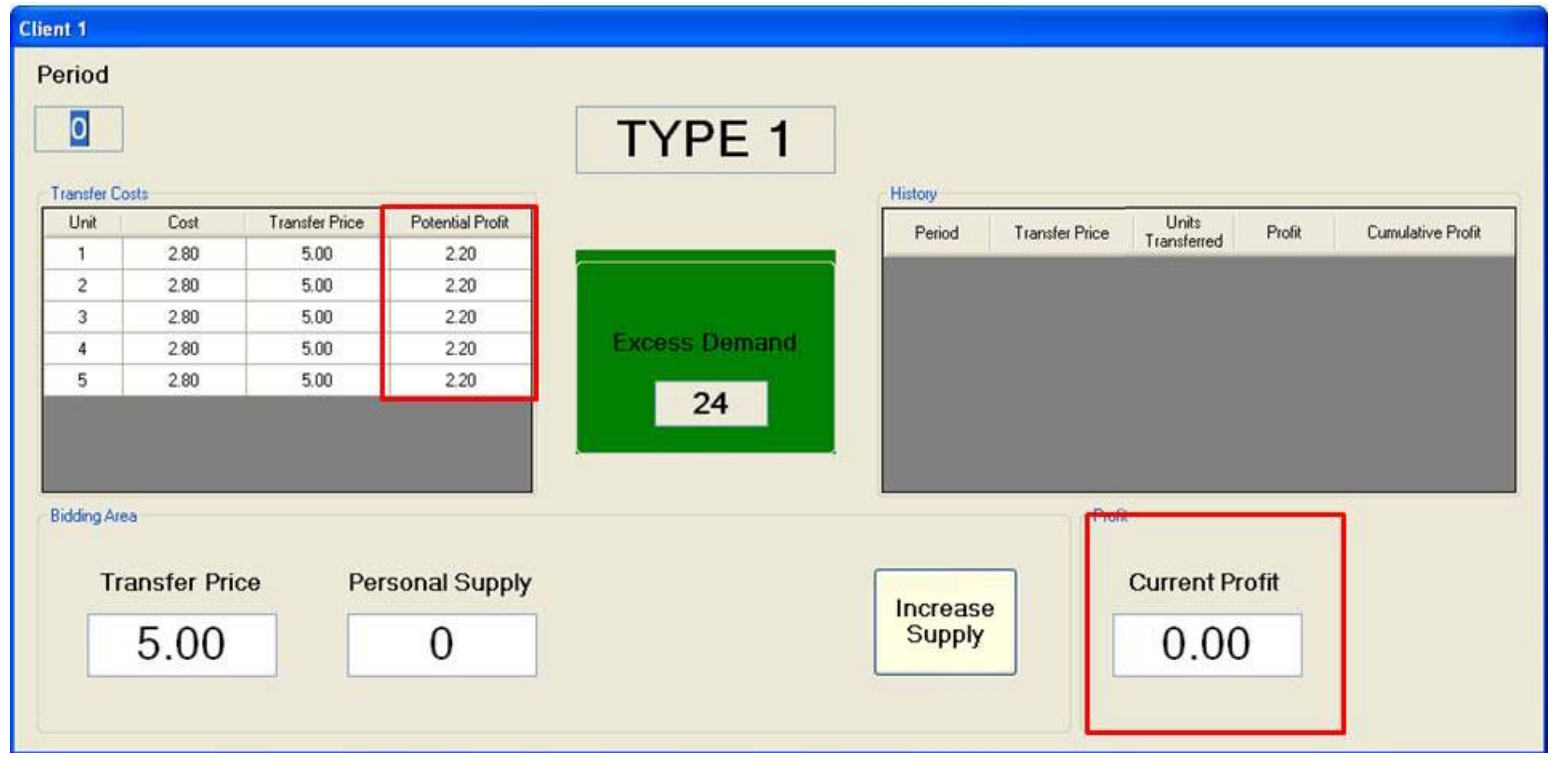

Slide 8

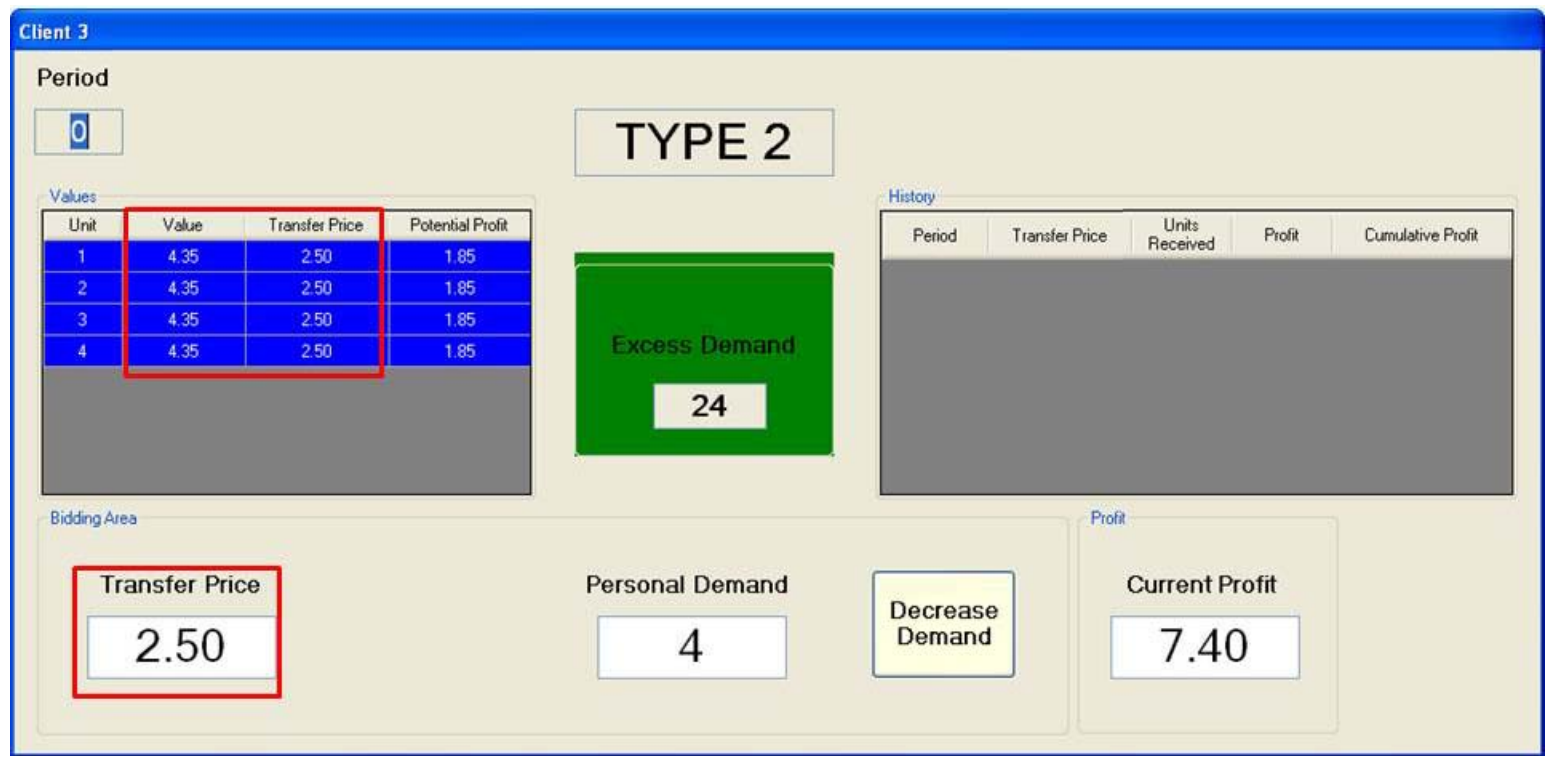


Slide 9

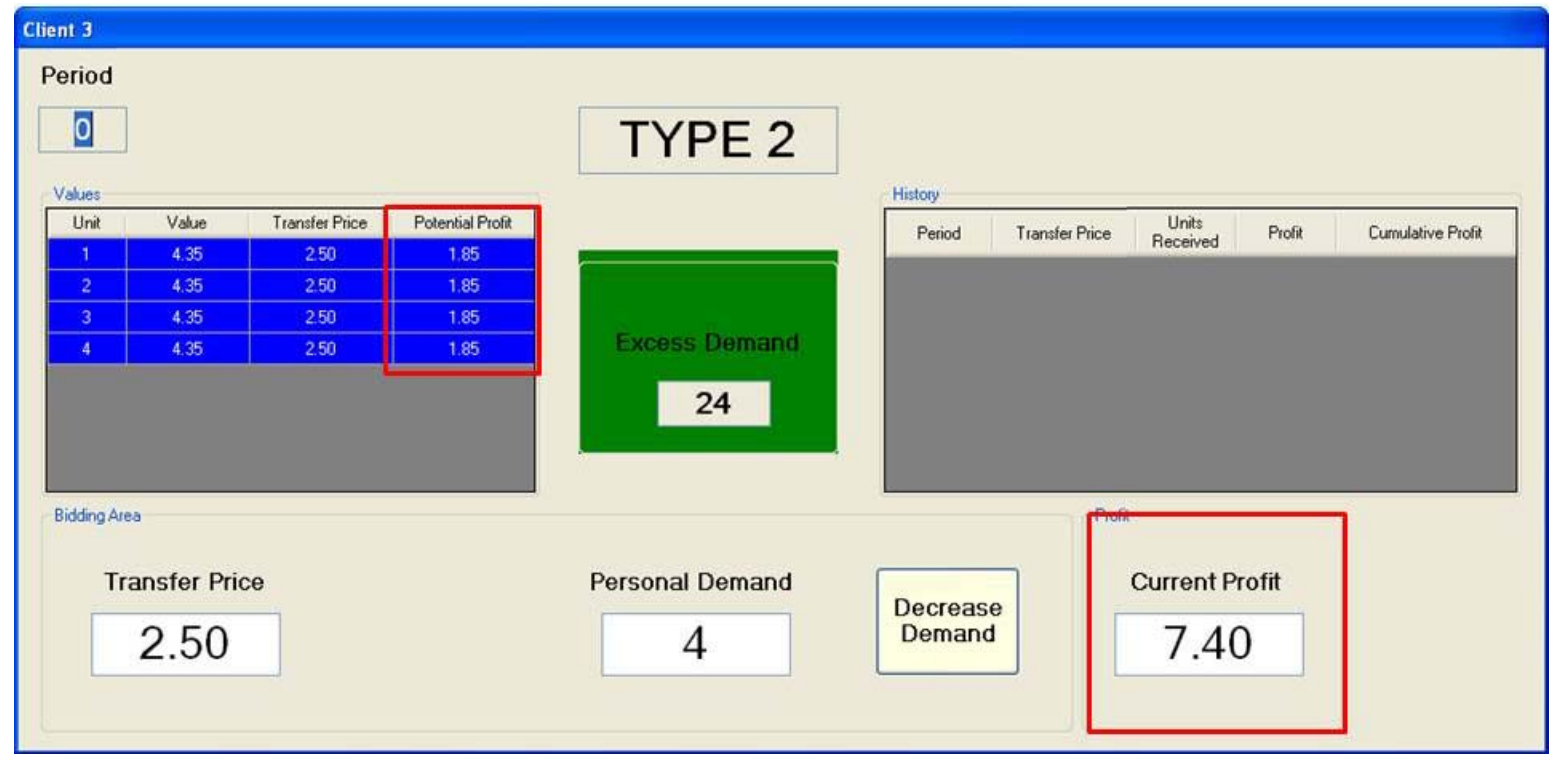

Slide 10

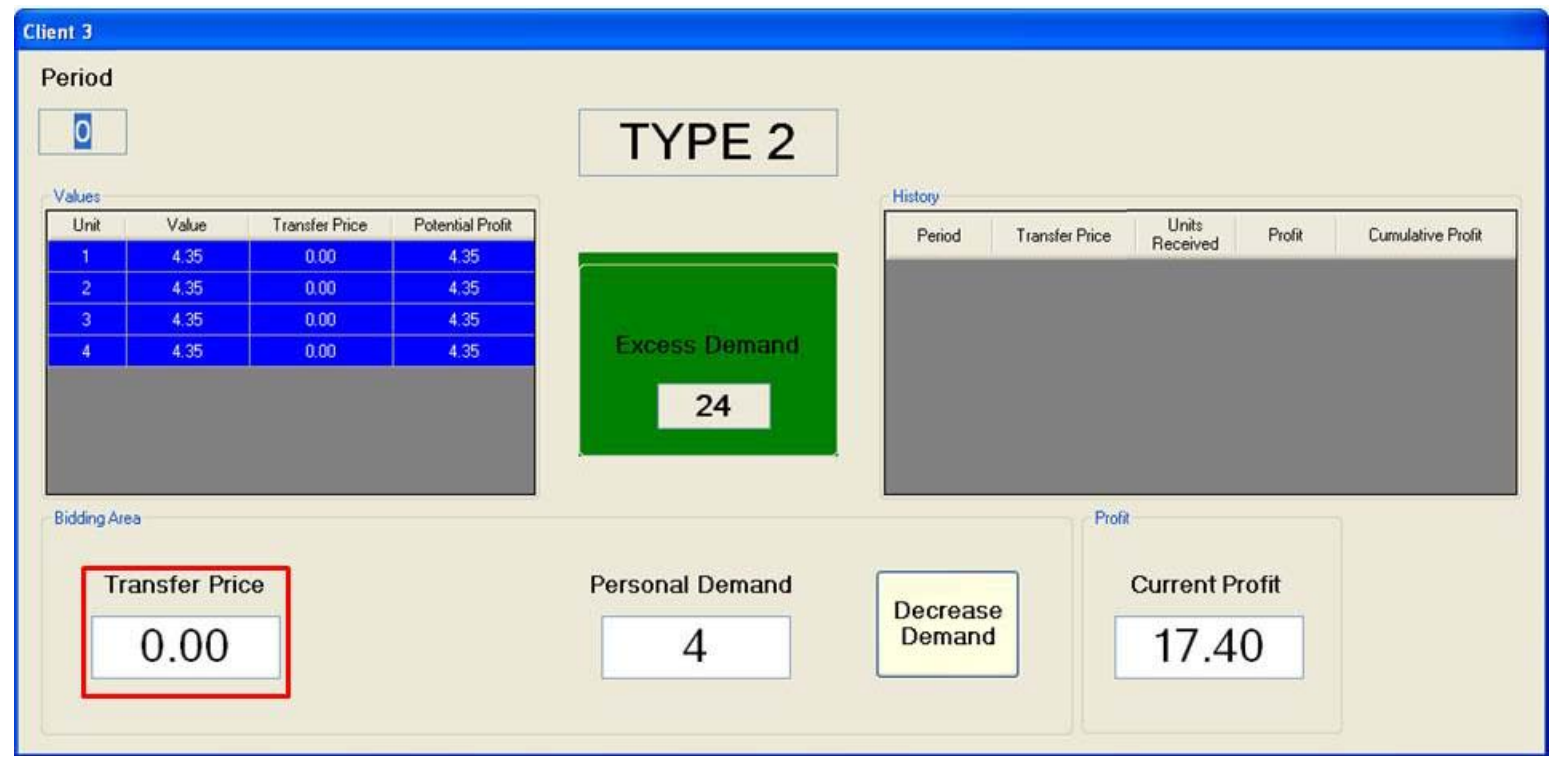


Slide 11

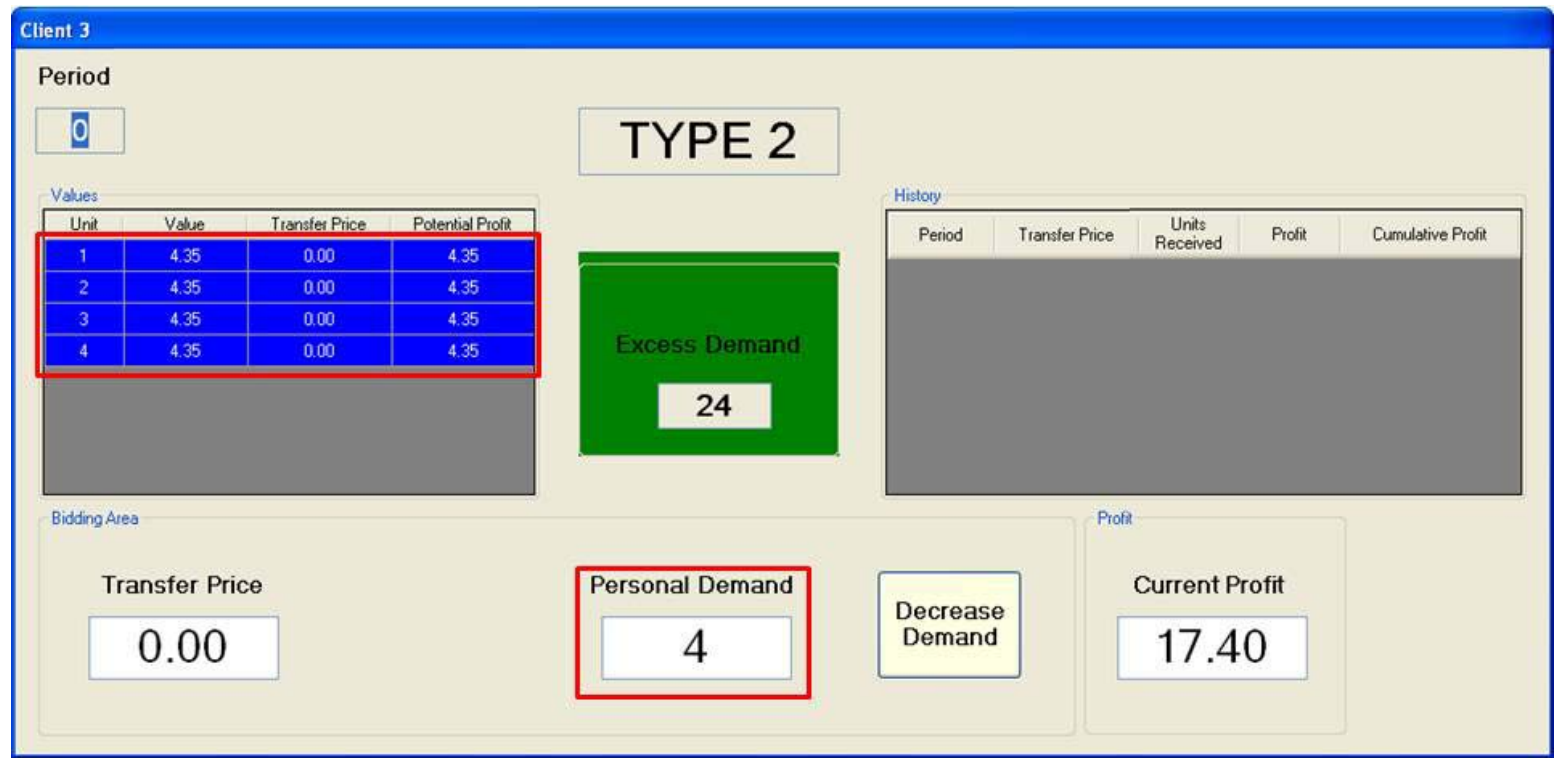

Slide 12

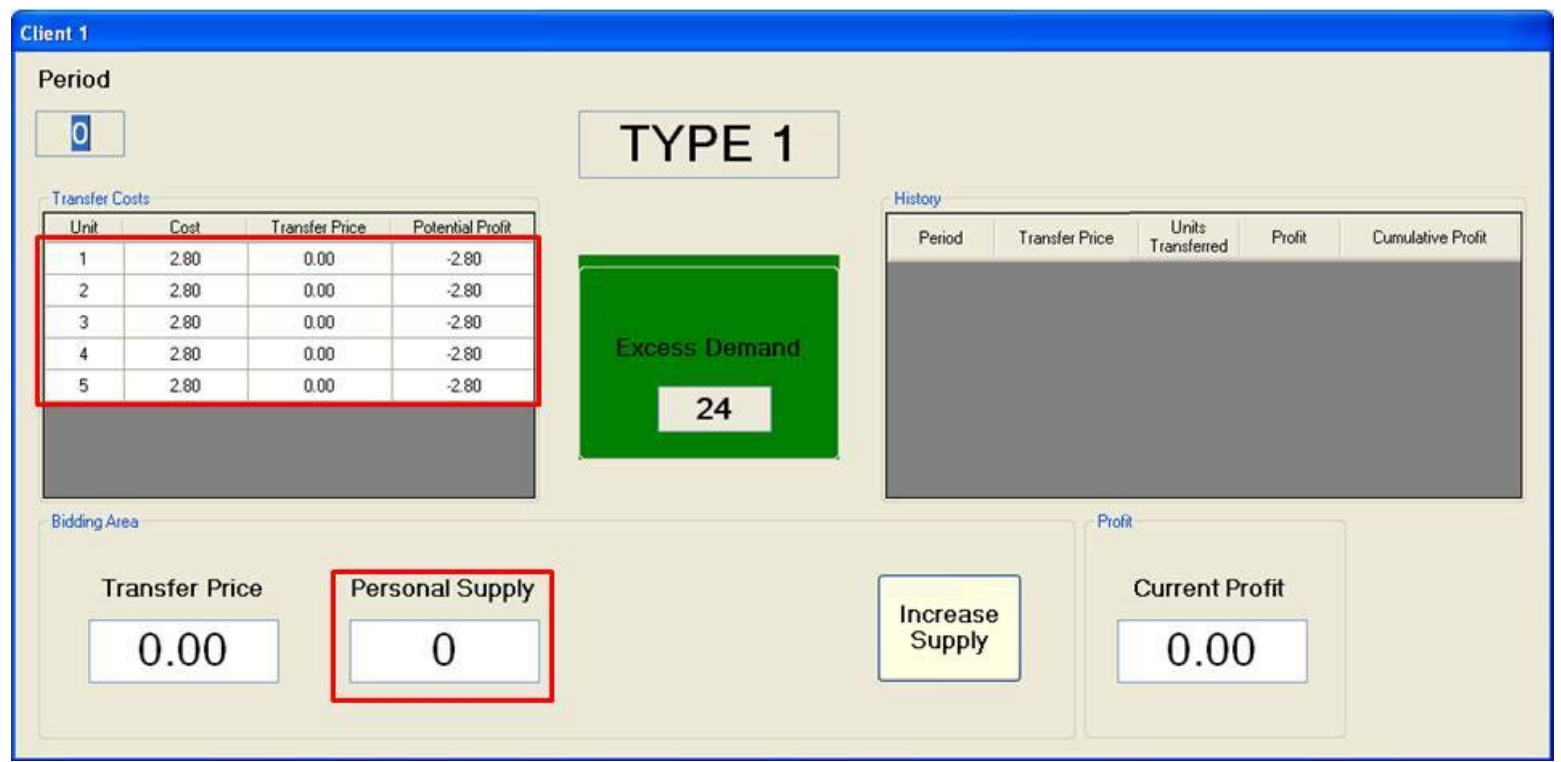


Slide 13

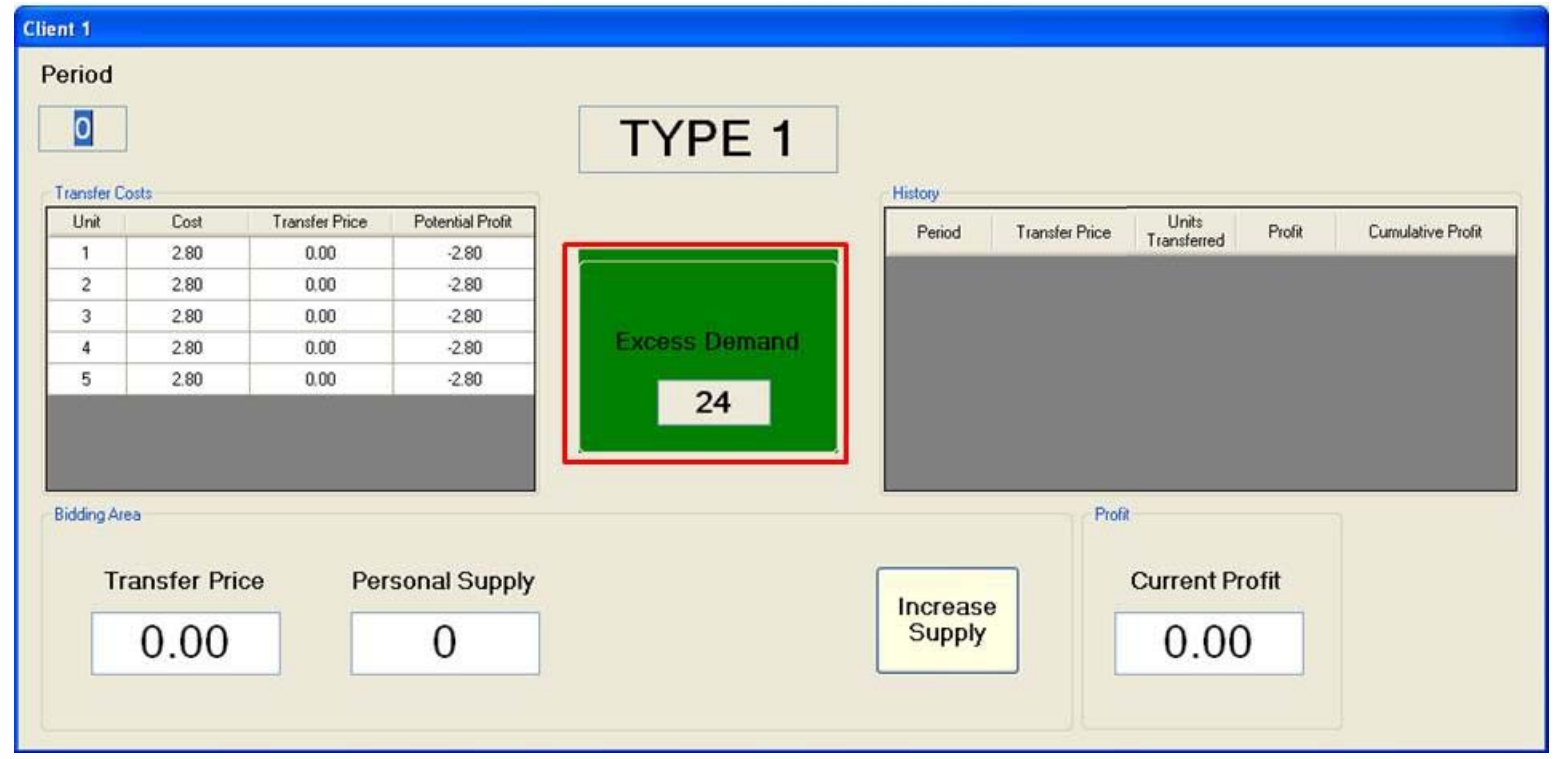

Slide 14

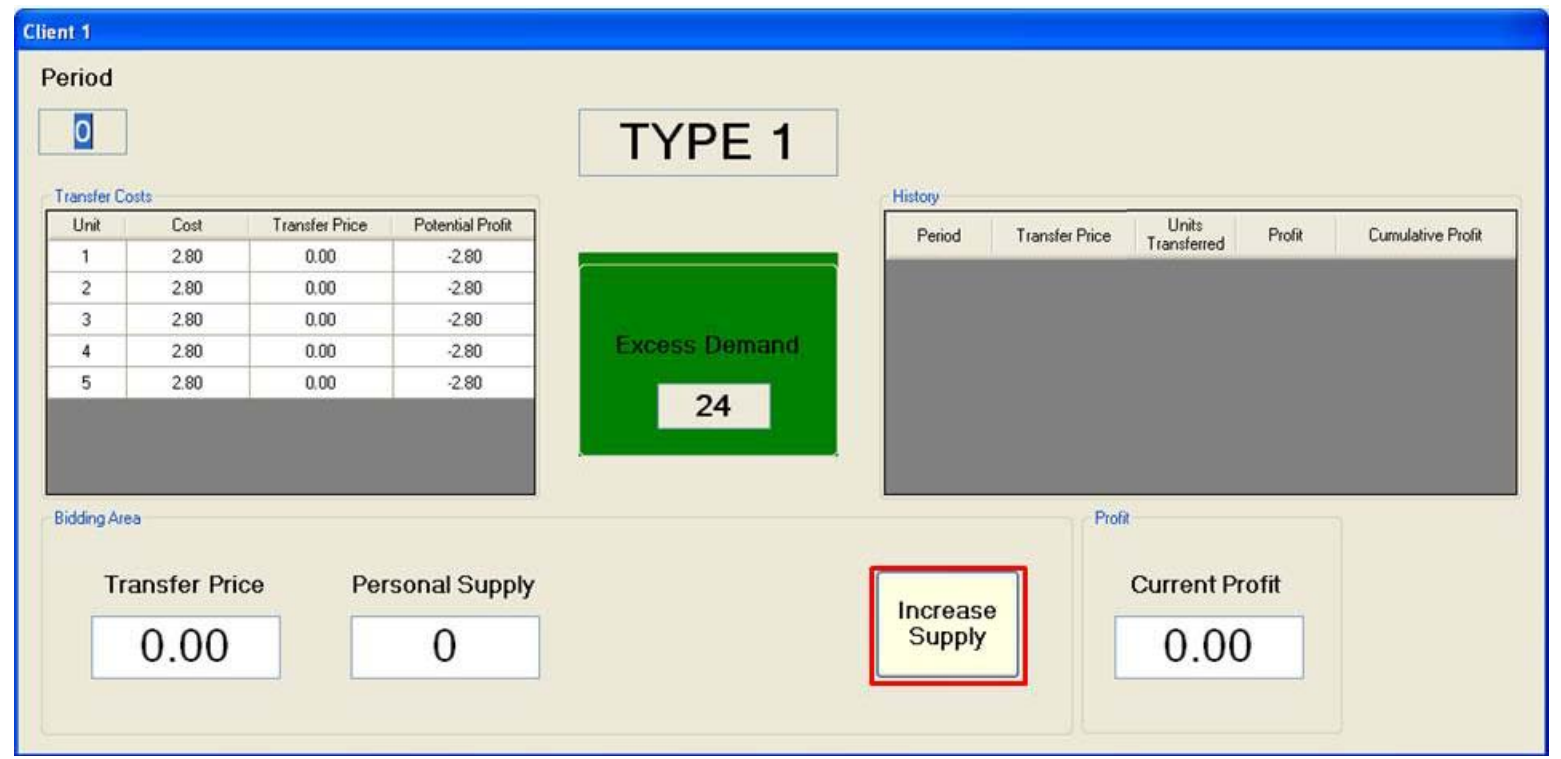


Slilde 15

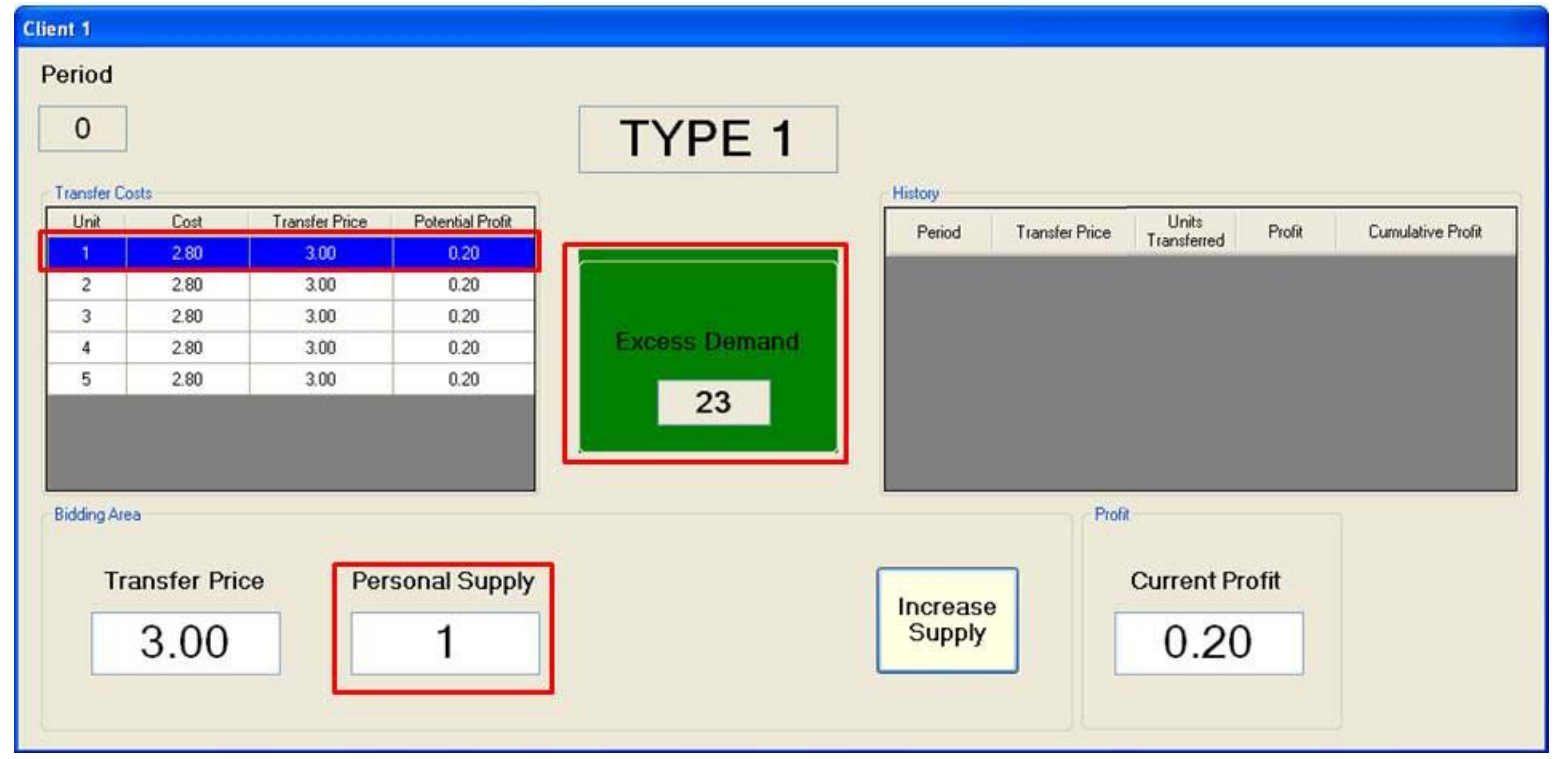

Slide 16

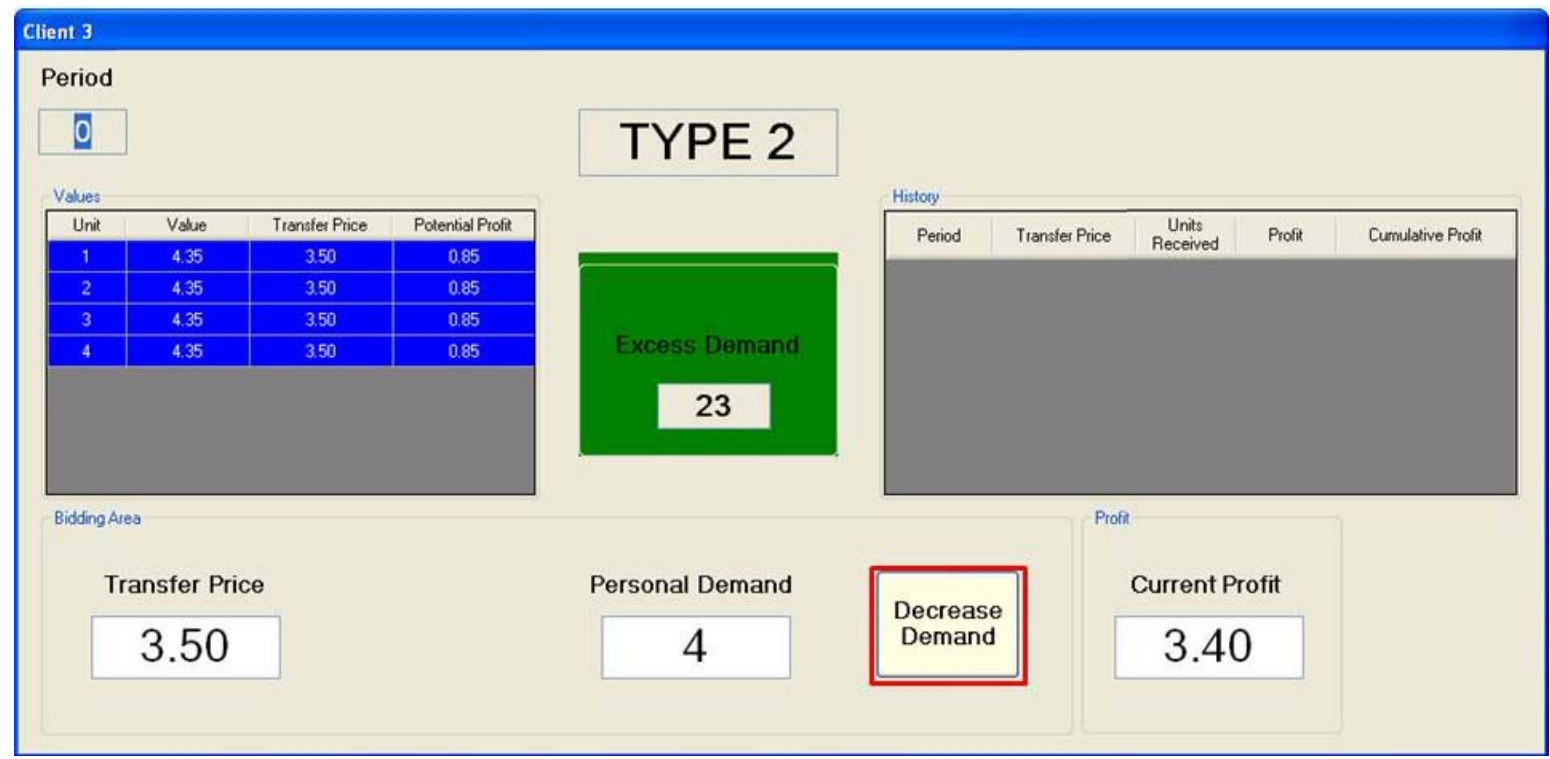


Slide 17

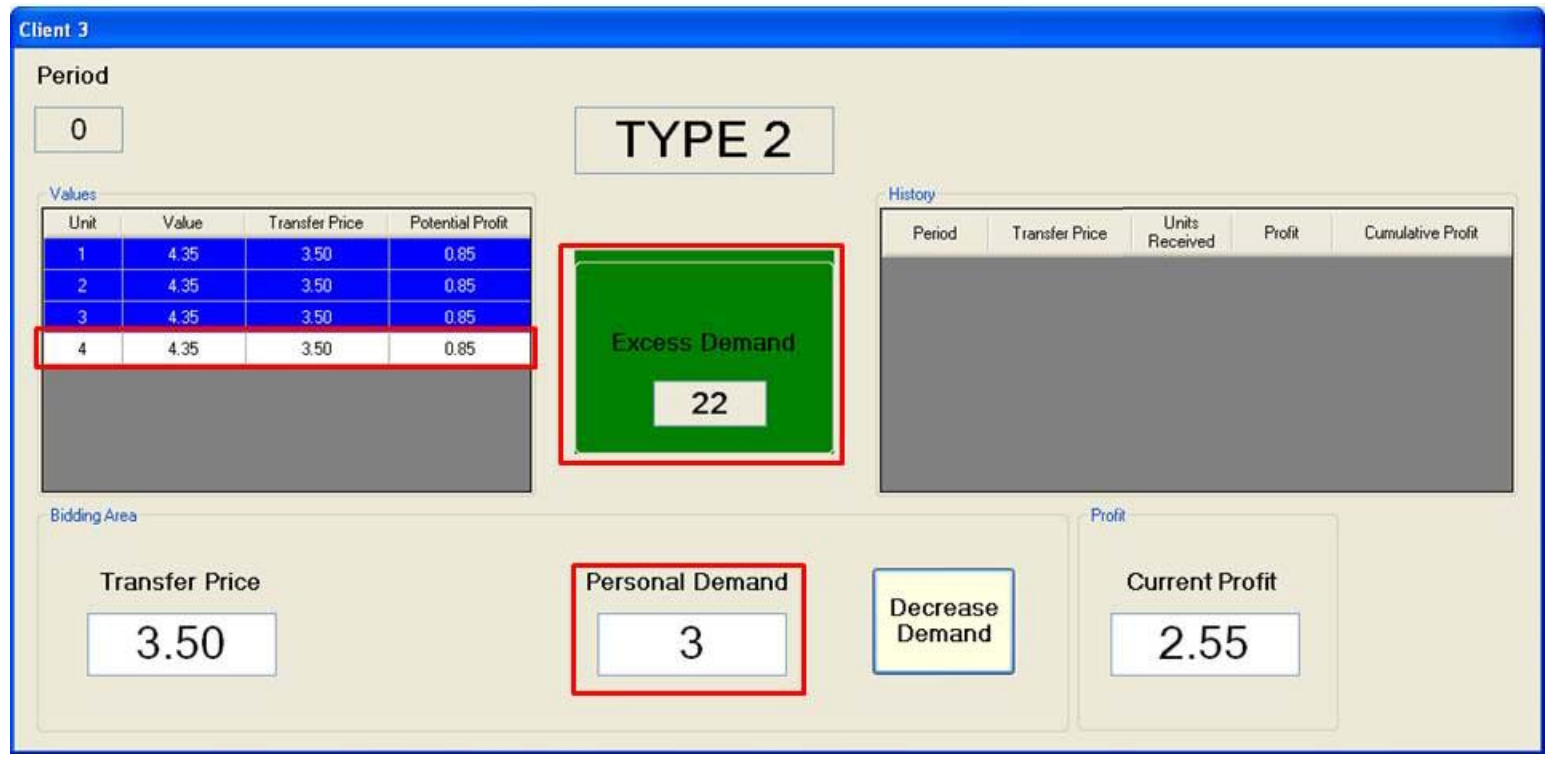

Slide 18

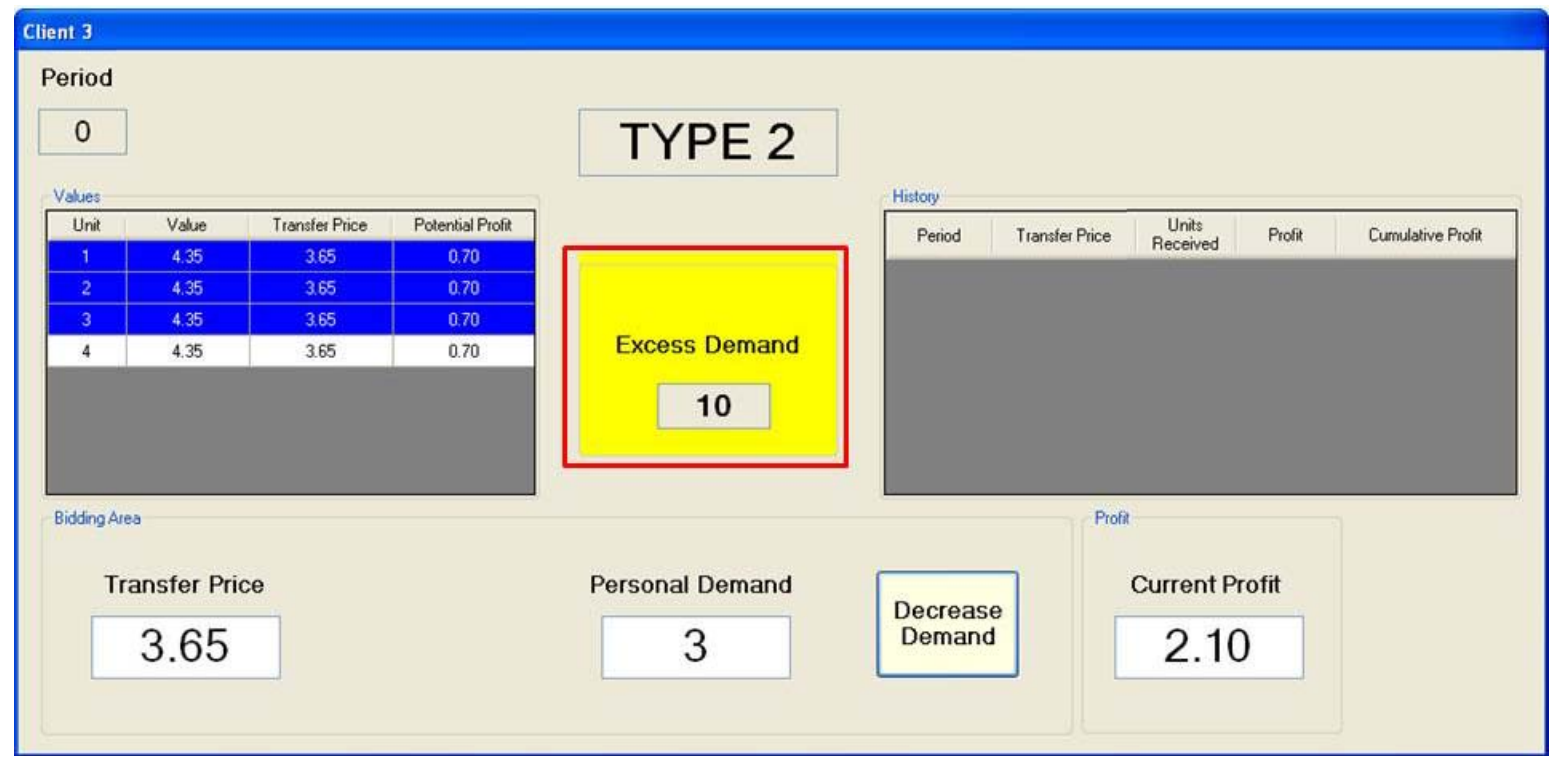


Slide 19

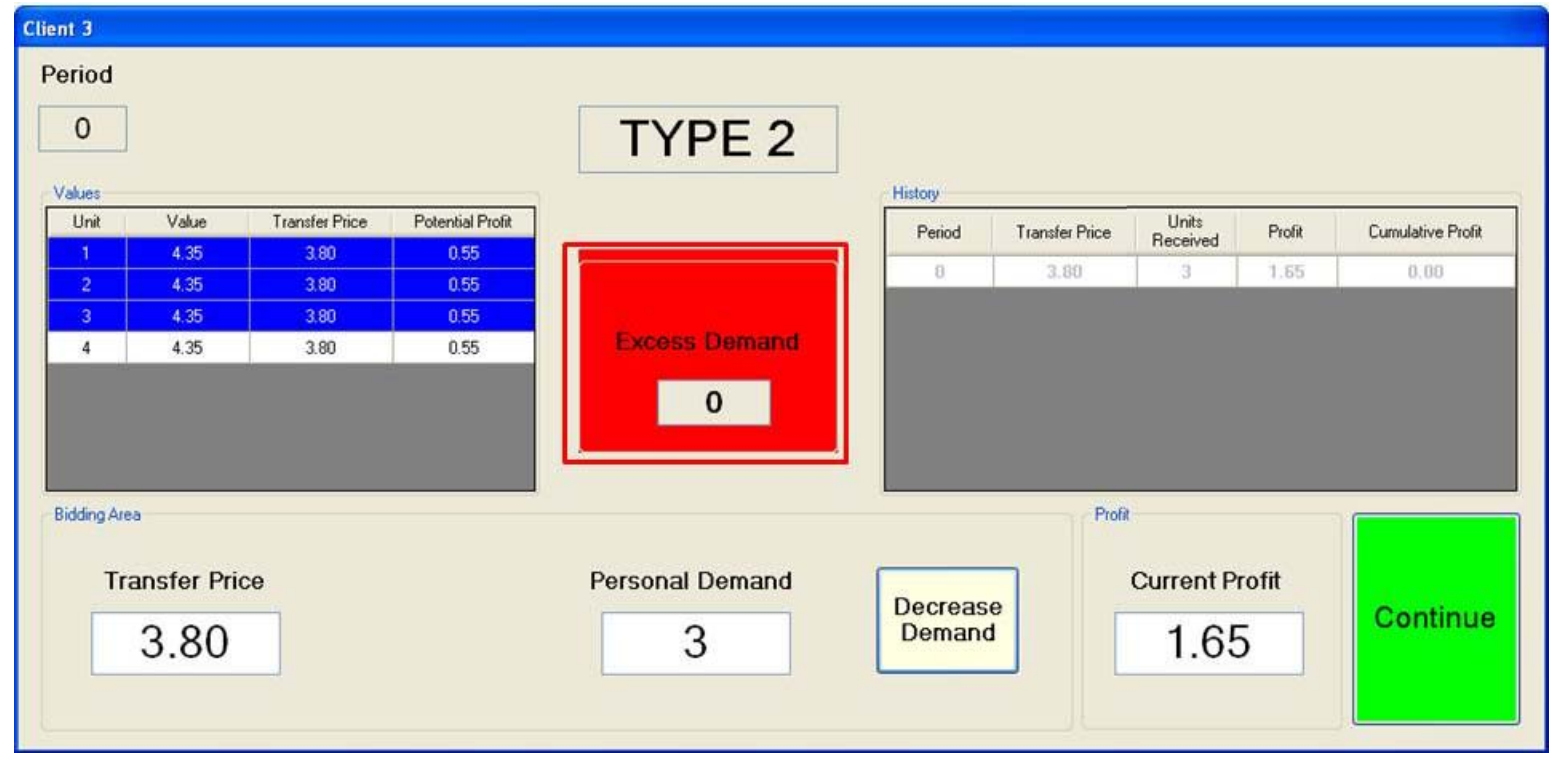

Slide 20

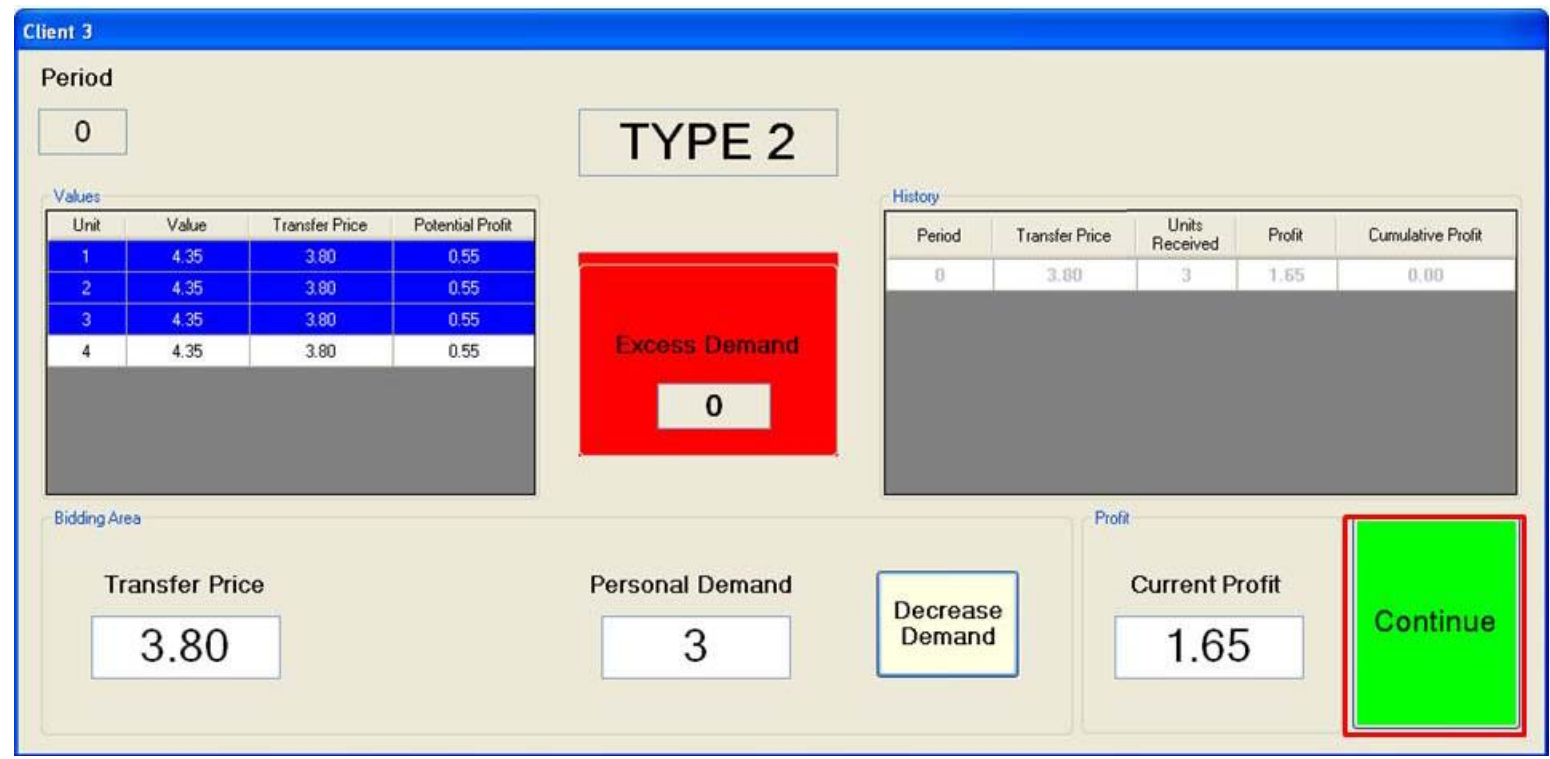


Slide 21

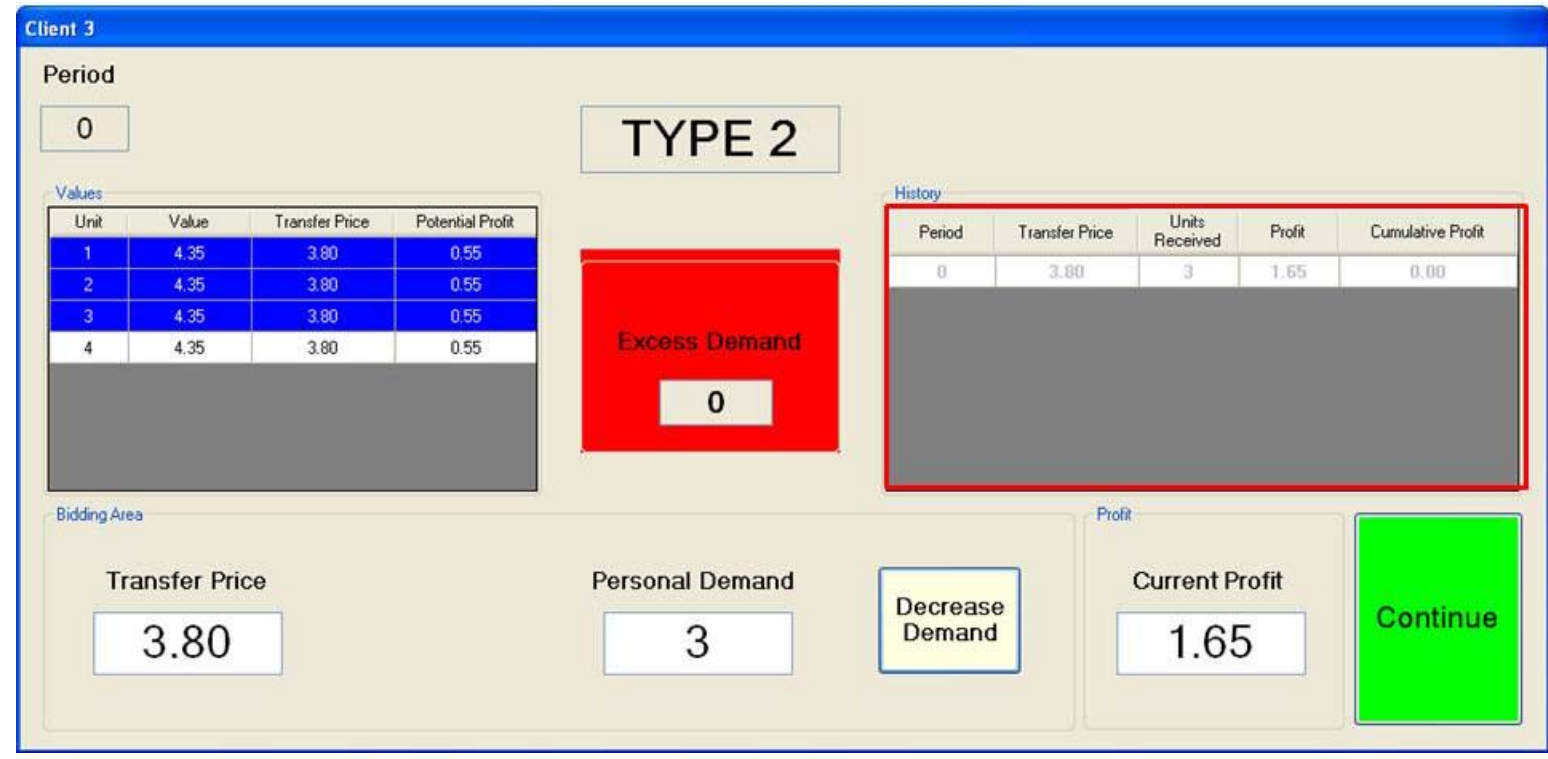




\section{Dutch-English Auctions}

\section{Slide 1}

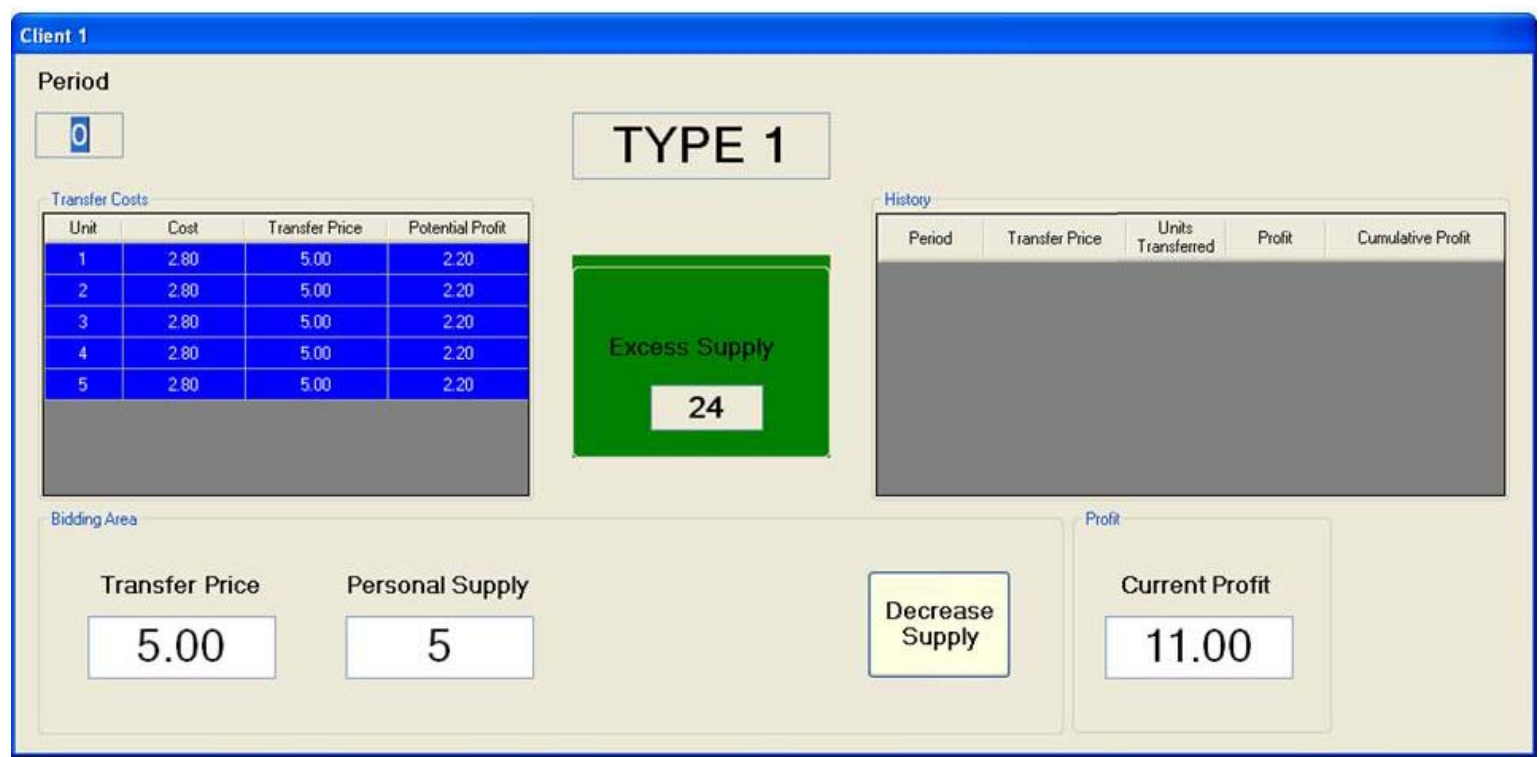

Slide 2

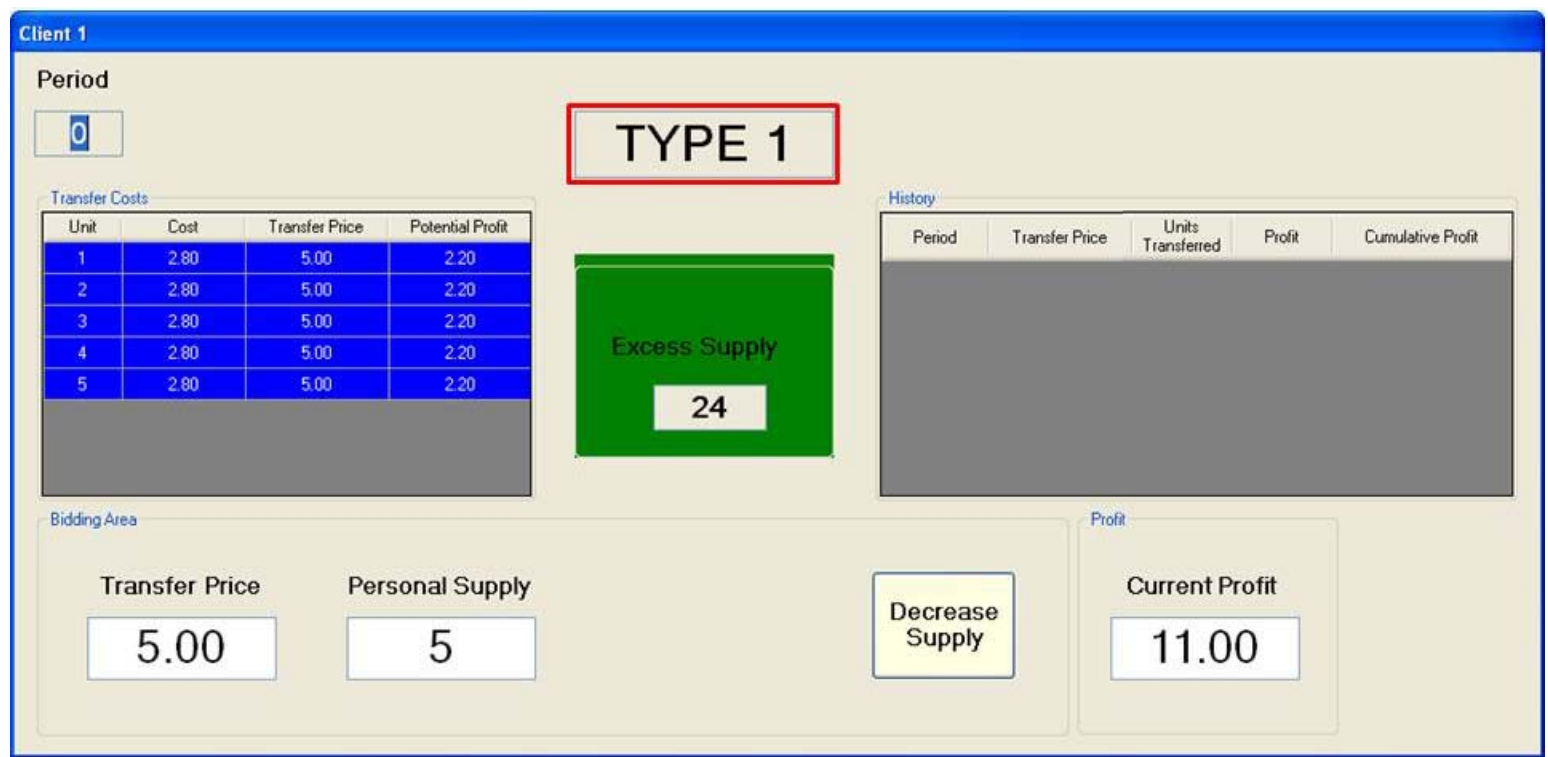


Slide 3

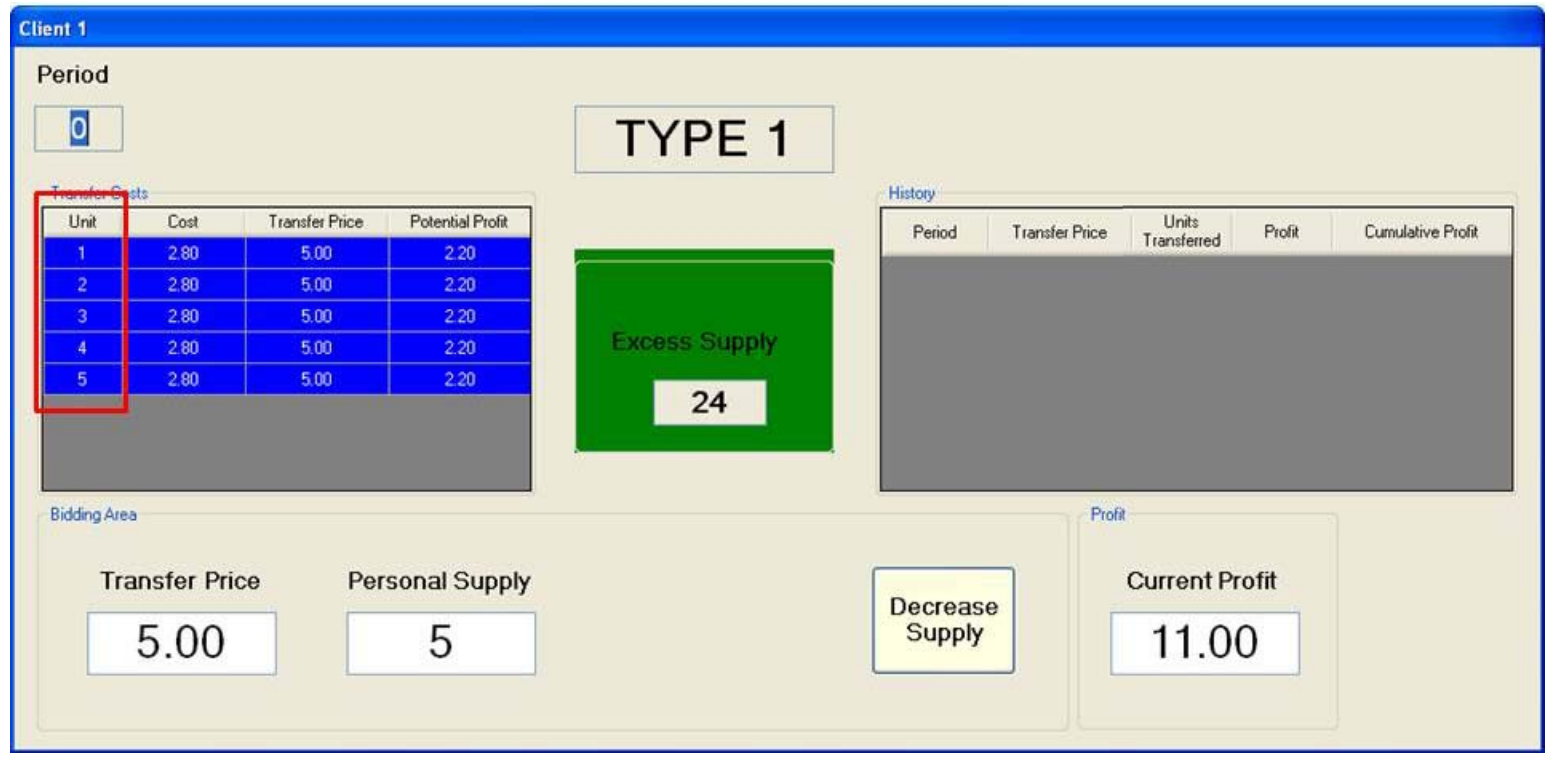

Slide 4

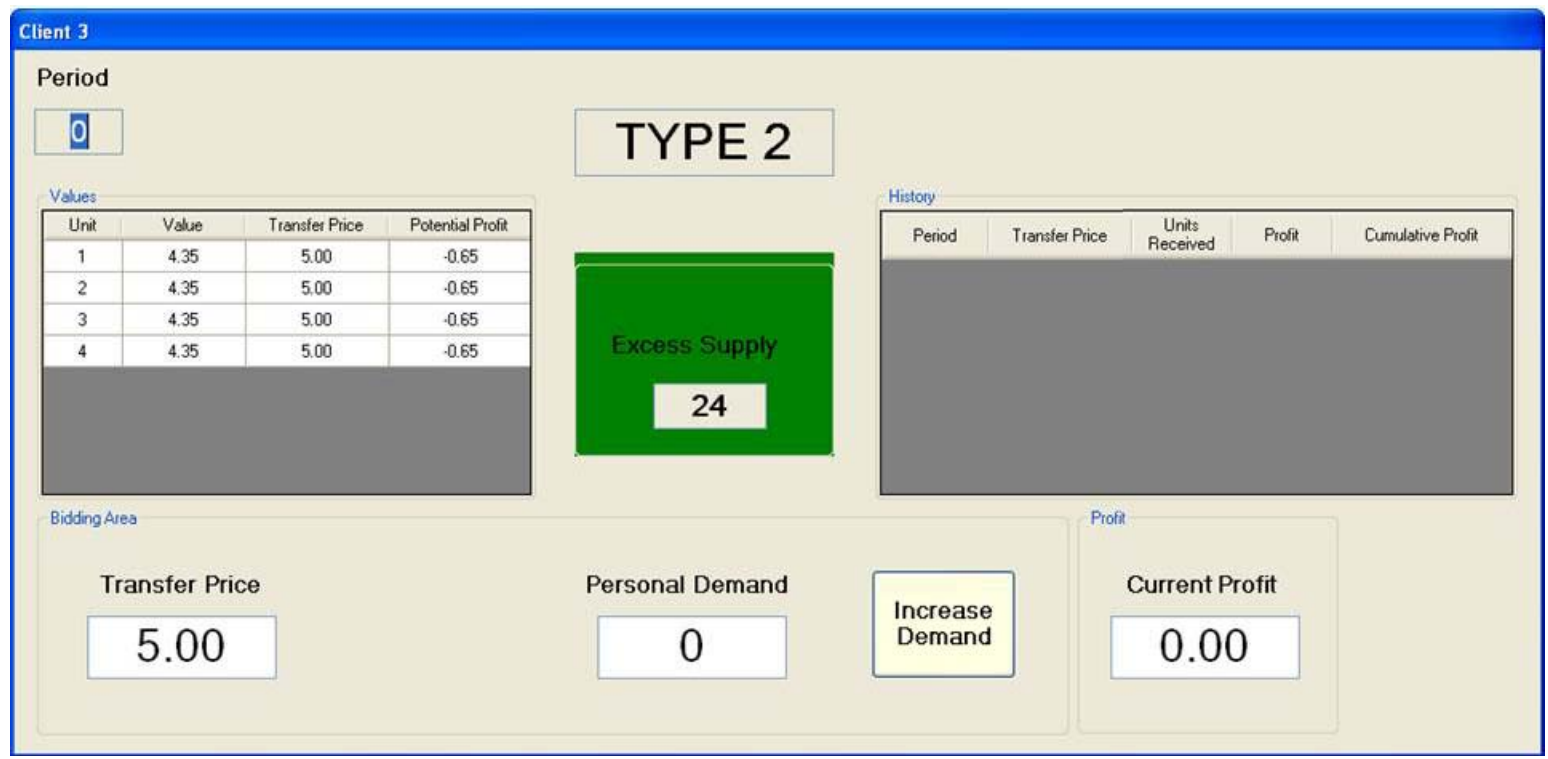


Slide 5

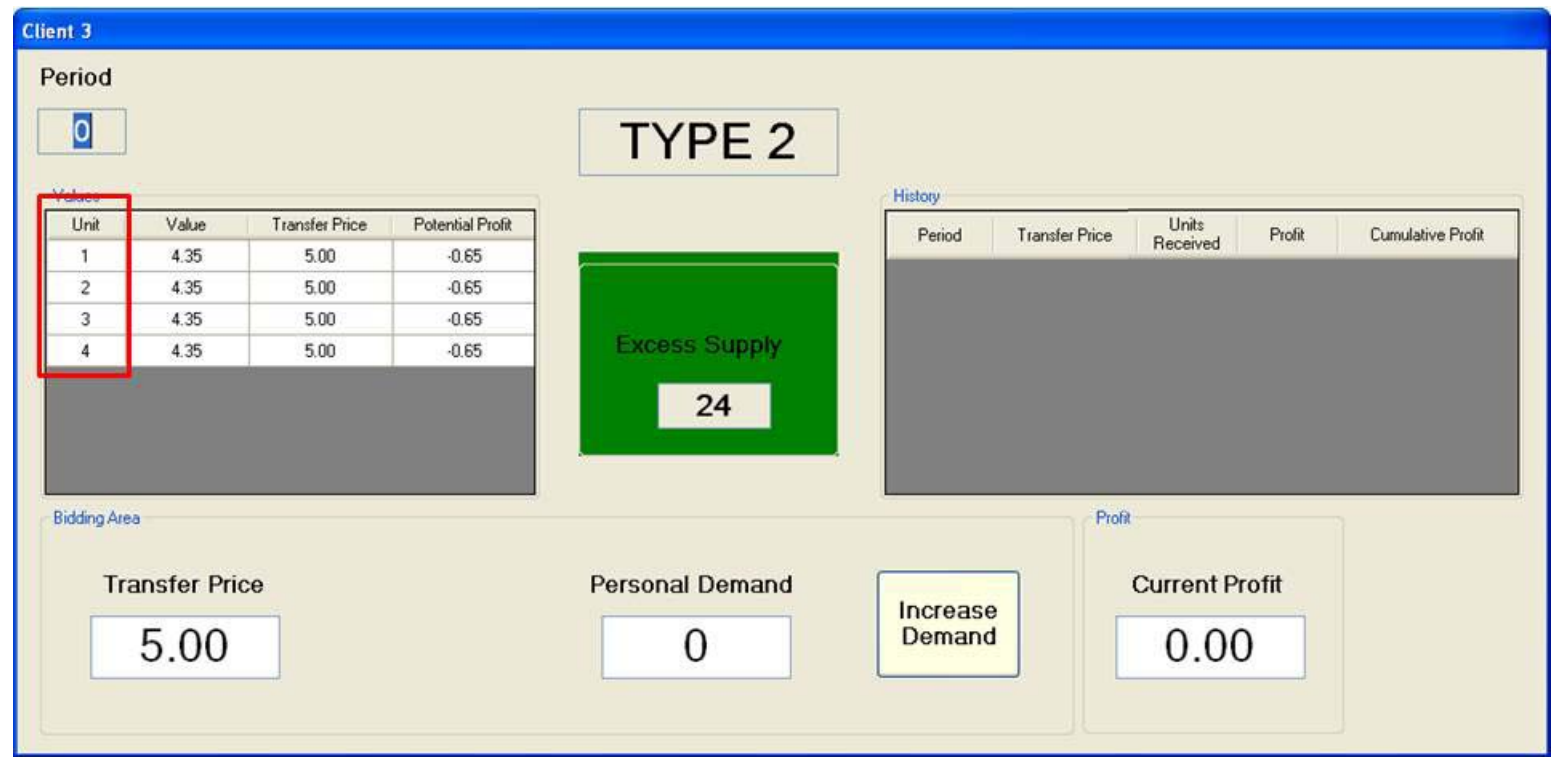

Slide 6

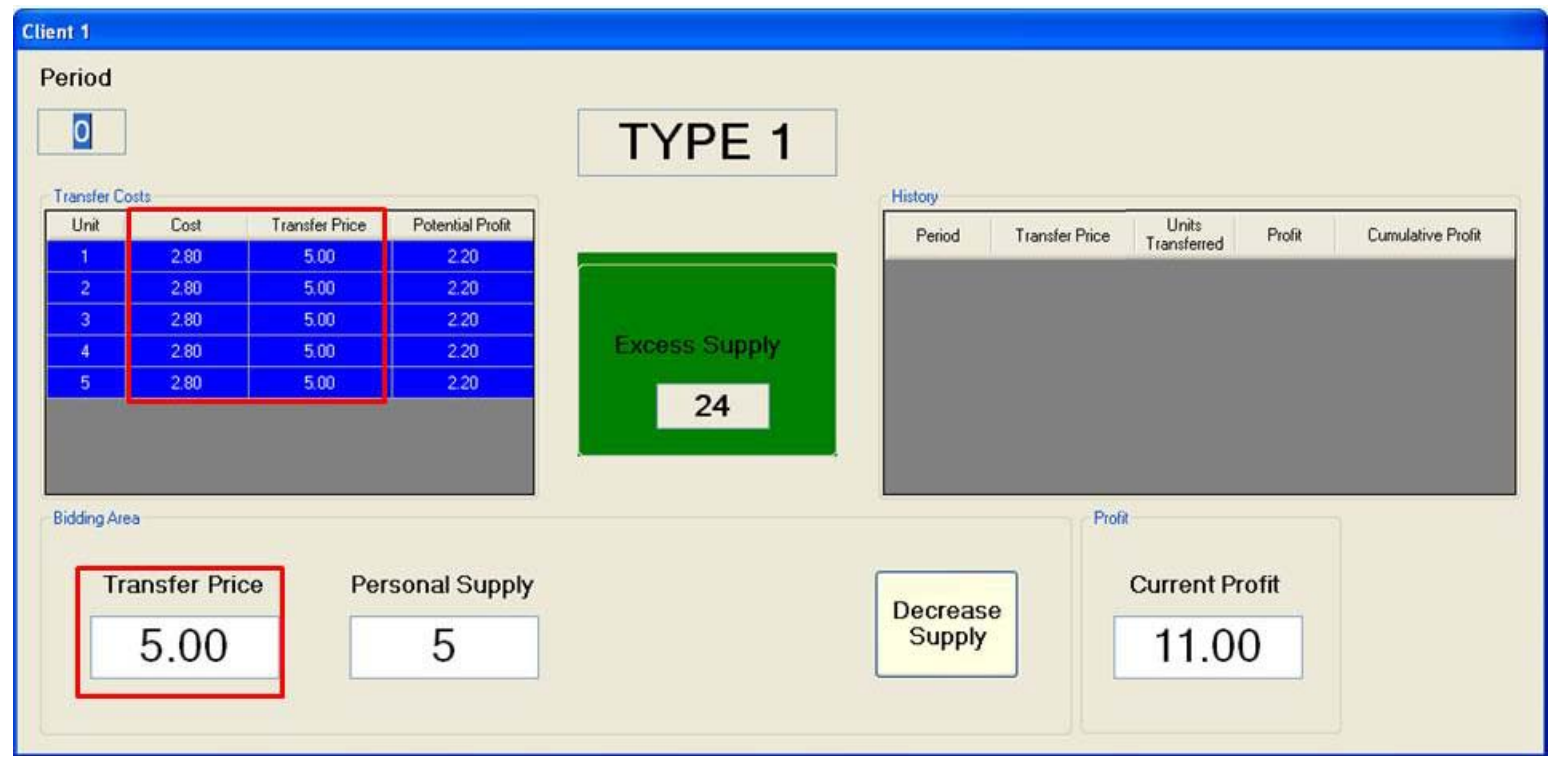


Slide 7

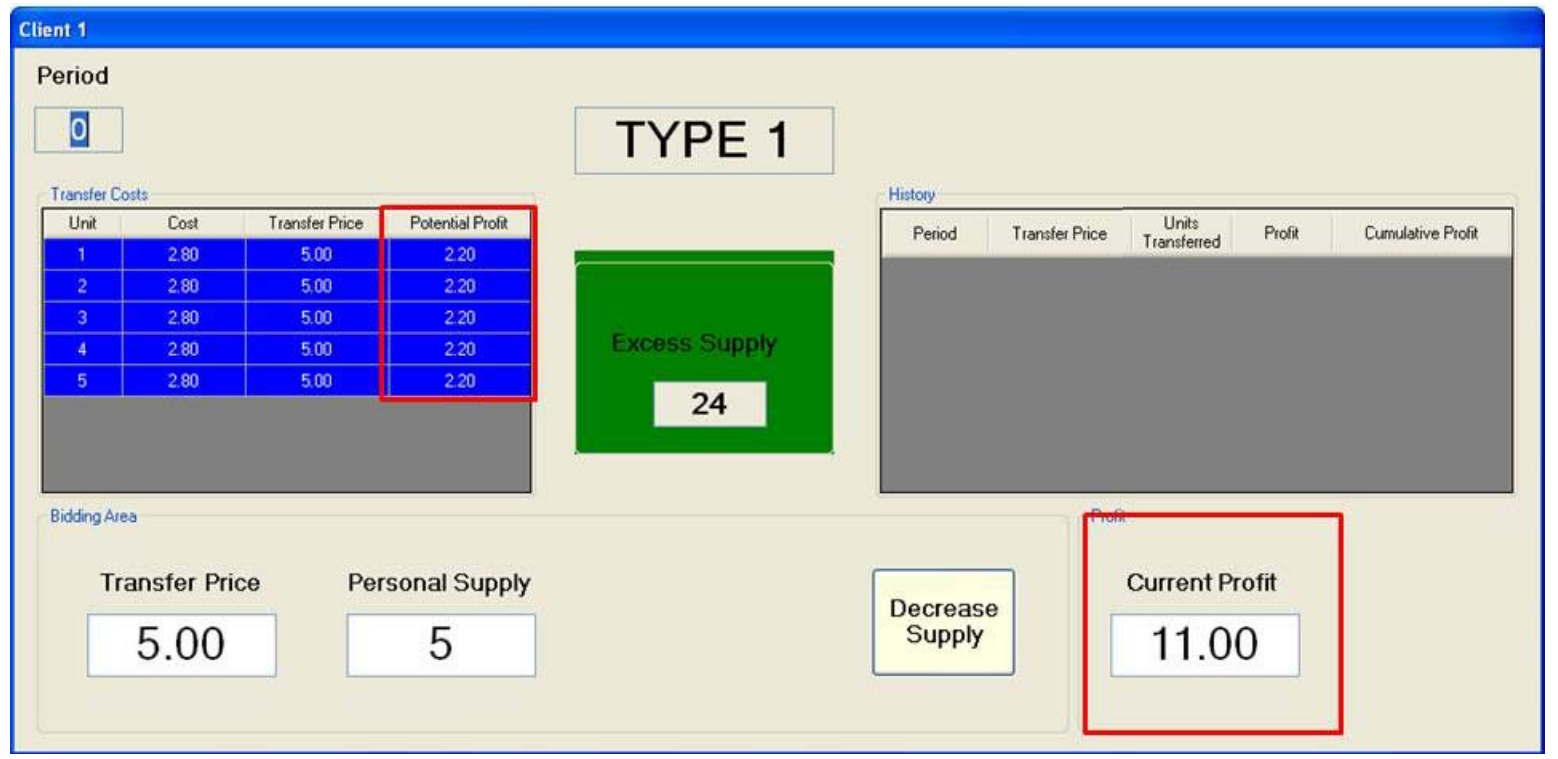

Slide 8

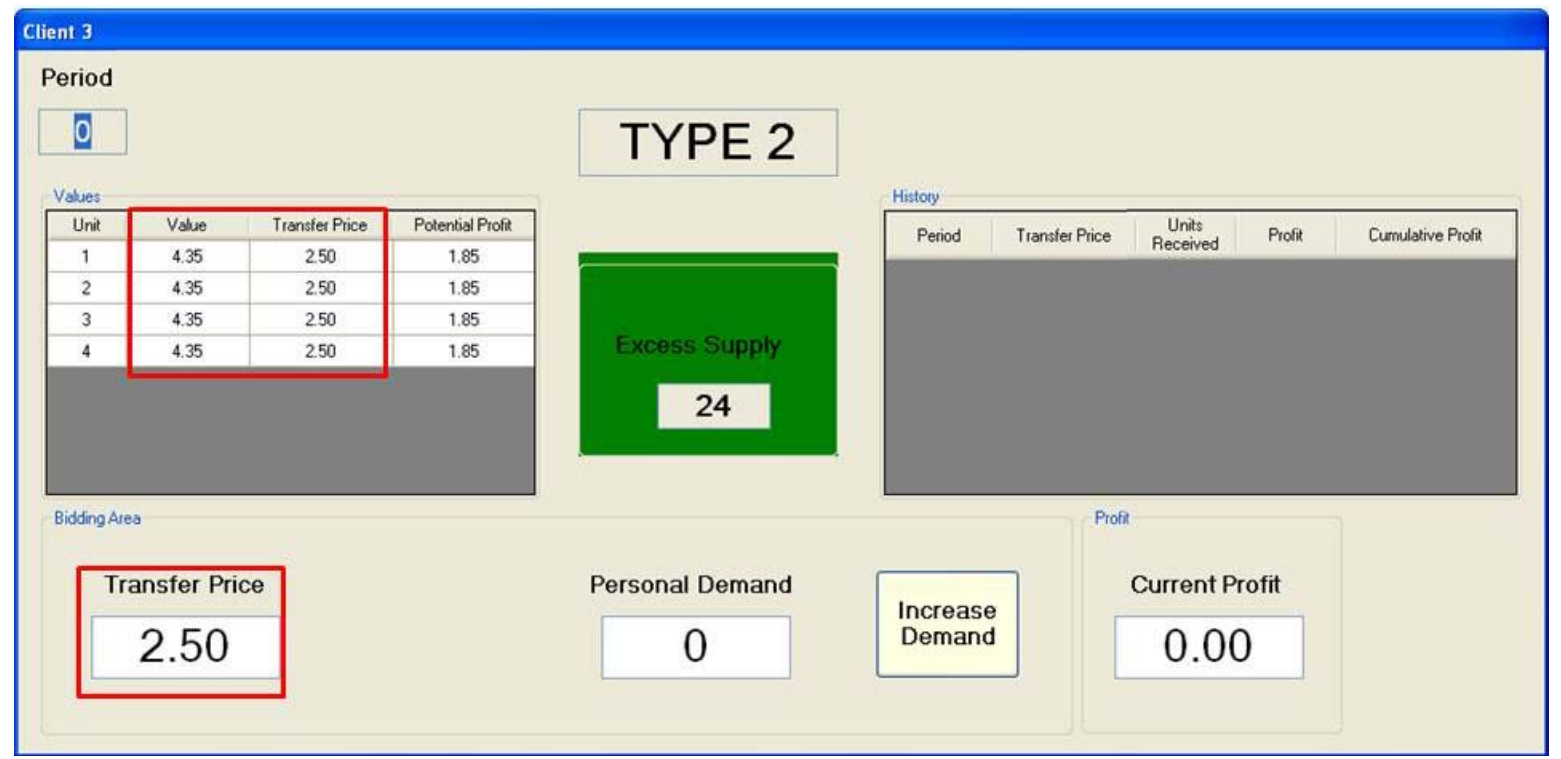


Slide 9

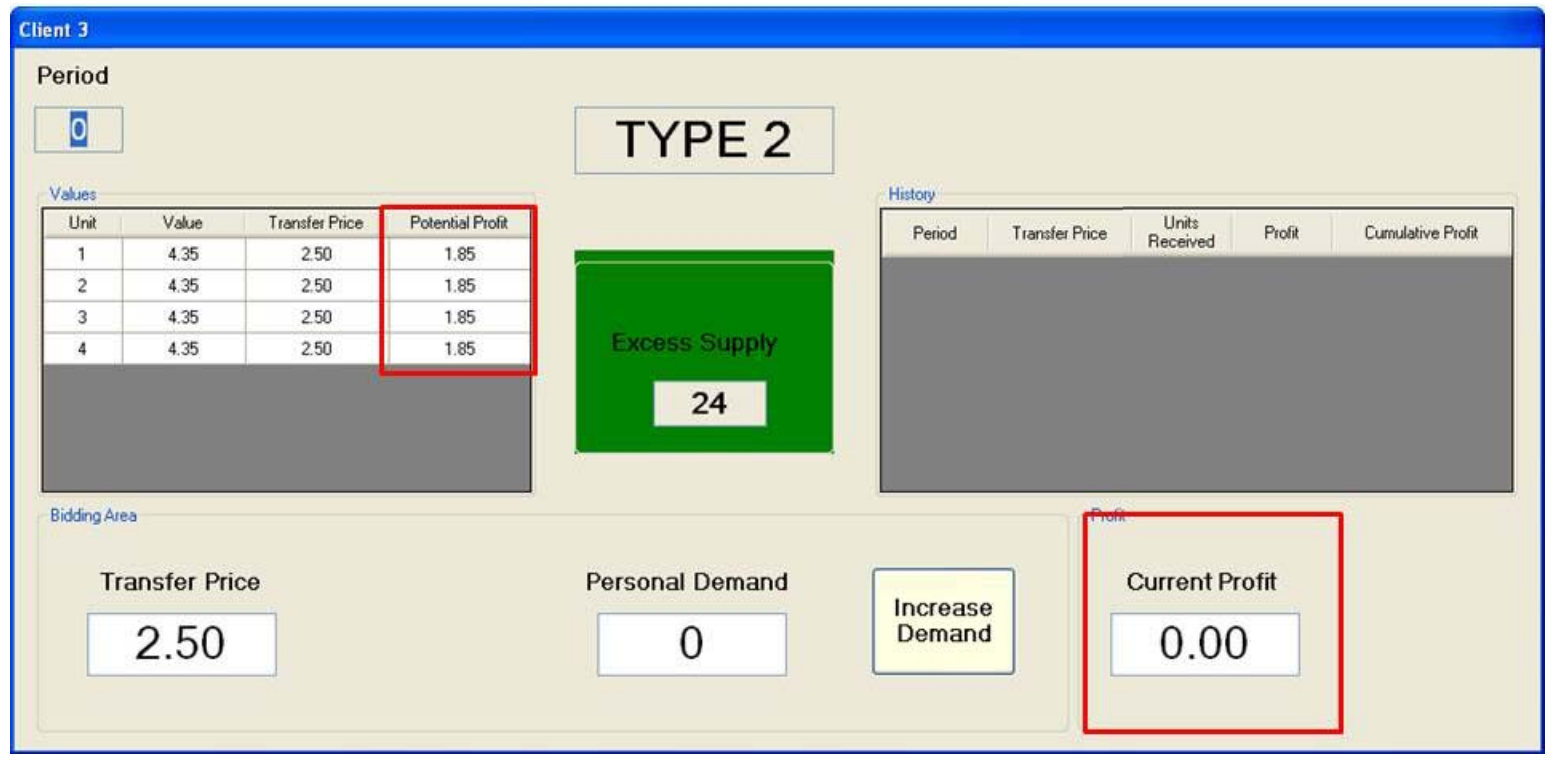

Slide 10

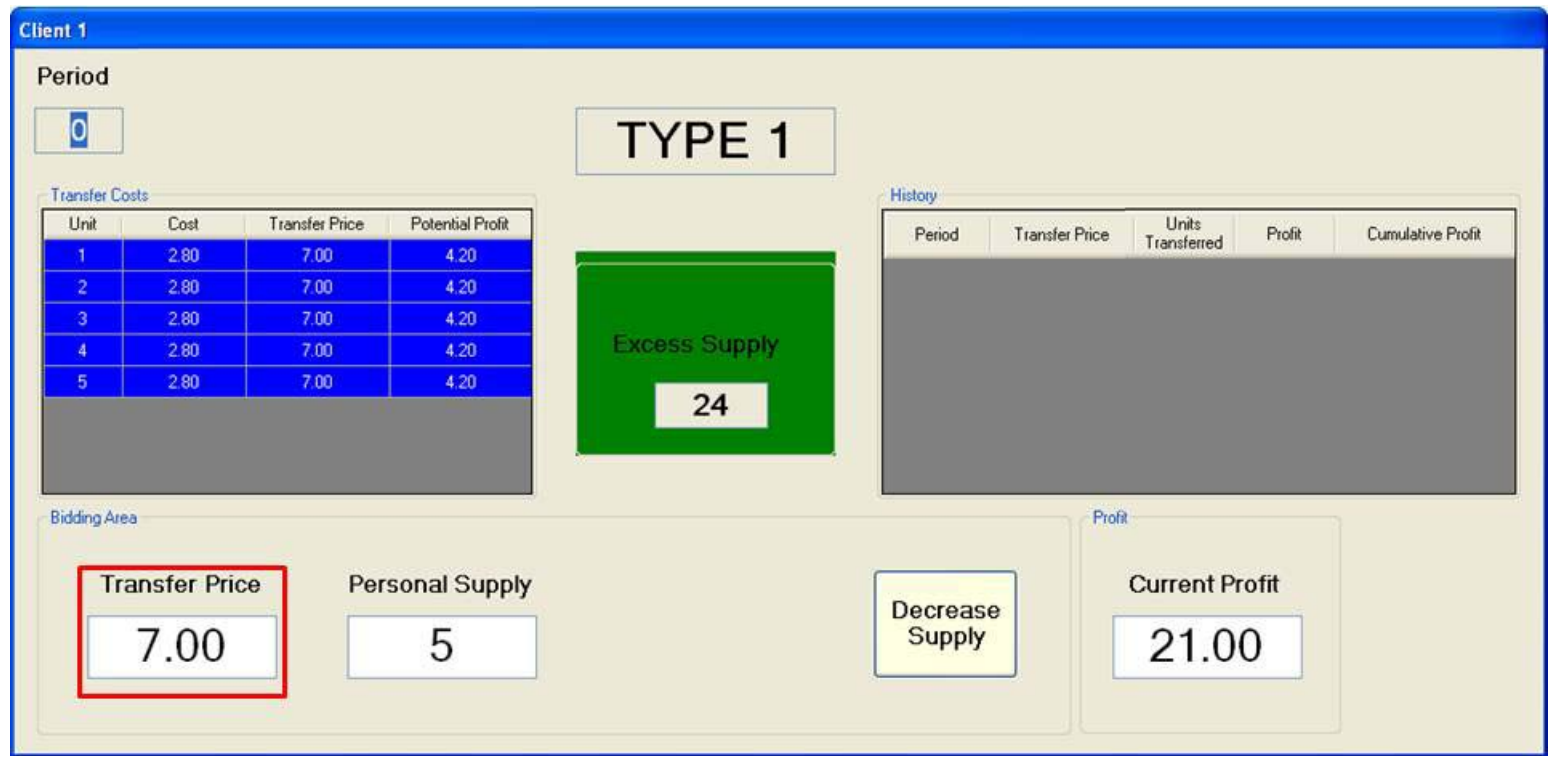


Slide 11

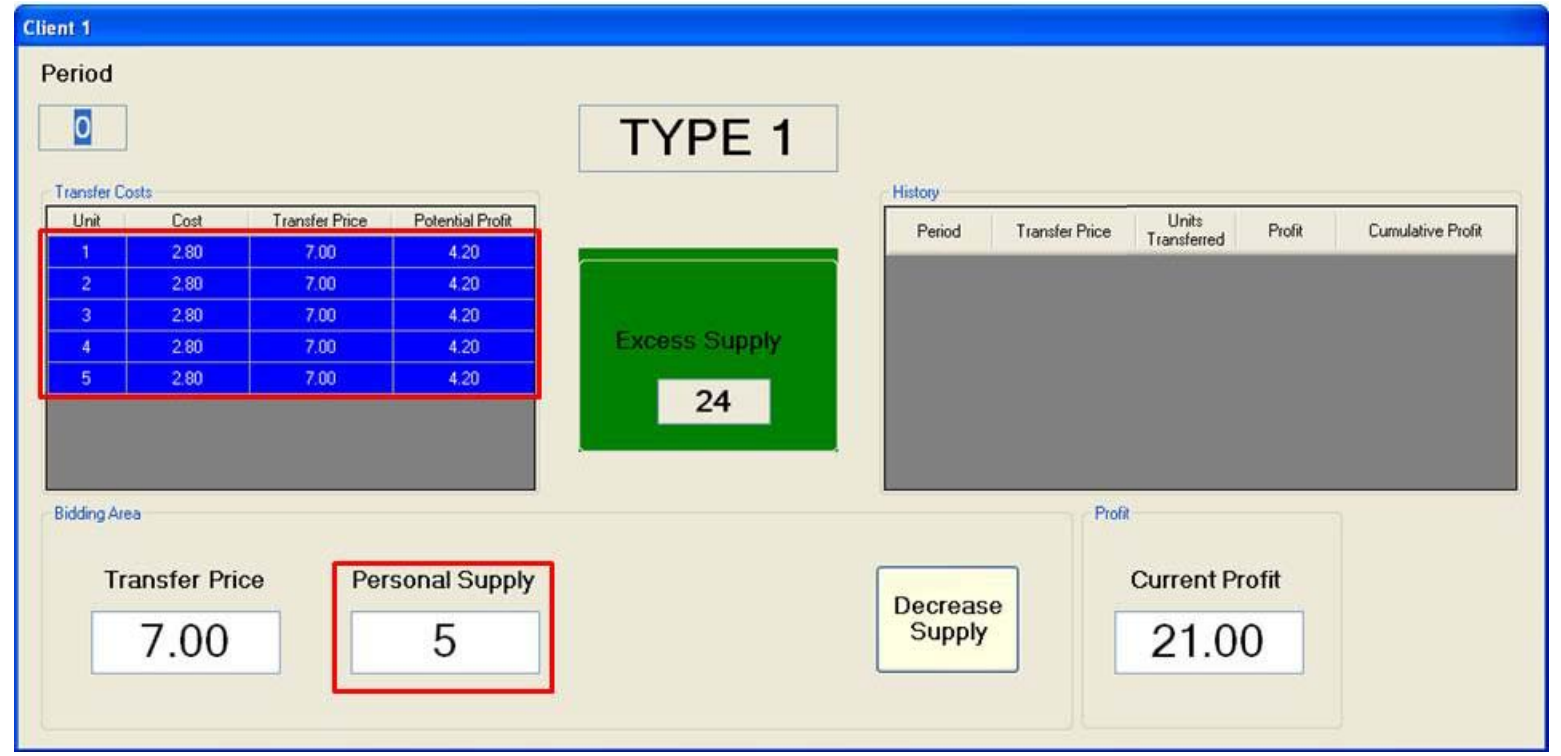

Slide 12

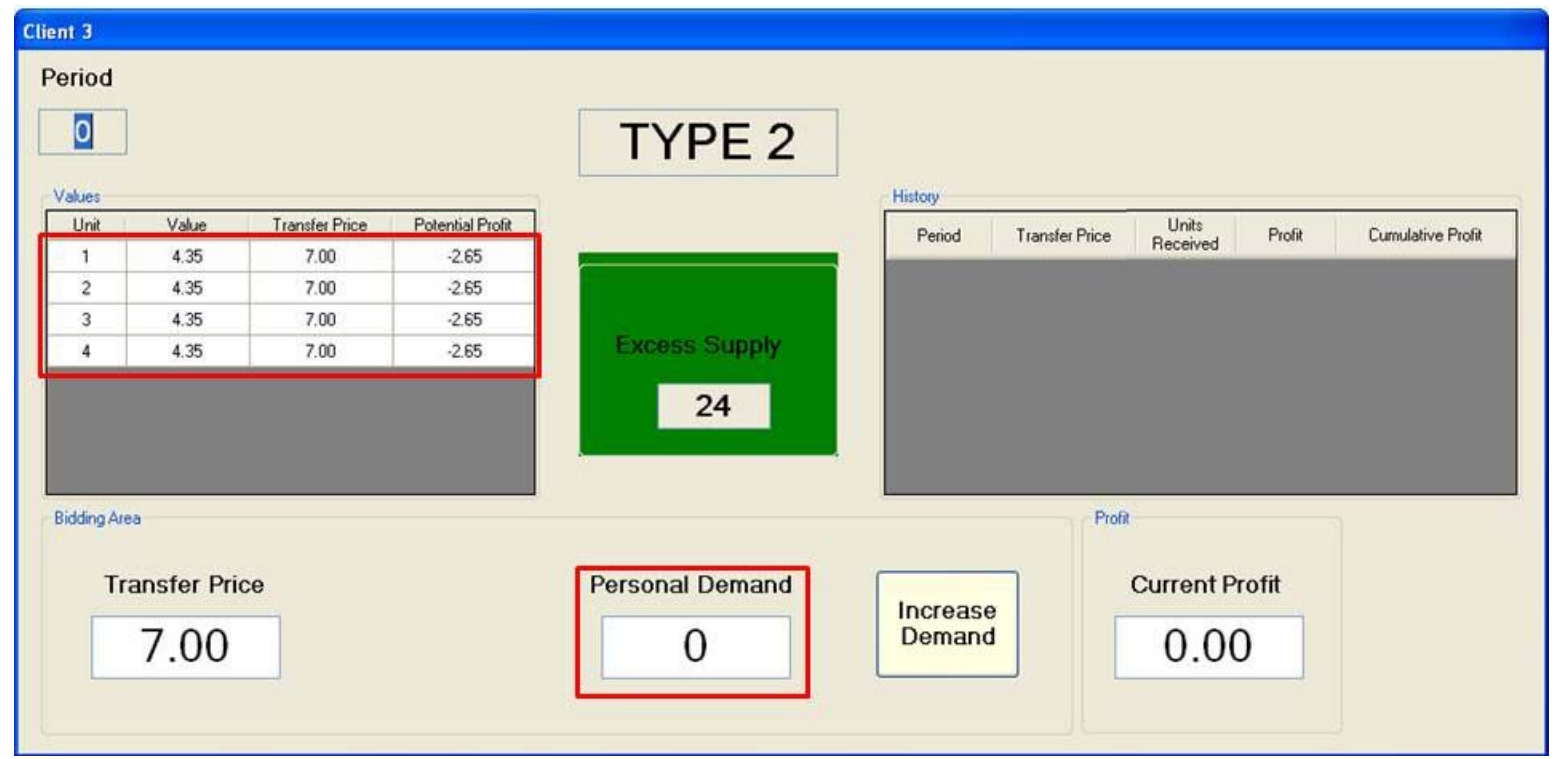


Slide 13

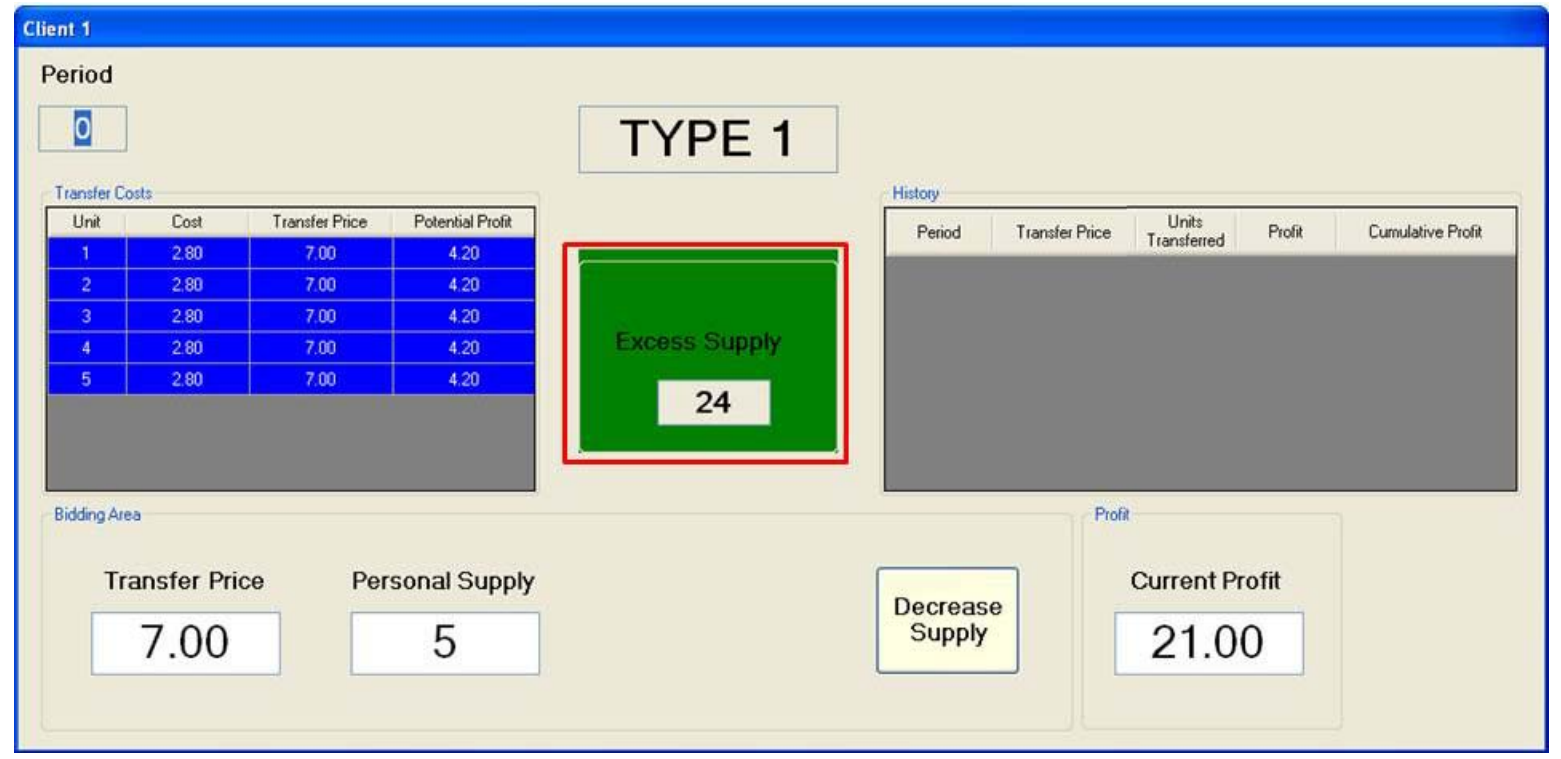

Slide 14

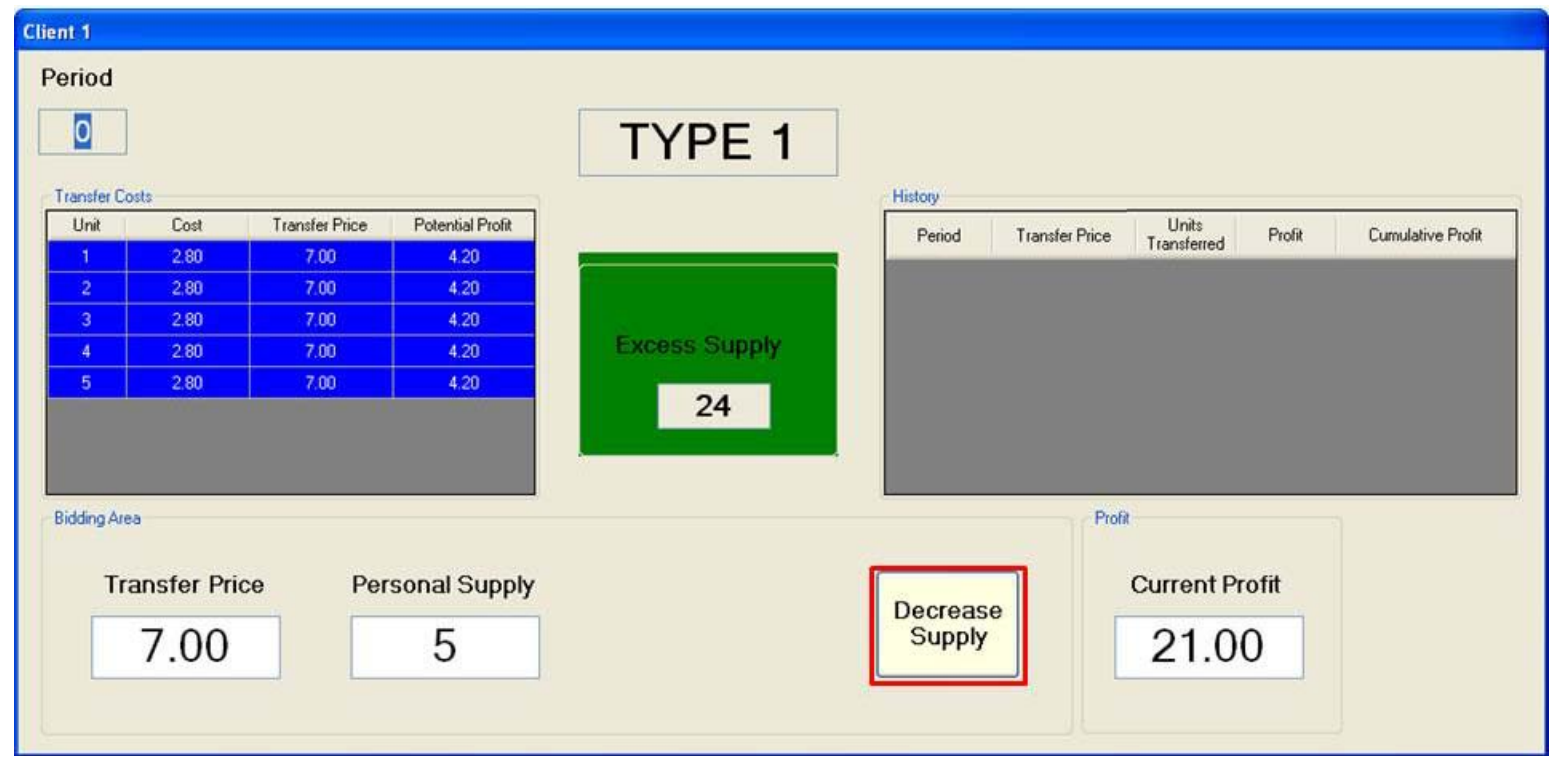


Slilde 15

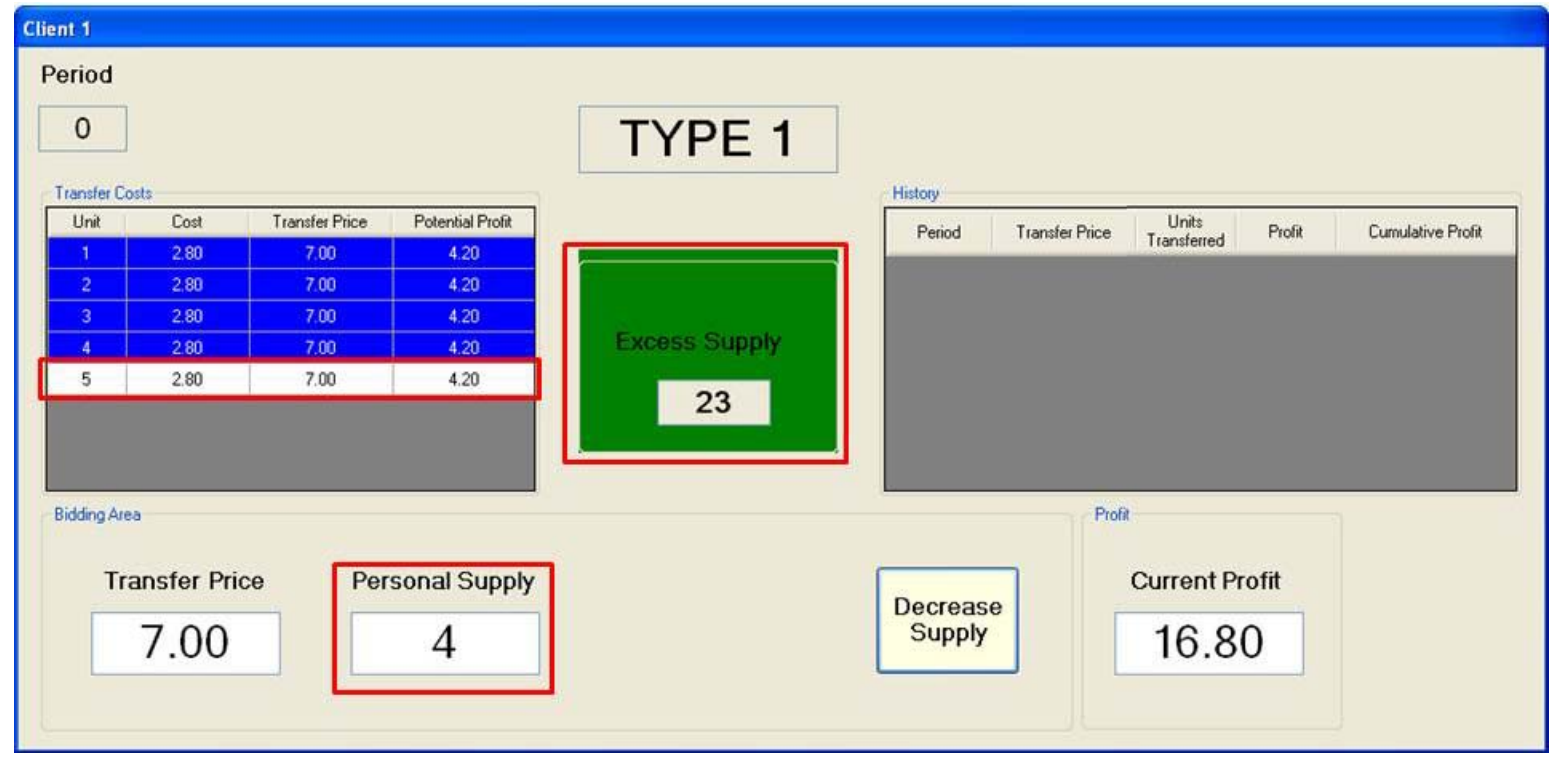

Slide 16

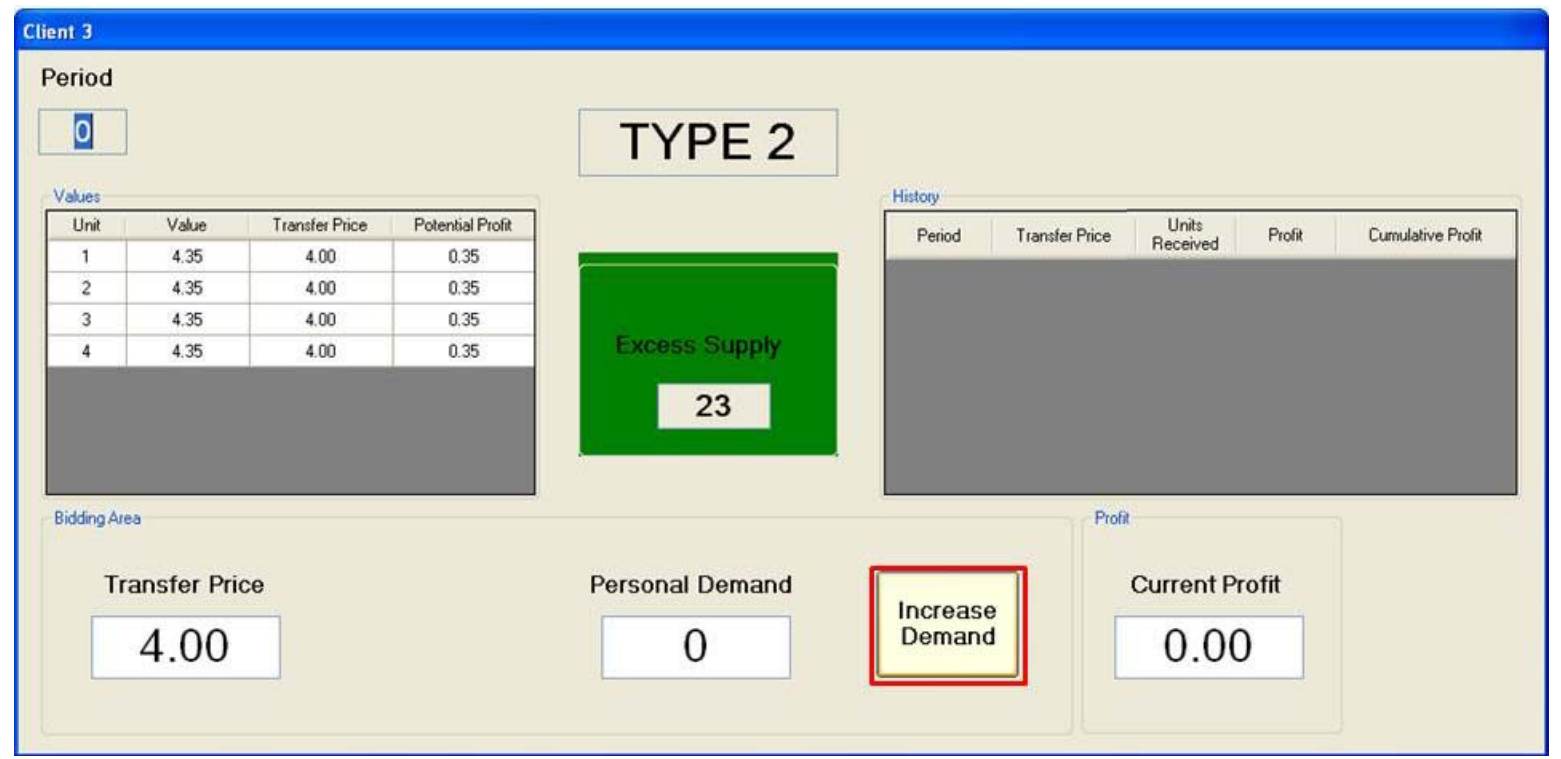


Slide 17

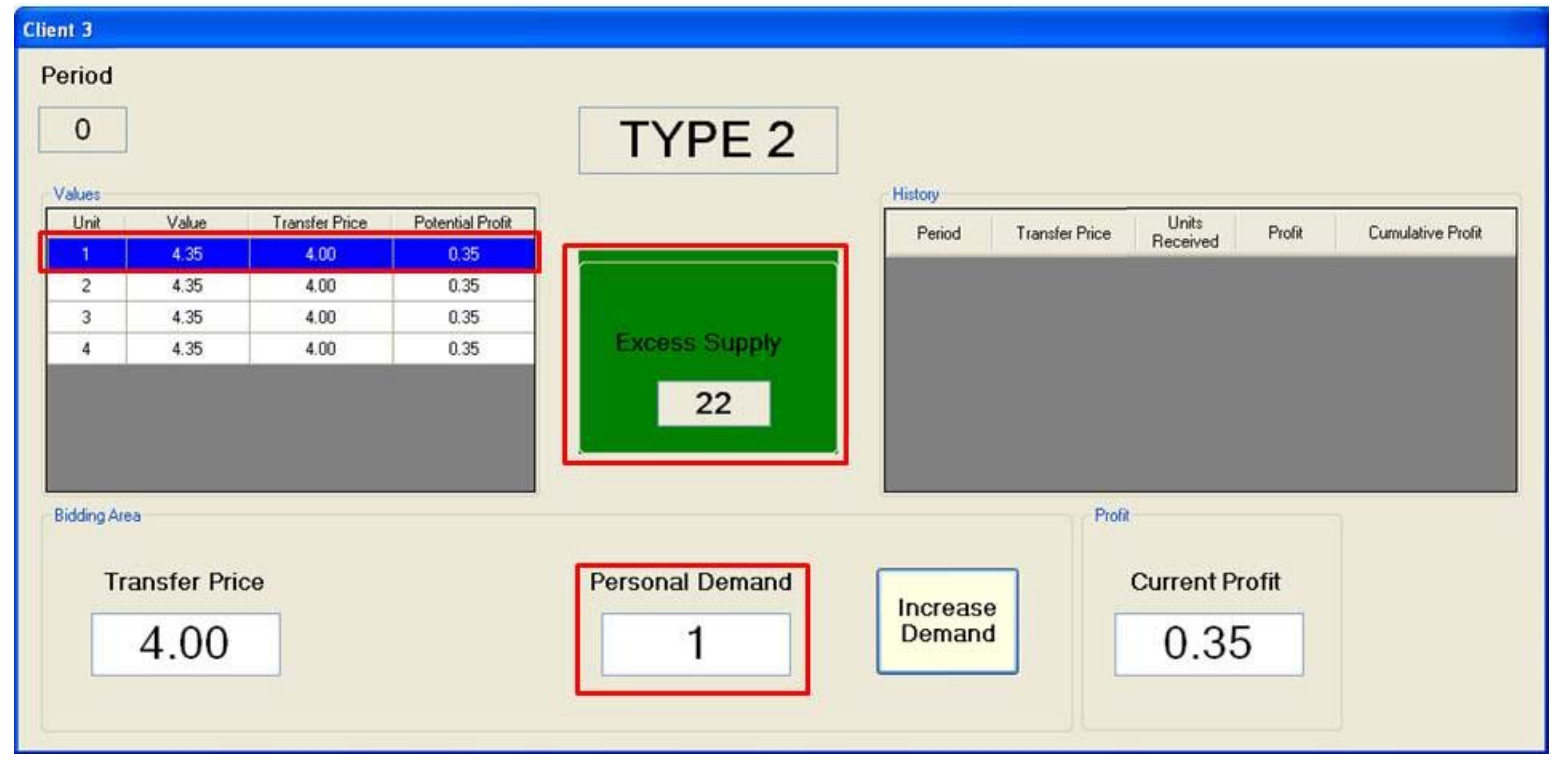

Slide 18

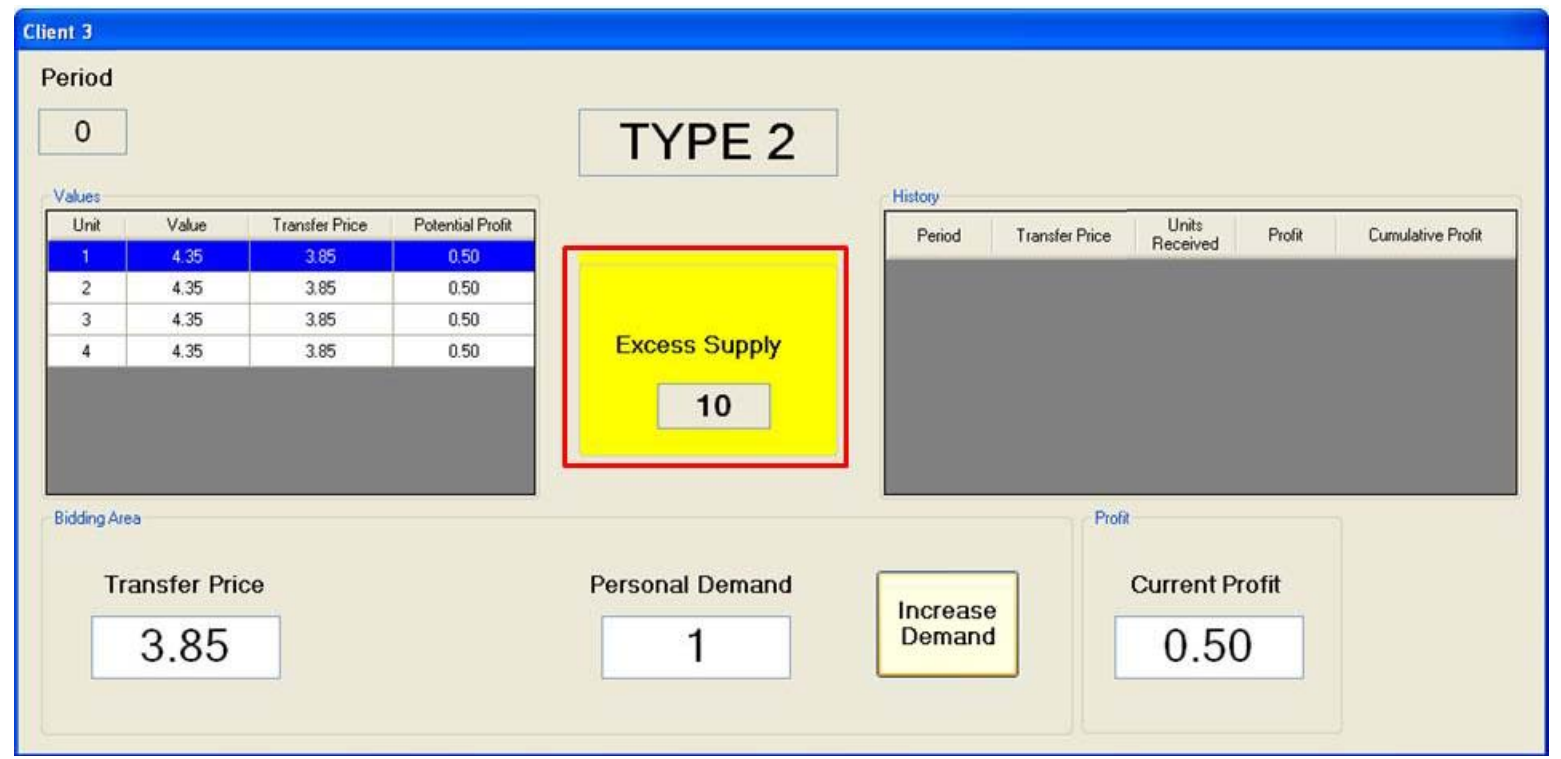


Slide 19

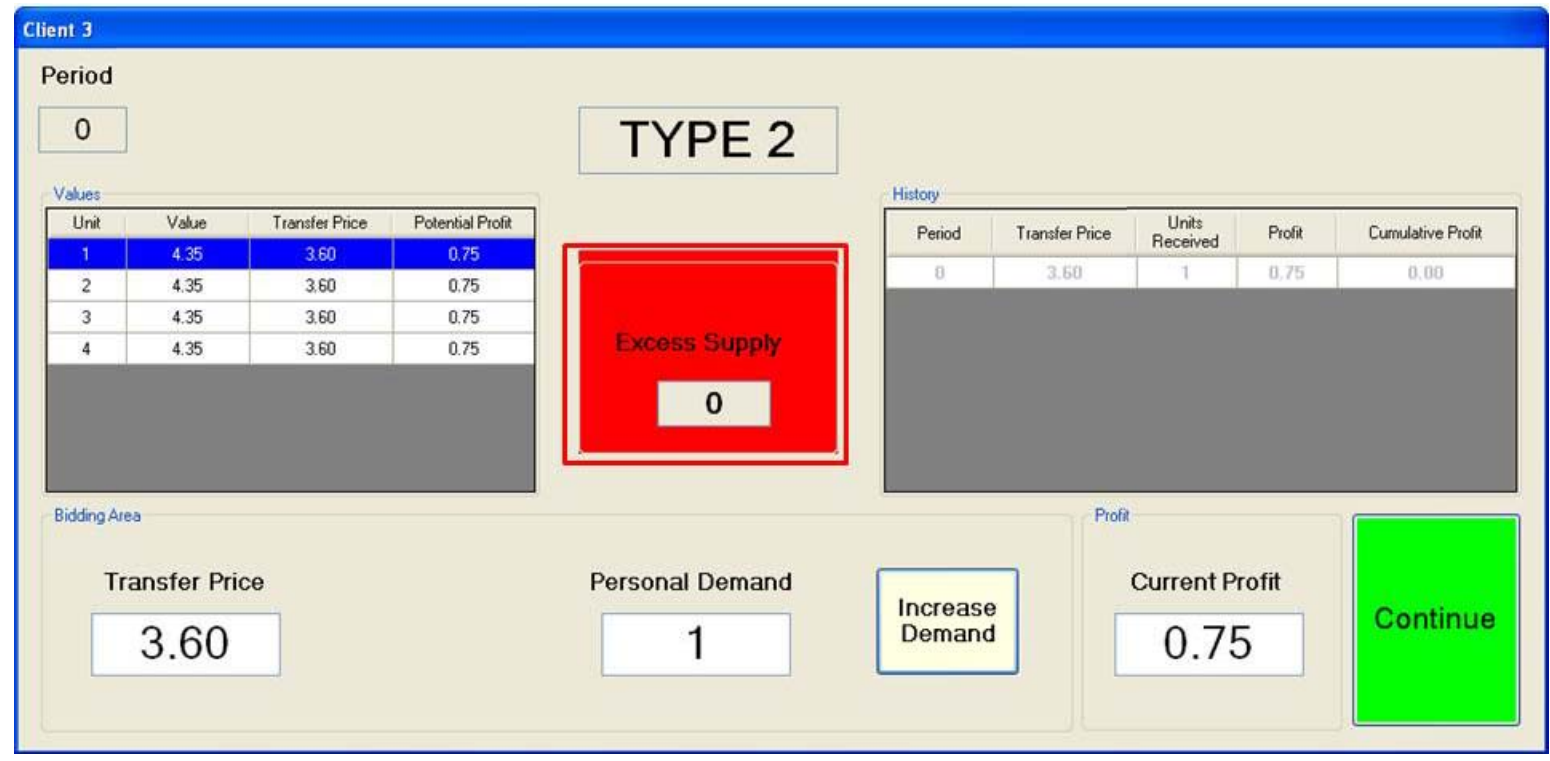

Slide 20

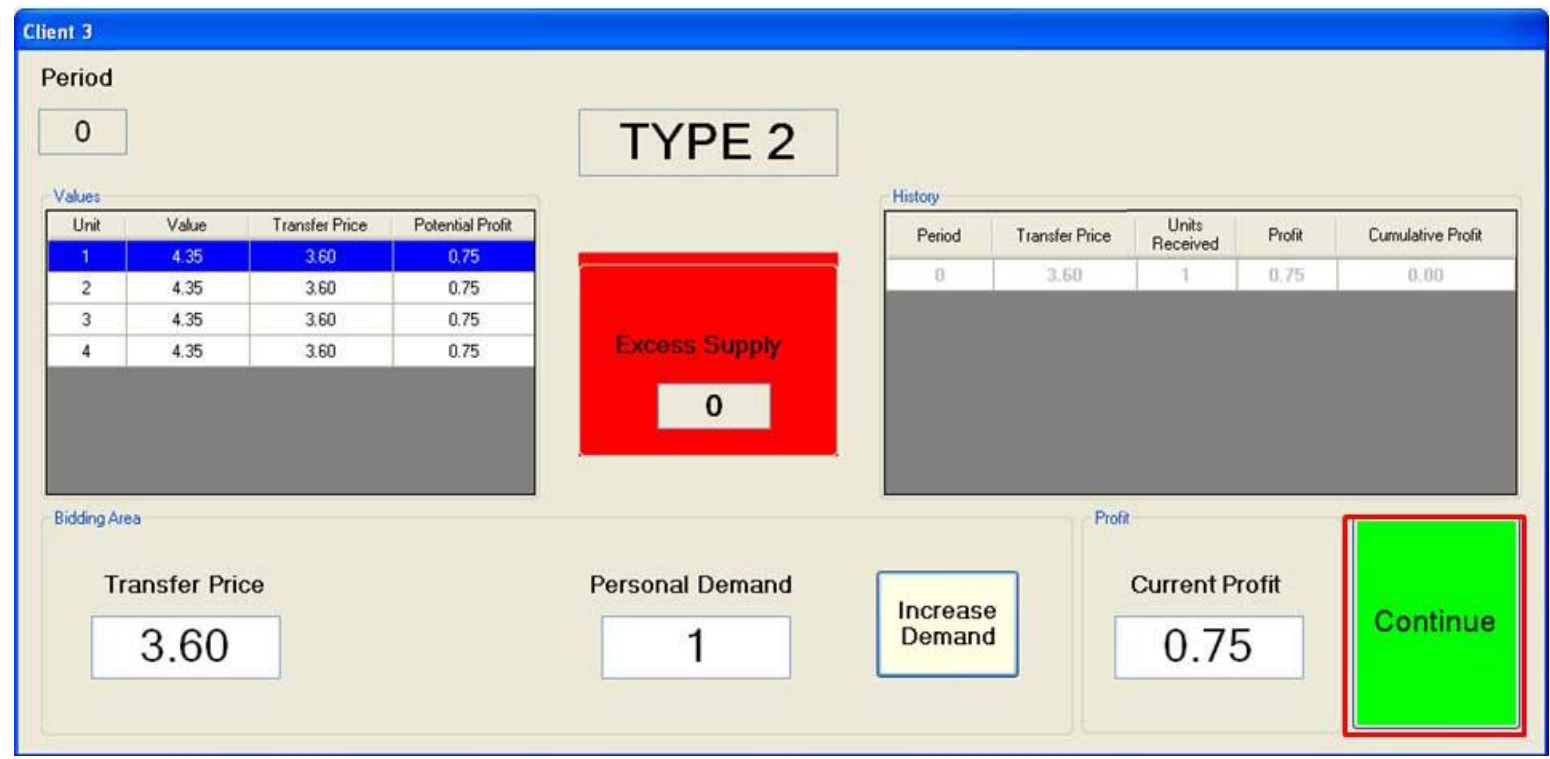


Slide 21

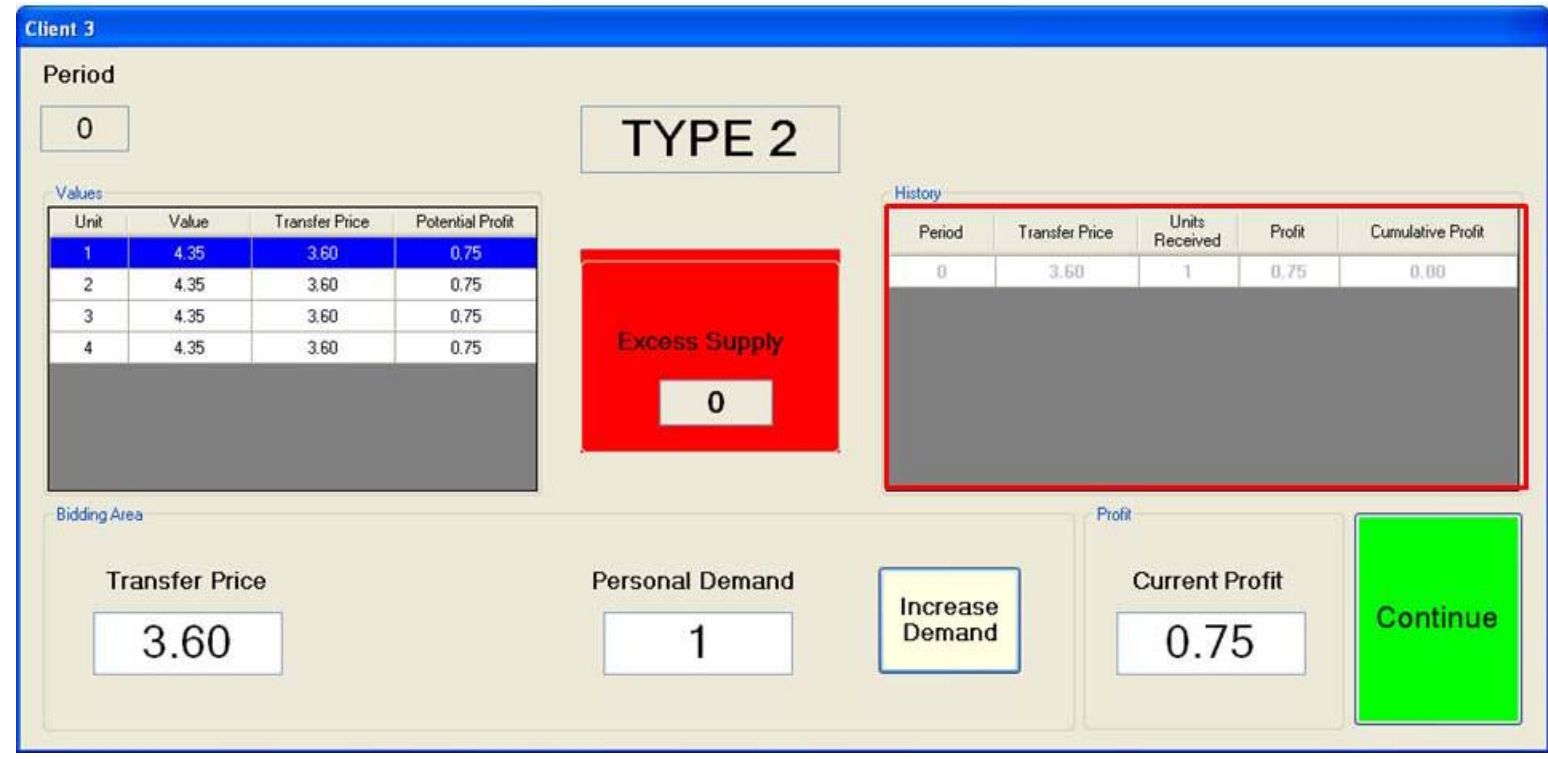

